\title{
Assessment of Bleeding Risk of Interventional Techniques: A Best Evidence Synthesis of Practice Patterns and Perioperative Management of Anticoagulant and Antithrombotic Therapy
}

Laxmaiah Manchikanti, MD1, Frank J.E. Falco, MD², Ramsin M. Benyamin, MD³, David L. Caraway, $\mathrm{MD}^{4}$, Alan D. Kaye, MD, PhD ${ }^{5}$, Standiford Helm II, MD, Bradley W. Wargo, DO7, Hans Hansen, $\mathrm{MD}^{8}$, Allan T. Parr, MD ${ }^{9}$, Vijay Singh, MD ${ }^{10}$, John R. Swicegood, MD ${ }^{11}$, Howard S. Smith, MD ${ }^{12}$, David M. Schultz, MD ${ }^{13}$, Yogesh Malla, MD ${ }^{14}$, and Joshua A. Hirsch, MD ${ }^{15}$

From: ${ }^{1,14}$ Pain Management Center of Paducah, Paducah, $\mathrm{KY}$, and ${ }^{~}$ University of Louisville, Louisville, KY; ${ }^{2}$ Mid Atlantic Spine \& Pain Physicians of Newark, Newark, DE, and Temple University Hospital, Philadelphia, PA; ${ }^{3}$ Millennium Pain Center,

Bloomington, IL, and University of Illinois, Urbana-Champaign, IL; ${ }^{4}$ St. Mary's Pain Relief Center, Huntington, WV; ' $L S U$ Health Science Center, New Orleans, $\mathrm{LA} ;{ }^{6}$ The Helm Center for Pain Management, Laguna Hills, CA ${ }^{7}$ Mary Greeley Medical Center, Ames, IA; ${ }^{8}$ Pain Relief Centers, Conover, NC; ${ }^{9}$ Premier Pain Center, Covington, LA; ${ }^{10}$ Spine

Pain Diagnostics Associates, Niagara, WI; ${ }^{11}$ Advanced Interventional Pain and Diagnostics of Western Arkansas, Fort Smith, AR; ${ }^{12}$ Albany Medical College, Albany, NY; ${ }^{13}$ MAPS Medical Pain Clinics, Minneapolis, $\mathrm{MN}$; ${ }^{15}$ Massachusetts General Hospital, and Harvard Medical School, Boston, MA.

Additional author affiliation information on Pp. SE296-SE297.

Address correspondence: Laxmaiah Manchikanti, M.D. 2831 Lone Oak Road

Paducah, Kentucky 42003

E-mail: drlm@thepainmd.com:

Disclaimer: There was no external funding in the preparation of this manuscript.

Conflict of interest: None.

Manuscript received: 02/10/2013 Accepted for publication: 04/10/2013

Free full manuscript: www.painphysicianjournal.com
Background: Interventional pain management is a specialty that utilizes invasive procedures to diagnose and treat chronic pain. Patients undergoing these treatments may be receiving exogenous anticoagulants and antithrombotics. Even though the risk of major bleeding is very small, the consequences can be catastrophic. However, the role of antithrombotic therapy for primary and secondary prevention of cardiovascular disease to decrease the incidence of acute cerebral and cardiovascular events is also crucial.

Overall, there is a paucity of literature on the subject of bleeding risk in interventional pain management along with practice patterns and perioperative management of anticoagulant and anti-thrombotic therapy.

\section{Study Design: Best evidence synthesis.}

Objective: To critically appraise and synthesize the literature with assessment of the bleeding risk of interventional techniques including practice patterns and perioperative management of anticoagulant and antithrombotic therapy.

Methods: The available literature on the bleeding risk of interventional techniques and practice patterns and perioperative management of anticoagulant and antithrombotic therapy was reviewed.

Data sources included relevant literature identified through searches of PubMed and EMBASE from 1966 through December 2012 and manual searches of the bibliographies of known primary and review articles.

Results: There is good evidence for the risk of thromboembolic phenomenon in patients who discontinue antithrombotic therapy, spontaneous epidural hematomas occur with or without traumatic injury in patients with or without anticoagulant therapy associated with stressors such as chiropractic manipulation, diving, and anatomic abnormalities such as ankylosing spondylitis, and the lack of necessity of discontinuation of nonsteroidal anti-inflammatory drugs (NSAIDs), including low dose aspirin prior to performing interventional techniques.

There is fair evidence that excessive bleeding, including epidural hematoma formation may occur with interventional techniques when antithrombotic therapy is continued, the risk of thromboembolic phenomenon is higher than the risk of epidural hematomas with discontinuation of antiplatelet therapy prior to interventional techniques, to continue phosphodiesterase inhibitors (dipyridamole [Persantine], cilostazol [Pletal], and Aggrenox [aspirin and dipyridamole]), and that anatomic conditions such as spondylosis, ankylosing spondylitis and spinal stenosis, and procedures involving the cervical spine; multiple attempts; and large bore needles increase the risk of epidural hematoma; and rapid assessment and surgical or nonsurgical intervention to manage patients with epidural hematoma can avoid permanent neurological complications. 
There is limited evidence to discontinue antiplatelet therapy with platelet aggregation inhibitors to avoid bleeding and epidural hematomas and/or to continue antiplatelet therapy clopidogrel (Plavix), ticlopidine (Ticlid), or prasugrel (Effient) during interventional techniques to avoid cerebrovascular and cardiovascular thromboembolic fatalities.

There is limited evidence in reference to newer antithrombotic agents dabigatran (Pradaxa $($ ) and rivaroxaban (Xarelto@) to discontinue to avoid bleeding and epidural hematomas during interventional techniques and to continue to avoid cerebrovascular and cardiovascular thromboembolic events.

Recommendations: The recommendations derived from the comprehensive assessment of the literature and guidelines are to continue NSAIDs and low dose aspirin, and phosphodiesterase inhibitors (dipyridamole, cilostazol, Aggrenox) during interventional techniques. However, the recommendations for discontinuation of antiplatelet therapy with platelet aggregation inhibitors (clopidogrel, ticlopidine, prasugrel) is variable with clinical judgment to continue or discontinue based on the patient's condition, the planned procedure, risk factors, and desires, and the cardiologist's opinion. Low molecular weight heparin $(\mathrm{LMWH})$ or unfractionated heparin may be discontinued 12 hours prior to performing interventional techniques. Warfarin should be discontinued or international normalized ratio (INR) be normalized to 1.4 or less for high risk procedures and 2 or less for low risk procedures based on risk factors. It is also recommended to discontinue Pradaxa for 24 hours for paravertebral interventional techniques in 2 to 4 days for epidural interventions in patients with normal renal function and for longer periods of time in patients with renal impairment, and to discontinue rivaroxaban for 24 hours prior to performing interventional techniques.

Limitations: The paucity of the literature.

Conclusion: Based on the available literature including guidelines, the recommendations in patients with antithrombotic therapy for therapy prior to interventional techniques are provided.

Key words: Perioperative bleeding, bleeding risk, practice patterns, anticoagulant therapy, antithrombotic therapy, interventional techniques, safety precautions

Pain Physician 2013; 16:-SE261-SE318

$\Delta$ mong various issues facing interventional pain physicians on a daily basis, bleeding risk and perioperative management of patients on anticoagulants and antithrombotic therapy is one of the major ones without appropriate guidance or literature to support the existing opinions. The majority of guidelines developed thus far are not based on appropriate evidence, due to the paucity of evidence in this area. Cardiovascular and cerebrovascular diseases are among the leading causes of morbidity and mortality (1-5), and chronic persistent pain is the leading cause of disability and functional impairment across the globe (6-13). Thus, chronic persistent pain and cardiovascular disease are associated with significant impairment of physical and psychological health and performance of social responsibilities, including work and family life (1-13). Antithrombotic therapy has been established with a favorable risk benefit ratio for prevention of cardiovascular disease and in limiting the present and future burden of cardiovascular and cerebrovascular disorders (14-36). It has been estimated that a significant proportion of patients with cardiovascular, cerebrovascular, or peripheral vascular disease, receiving antithrombotic therapy, undergo surgical interventions including interventional techniques.

Interventional techniques are performed with increasing frequency to manage chronic persistent pain, even though it is often debated in reference to their effectiveness, safety, and appropriate indications (37-80). Based on a recent survey it appears that the majority of interventional pain physicians discontinue antiplatelet therapy and anticoagulant therapy (81), even though continuation of antithrombotic therapy is considered as "safe" (82-84). Based on the multiple guidelines published with evidence derived from case reports, it has been generally accepted to stop antiplatelet therapy and is considered as standard of care by some (85-95). However, there is also significant disagreement among the guidelines. Even though, epidural hematomas have been reported in one in 150,000 of all epidurals, the incidence has been higher in cervical and thoracic spine. There is also a trend of increasing epidural hematoma cases following neuraxial blocks $(81,88,89,96,97)$; however, one report indicates decreasing tendencies (98). Epidural hematoma is a serious complication that may result in spinal cord injury but only occurs with proce- 
dures that involve placing a needle into the spinal canal (i.e. posterior interlaminar epidural steroid injection). Epidural hematoma is not a risk of injections of the exterior spine such as medial branch blocks.

The risks of withdrawing antiplatelet therapy include cardiovascular, cerebrovascular, and peripheral vascular thrombosis which may results in ominous consequences including stroke and death. In a systematic review and meta-analysis of the hazards of discontinuing or not adhering to aspirin regimens among patients at risk for coronary artery disease (14), noncompliance or withdrawal of aspirin treatment was associated with significant complications in those with or at moderate to high risk for coronary artery disease. This study showed aspirin non-adherence or withdrawal being associated with a 3-fold higher risk of major adverse cardiac events which was magnified in patients with intracoronary stents with the conclusion that aspirin discontinuation in such patients should be advocated only when bleeding risk clearly overwhelms that of atherothrombotic events. In a study of the evaluation of incidence of death and acute myocardial infarction (MI) associated with the discontinuation of clopidogrel (Plavix®) after acute coronary artery syndrome (19), the authors observed a clustering of adverse events in the initial 90 days after discontinuation among both medically treated and percutaneous coronary intervention treated patients with acute coronary syndrome, supporting the possibility of clopidogrel rebound effect. It has been described that more than two-thirds of the sudden cardiac events (acute coronary syndrome or sudden cardiac death) (99-101) and half of the postoperative Mls $(99,102-105)$ are due to the disruption and thrombosis of an unstable plaque. The data on cerebrovascular events are not known; however, acute coronary syndrome is linked with pro-inflammatory and pro-thrombotic conditions that involve an increase in fibrinogen, C-reactive protein, and plasminogen activator inhibitor (106). Thus, in the postoperative setting, the risk of acute coronary syndrome is further aggravated by augmented release of endogenous catecholamines, increased platelet adhesiveness, and decreased fibrinolysis, which are characteristic of the acute phase reaction $(104,107,108)$.

It has also been described that stoppage of antiplatelet therapy may result in either hypercoagulability with thrombosis or bleeding complications $(14,17,18,109-148)$. Studies assessing the risk of maintaining antiplatelet therapy have shown increased surgical blood loss of $2.5 \%$ to $20 \%$ with aspirin and $30 \%$ to
$50 \%$ with aspirin and clopidogrel $(126,149)$. However, no increase in surgical mortality has been linked to the increased bleeding, except during intracranial surgery $(115,126)$. An average increase of $30 \%$ in transfusion rate with a complication rate of red blood cell transfusion in only $0.4 \%$ of the patients (150) and mortality linked directly to massive surgical blood loss of less than 3\% has been reported (151). However, the risks of withdrawing the antiplatelet therapy also have been described with a rebound effect with increased platelet adhesiveness $(130,132,136,137)$; simultaneously, the systemic inflammatory syndrome and the acute phase reaction to surgery increases platelet adhesiveness and decreases fibrinolysis $(27,99,104)$; and some pathologies, such as carcinoma and diabetes, are accompanied by hyper-coagulability. It has also been shown that infarction and death rates in acute coronary syndrome were doubled (136). Further, during the re-endothelialization phase of coronary stents, a myocardiac infarction rate of up to $85 \%$ due to stent thrombosis has been reported in one postoperative study (141) with an increase of the perioperative cardiac death rate by 5 to 10 times, compared to the average stent thrombosis of $35 \%$ and the average mortality of stent thrombosis of $20 \%$ to $40 \%(17,99,138,152)$ without noncardiac surgery.

Based on the available information, the risks of coronary events from withdrawing patients from antiplatelet agents in the perioperative period are generally higher than those of maintaining them through the perioperative period. Thus, Chassot et al (99) recommended that it is necessary to modify the approach of withdrawing patients from all antiplatelet agents 7 to 10 days before surgery, except when bleeding might occur in a closed cavity. After a comprehensive literature review, they (99) also proposed that even if large prospective studies with a high degree of evidence are still lacking on different antiplatelet regimens during noncardiac surgery, apart from low coronary risk situations, patients on antiplatelet drugs should continue their treatment throughout surgery, except when bleeding might occur in a closed space. They also recommended consideration of a therapeutic bridge with shorter-acting antiplatelet drugs. In fact, multiple guidelines have provided variable guidance (81-86,9095,153-166). In a systematic review, Dunn and Turpie (156) after evaluating 31 reports concluded that most patients can undergo dental procedures, arthrocentesis, cataract surgery, and diagnostic endoscopy without alteration of their anticoagulant regimen; however, for 
other invasive and surgical procedures, oral anticoagulation needs to be withheld and the decision whether to pursue an aggressive strategy of perioperative administration of intravenous heparin or subcutaneous low LMWH should be individualized. In a 2003 publication (167), current practice in the use of antiplatelet agents in the perioperative period by vascular surgeons showed that the general consensus of opinion from their survey suggested that most vascular surgeons do not stop antiplatelet drugs preoperatively. In fact, multiple recent publications also illustrated that endoscopy $(160,163)$, peripheral vascular surgery (161), and ophthalmic surgery (165) show no evidence of increased bleeding when the antiplatelet agents were continued through the perioperative period. In addition, Gerstein et al (166) also showed that for many operative procedures, the risk of perioperative bleeding while continuing aspirin is minimal, as compared with the concomitant thromboembolic risks associated with aspirin withdrawal. Lip et al (165), in evaluating perioperative management of ophthalmic patients taking antithrombotic therapy, based on the current evidence, recommended the continued use of aspirin and, with some exceptions, warfarin in the perioperative period. They described that the risk of thrombosis-related complications and disruption of anticoagulation may be higher than the risk of significant bleeding by continuing its use for most types of ophthalmic surgery. With the increasing performance of interventional procedures over the years, the number of patients undergoing interventional techniques, with not only coronary artery stenting, but a multitude of other cardiovascular, peripheral vascular, and cerebrovascular risk factors may be increasing. Thus, interventional pain physicians managing these patients are confronted with the complex issue of weighing the risks of hemorrhagic complications when continuing the antiplatelet agents in the perioperative period against the risk of cerebral and cardiovascular events if the drugs are discontinued abruptly. Even though data suggest that traditional attitude of discontinuing the medication 7 days before interventions poses considerable risk, multiple guidelines recommend these polices and it has been a general practice to discontinue these drugs (81-99). A recent evaluation by Manchikanti et al (82) of over 18,000 procedures with over 12,000 encounters and over 3,000 patients, showed no significant prevalence of adverse events observed in those who continued with or ceased antithrombotic therapy. In addition, another issue related to interventional pain management is that most reports are related to regional anesthesia for surgical procedures, with few reports of epidural hematoma in patients undergoing interventional techniques for chronic pain with or without antithrombotic therapy continued or discontinued.

Thus, this comprehensive review with best evidence synthesis is undertaken to evaluate the role of the risk of bleeding in interventional pain management, with a best evidence synthesis of practice patterns and perioperative management of anticoagulant and antithrombotic therapy.

\subsection{Methods}

The methodology utilized in this systematic review followed the review process derived from evidencebased systematic reviews and a meta-analysis of randomized trials and observational studies (168-170), and Standards for Reporting Observational Studies (STROBE) (170).

\subsection{Criteria for Considering Studies for This Review}

\subsubsection{Types of Studies}

Randomized controlled trials

Non-randomized observational studies

Case reports and reviews

\subsubsection{Types of Facilities}

Hospital outpatient facilities, ambulatory surgery centers (ASCs), and office practices performing interventional techniques were included.

\subsubsection{Types of Interventions}

All types of interventions, from simple injections to major procedures such as disc decompression and implantables, were included.

\subsubsection{Types of Outcome Measures}

The primary objectives were to assess overall bleeding risk and risk of thrombosis in patients receiving anticoagulant or antiplatelet therapy undergoing interventional techniques.

\subsection{Literature Search}

Searches were performed from the following sources without language restrictions:

1. PubMed from 1966

www.ncbi.nlm.nih.gov/sites/entrez?db=pubmed

2. EMBASE from 1980 
www.embase.com

3. Cochrane Library www.thecochranelibrary.com/view/0/index.html

4. U.S. National Guideline Clearinghouse (NGC) www.guideline.gov

5. Previous systematic reviews and cross references

6. Clinical Trials www.clinicaltrials.gov

7. FDA www.fda.gov

The search period was from 1966 through December 2012.

\subsection{Search Strategy}

The search strategy emphasized bleeding risk, antithrombotics, antiplatelets, cardiovascular events, cerebrovascular events, thrombotic events, interventional techniques, bleeding complications, and epidural hematoma related to interventional techniques.

At least 2 of the review authors independently, in an unblinded standardized manner, performed each search. Accuracy was confirmed by a statistician. All searches were combined to obtain a unified search strategy. Any disagreements between reviewers were resolved by a third author and consensus.

\subsection{Data Collection and Analysis}

The review focused on all types of reports including case reports and reviews.

\subsubsection{Selection of Studies}

- In an unblinded standardized manner, 2 review authors screened the abstracts of all identified studies.

- All articles with possible relevance were then retrieved in full text for comprehensive assessment.

\subsubsection{Methodological Quality or Validity Assessment}

Due to the inherent difficulty with the literature describing adverse effects such as bleeding and rare occurrence of fatal complications of thrombosis and bleeding, all available literature was included without methodologic quality or validity assessment. However, critical assessment of the literature was performed.

Each study was evaluated by at least 2 authors and any disagreements about conclusions were discussed with a third reviewer. Authors with a perceived conflict of interest for any manuscript were recused from reviewing the manuscript.

\subsubsection{Data Extraction and Management}

Two review authors independently, in an unblinded standardized manner, extracted the data from the included studies. Disagreements were resolved by discussion between the 2 reviewers; if no consensus could be reached, a third author was called in to break the impasse.

\subsection{Summary Measures}

Summary measures included fatal thrombotic and bleeding events and other complications.

\subsection{Analysis of Evidence}

Due to the nature of the issue and available literature, criteria developed by the United States Preventive Services Task Force (USPSTF) (171) or other criteria could not be utilized, thus, the evidence was analyzed based on a preponderance indicating causal relationship.

\subsection{Results}

An extensive search of the literature yielded multiple manuscripts $(81-98,172-400)$. The majority of the reports were case reports except for some guidelines and studies of assessment of bleeding and thromboembolic risk.

\subsection{Risk of Bleeding with Interventional Techniques}

Table 1 shows multiple studies conducted to assess the risk of bleeding and thrombolic events (81$84,91,96,173,174,195,197,218,229,255,298)$.

\subsection{Case Reports of Spontaneous or Traumatic Epidural Hematoma}

Table 2 shows the case reports of spontaneous epidural hematoma or bleeding complications.

Overall, there were 41 case reports which were available with descriptions (181,202,203,20 $7,208,223,225,231,232,245,260,261,263,275, \quad 278$, $295,319,334,335,337,343-345,348-352,357,358$, $362,365,367,368,373,376,378-380,383,385)$. Some case reports were not available $(347,347)$. Further, many of them may not have been reported. There were 5 case reports of spontaneous epidural hematoma following chiropractic manipulation and strenuous activity $(203,208,231,383,385)$.

Table 3 shows the case reports of bleeding and epidural hematoma associated with interventional techniques in the absences of antithrombotic therapy. At least 8 case reports of epidural hematoma associated with antithrombotic therapy with interventional 


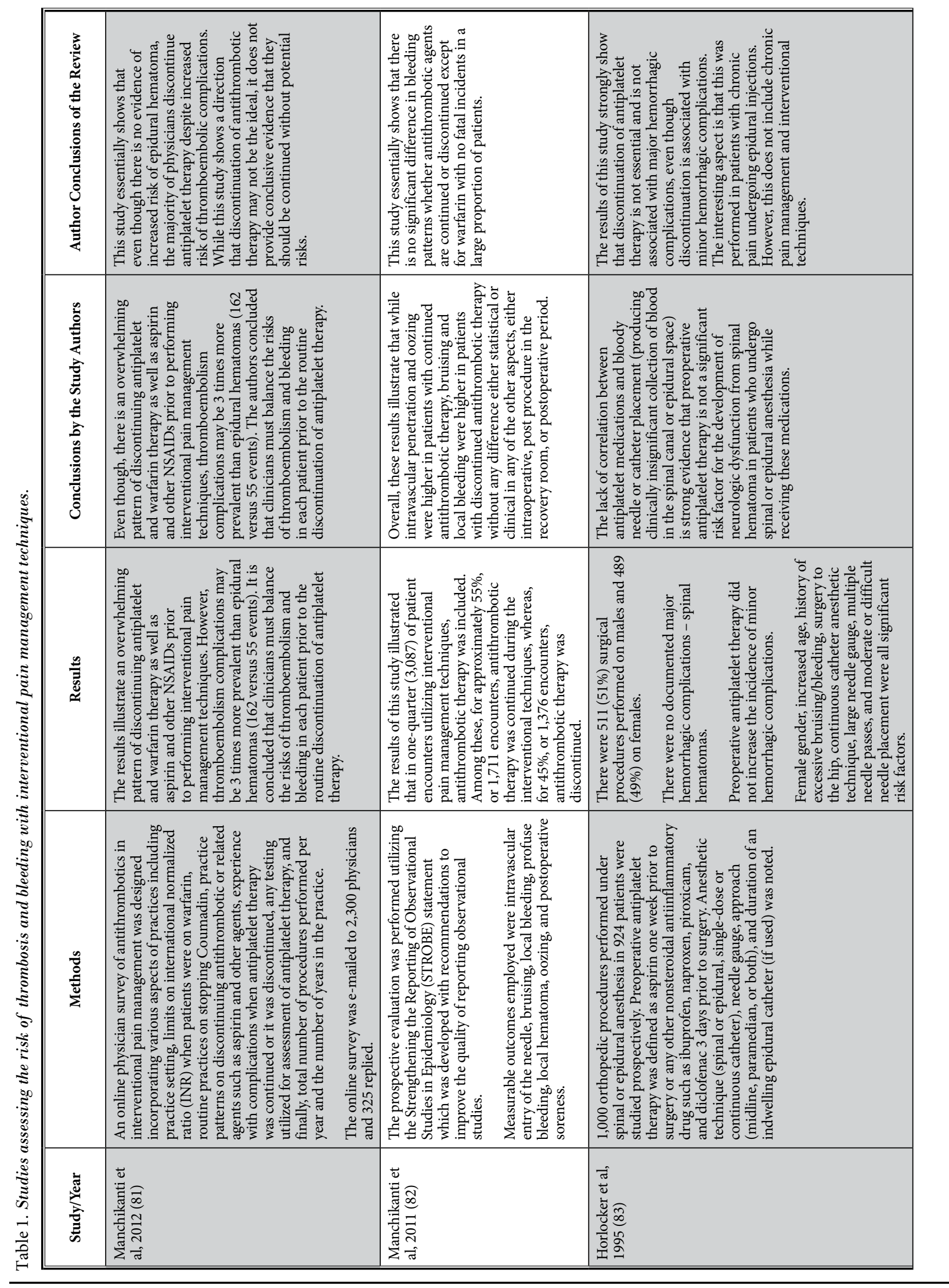




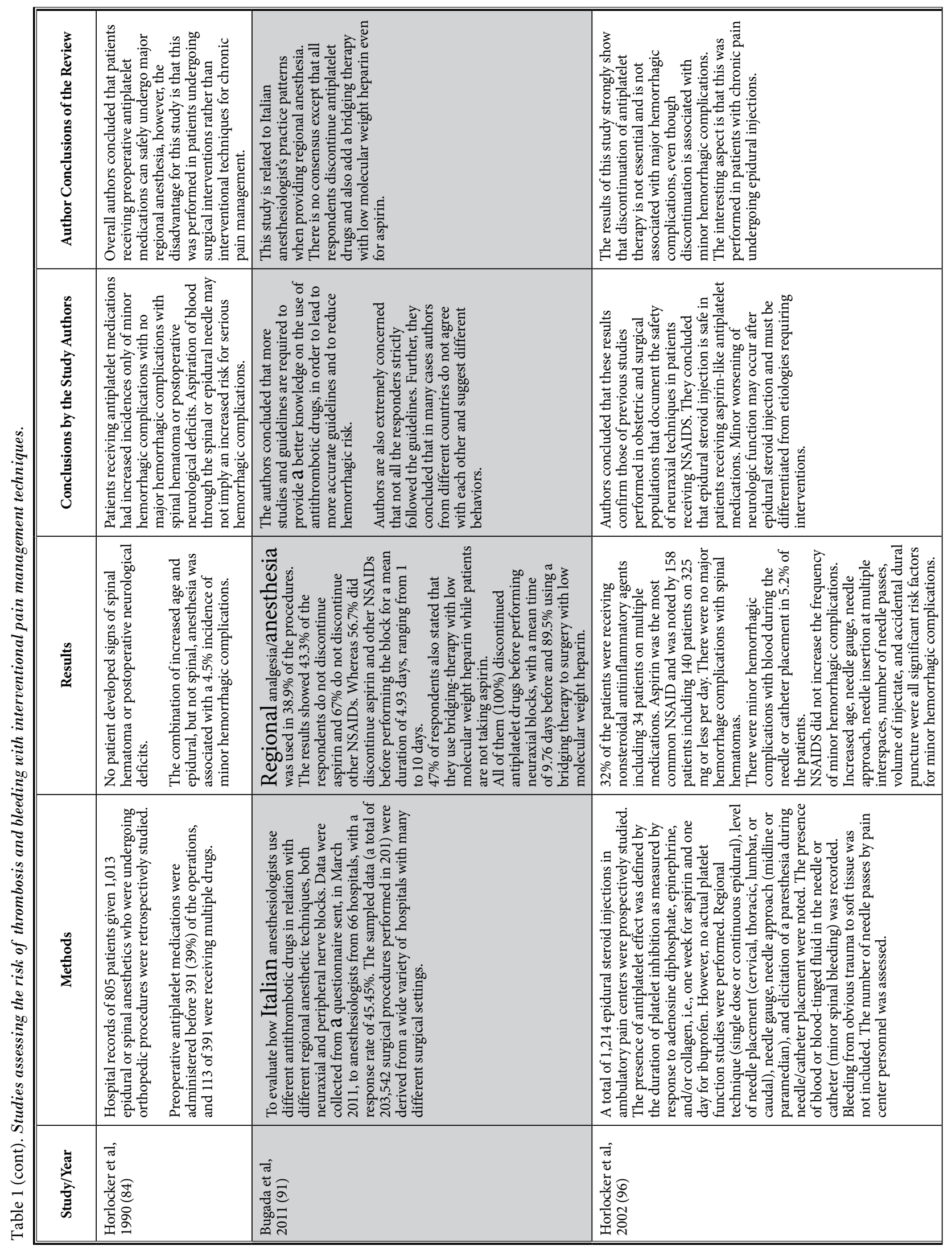

www.painphysicianjournal.com 


\begin{tabular}{|c|c|c|c|c|c|}
\hline 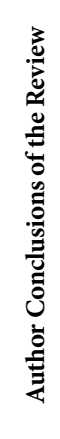 & \multicolumn{2}{|l|}{ 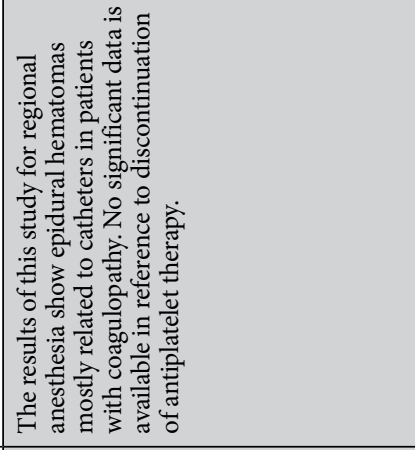 } & 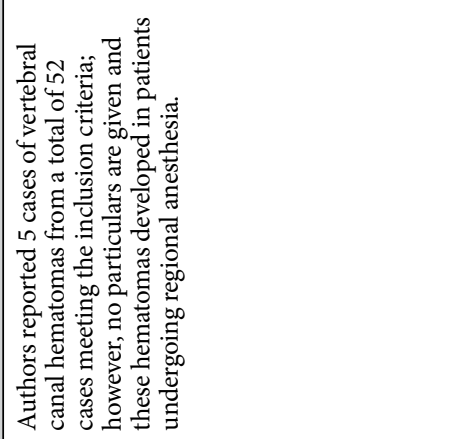 & 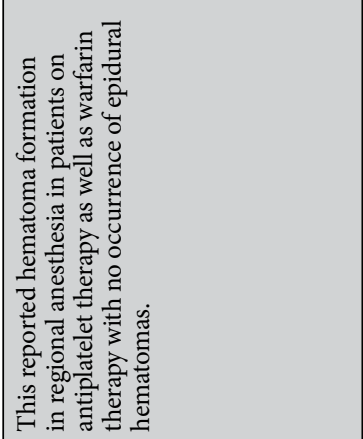 & 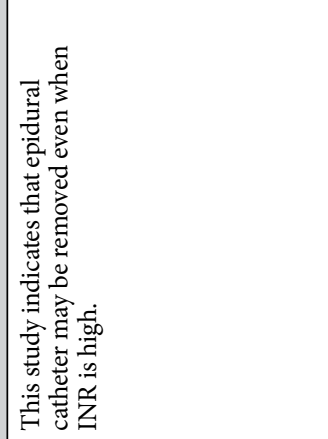 \\
\hline 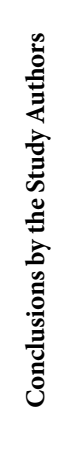 & \multicolumn{2}{|l|}{ 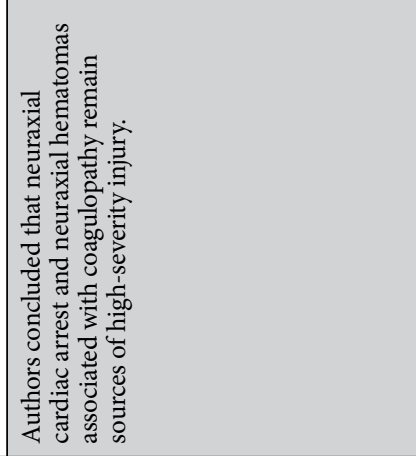 } & 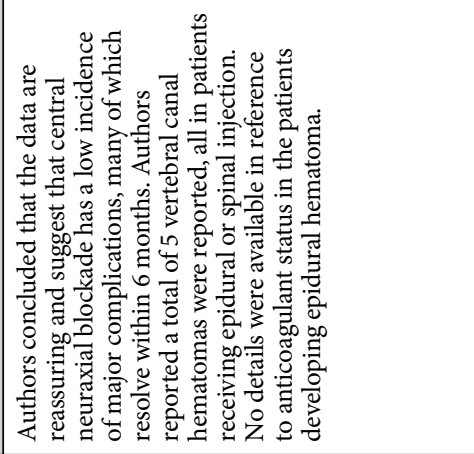 & 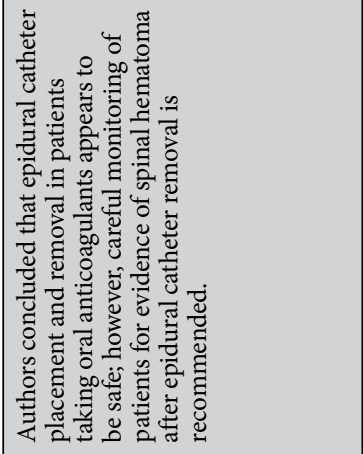 & 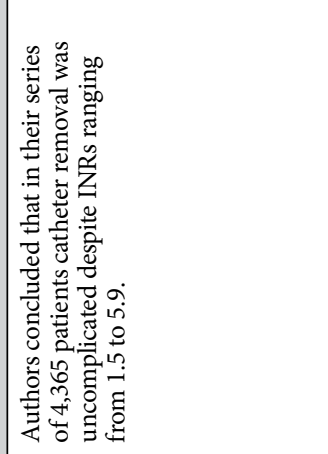 \\
\hline 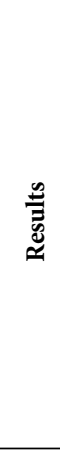 & \multicolumn{2}{|c|}{ 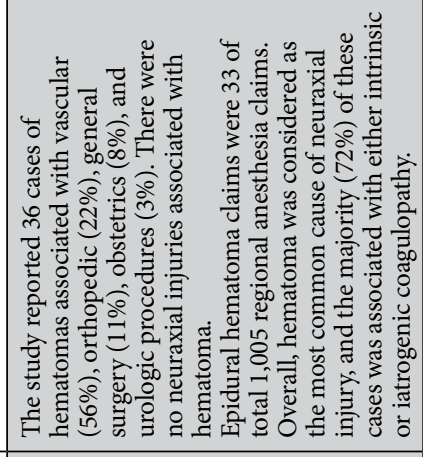 } & 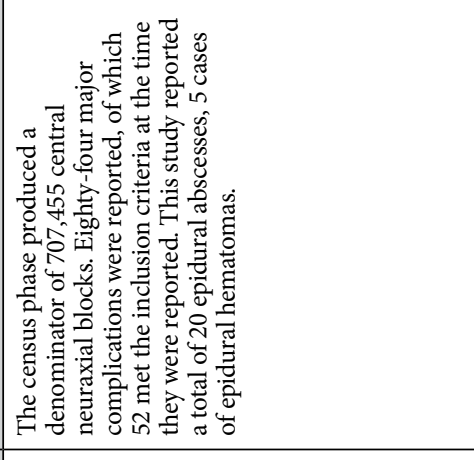 & 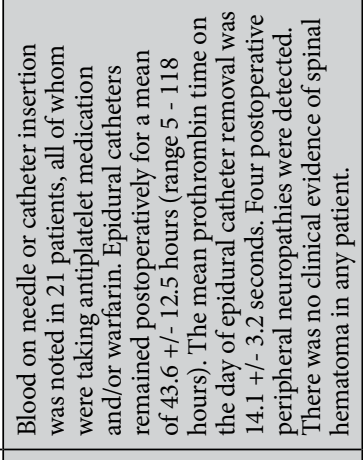 & 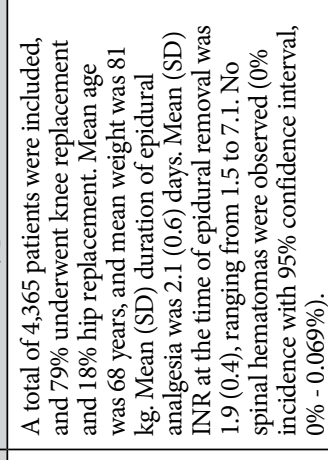 \\
\hline 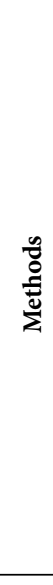 & 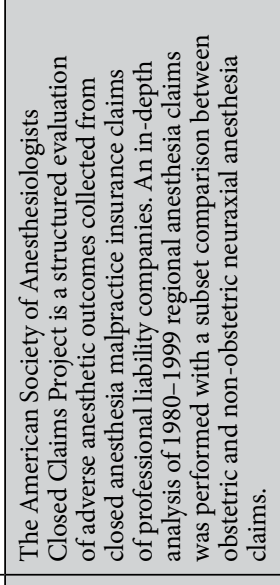 & 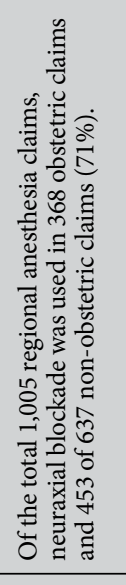 & 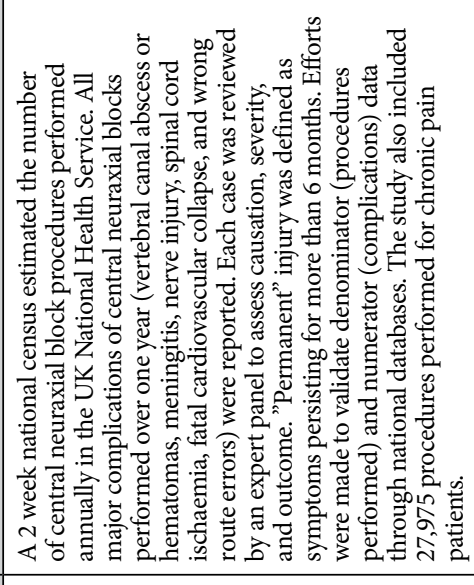 & 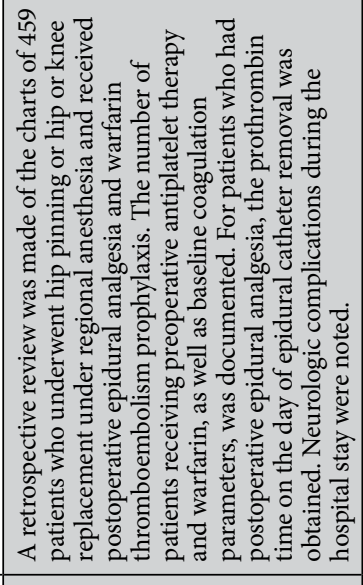 & 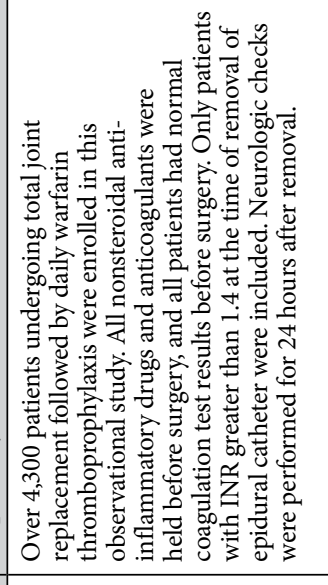 \\
\hline 营 & 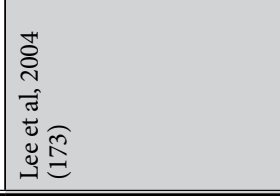 & & 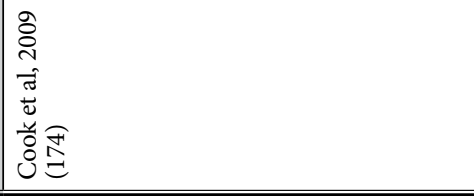 & 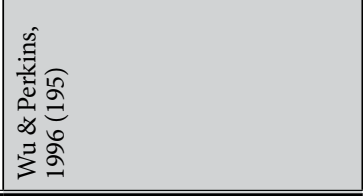 & 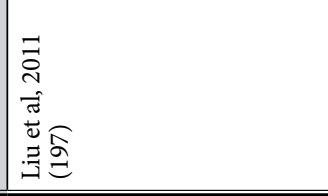 \\
\hline
\end{tabular}




\begin{tabular}{|c|c|c|c|c|}
\hline 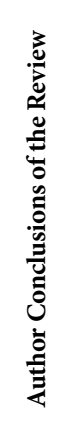 & 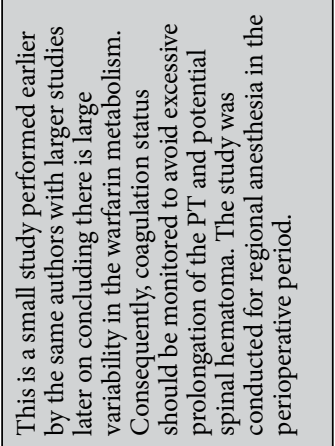 & 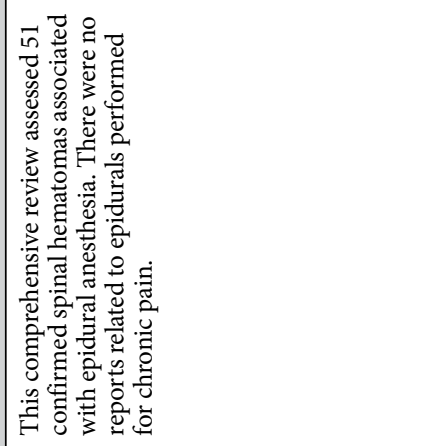 & 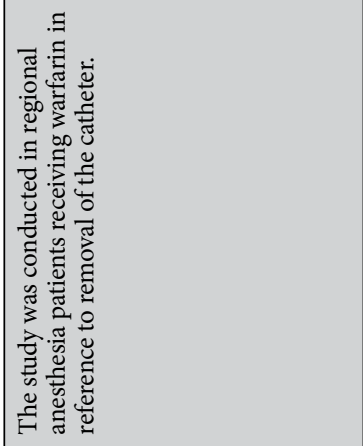 & 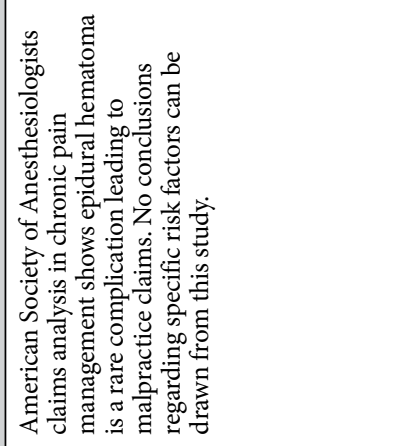 \\
\hline 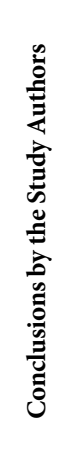 & 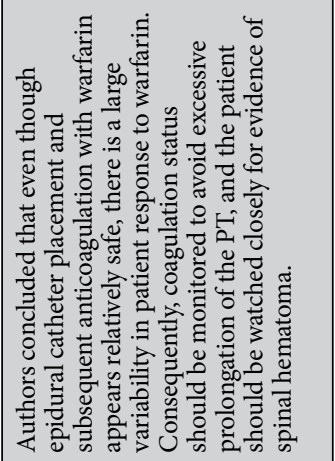 & 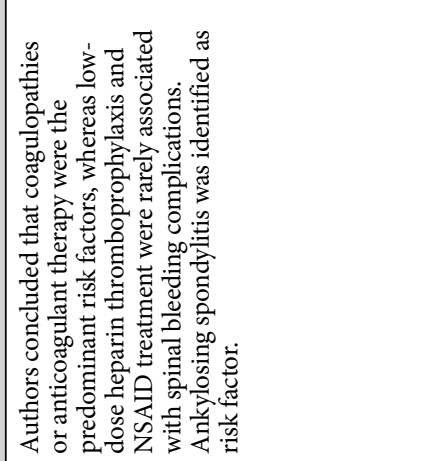 & 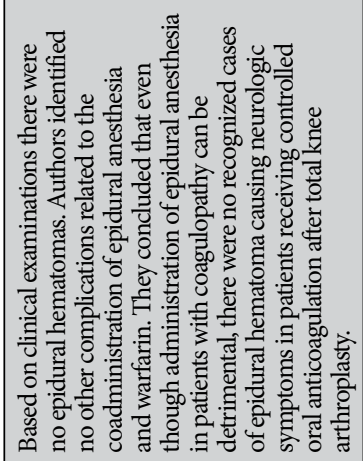 & 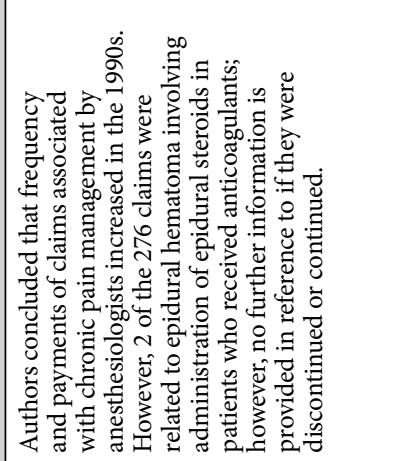 \\
\hline $\begin{array}{l}\frac{\mathscr{Q}}{\bar{z}} \\
\cong\end{array}$ & 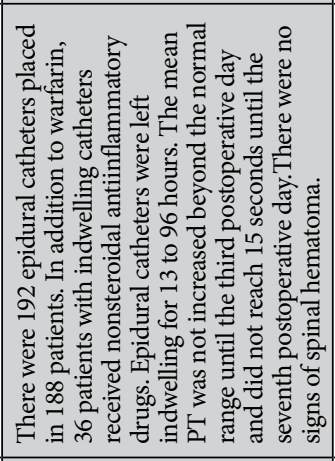 & 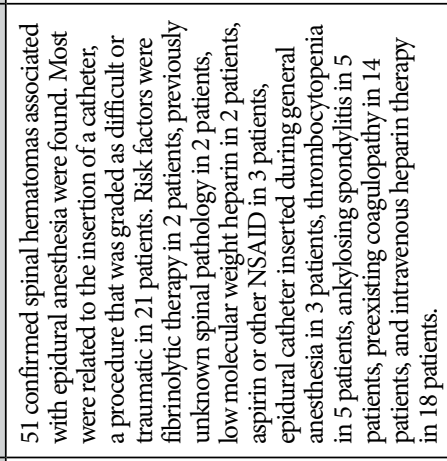 & 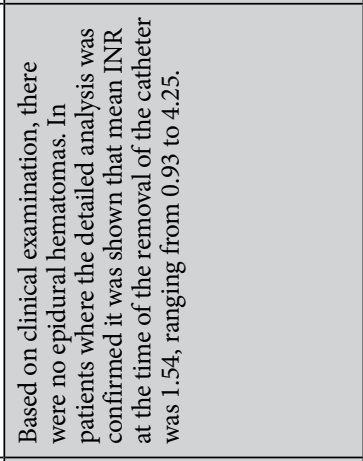 & 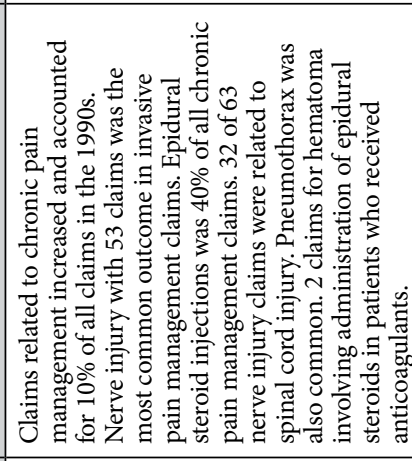 \\
\hline $\begin{array}{l}\frac{a}{0} \\
\frac{\vec{E}}{\Sigma} \\
\sum\end{array}$ & 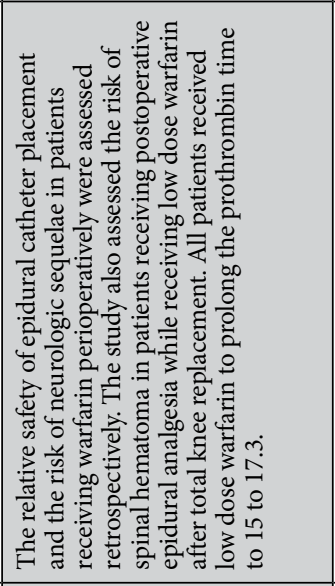 & 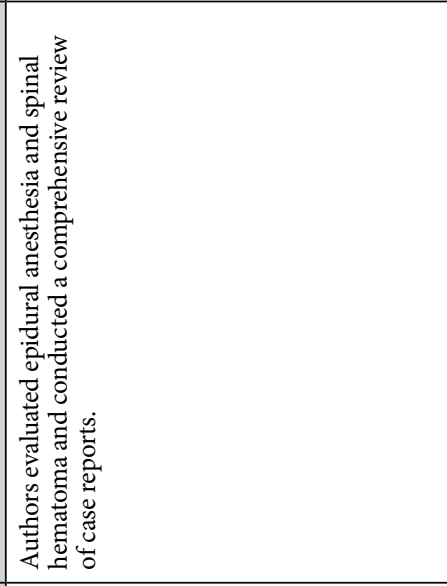 & 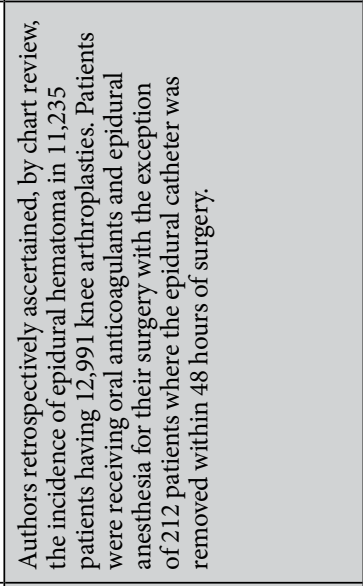 & 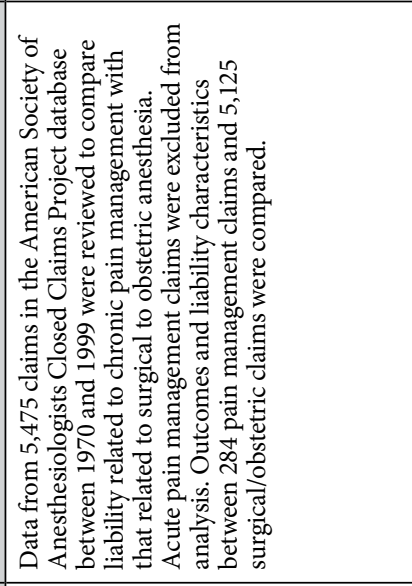 \\
\hline 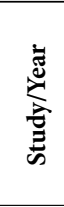 & 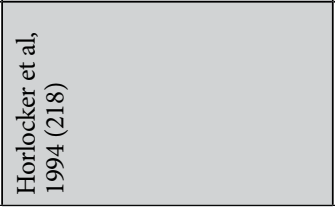 & 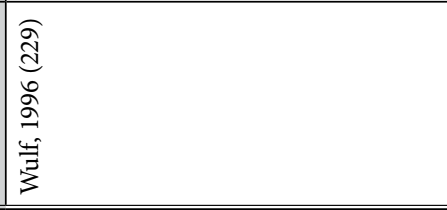 & 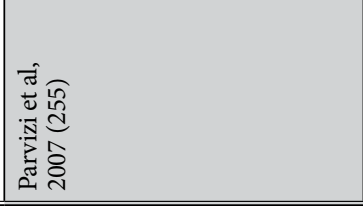 & 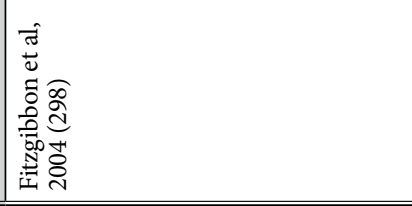 \\
\hline
\end{tabular}


Table 2. Descriptions of reports of spontaneous or traumatic bleeding.

\begin{tabular}{|c|c|c|c|}
\hline Study/Year & Case Report & Conclusions by the Study Authors & $\begin{array}{l}\text { Author Conclusions of } \\
\text { the Review }\end{array}$ \\
\hline $\begin{array}{l}\text { Anderson \& } \\
\text { Donaldson, } \\
1989 \text { (181) }\end{array}$ & $\begin{array}{l}\text { A patient with a spontaneous cervical spinal epidural hematoma } \\
\text { was described. There was complete clinical and radiological } \\
\text { resolution with non-operative treatment. This is the fifth } \\
\text { recorded case of spontaneous resolution of spinal epidural } \\
\text { hematoma as of publication of this case report in } 1989 .\end{array}$ & $\begin{array}{l}\text { Even though surgical decompression } \\
\text { is generally recorded as mandatory, } \\
\text { in selected patients with incomplete } \\
\text { and non-progressing deficit, } \\
\text { conservative management may be } \\
\text { possible. }\end{array}$ & $\begin{array}{l}\text { This case illustrates } \\
\text { spontaneous cervical spinal } \\
\text { epidural hematoma which } \\
\text { is successfully managed } \\
\text { conservatively without } \\
\text { surgical intervention. }\end{array}$ \\
\hline $\begin{array}{l}\text { Urculo } \\
\text { Bareño \& } \\
\text { Arrazola } \\
\text { Schlamich, } \\
1987 \text { (202) }\end{array}$ & $\begin{array}{l}\text { The author reported one case of spontaneous spinal epidural } \\
\text { hematoma in the cervical spine of unknown etiology extending } \\
\text { over C3 to C6. Cervical epidural hematoma was diagnosed by } \\
\text { CT. The clinical picture was characterized by sudden onset of } \\
\text { severe cervical or intrascapular pain, associated with radicular } \\
\text { radiation into the upper extremities, followed by development } \\
\text { of progressive signs of spinal cord compression with varying } \\
\text { degree of motor and sensory paralysis. Complete recovery was } \\
\text { accomplished after surgical treatment, within } 36 \text { hours after the } \\
\text { onset of symptoms. }\end{array}$ & $\begin{array}{l}\text { The authors emphasized the } \\
\text { importance of an early diagnosis } \\
\text { easily possible with CT in } 1987 \text {. } \\
\text { They also described that the CT } \\
\text { findings are similar to intracranial } \\
\text { acute epidural hematoma, showing a } \\
\text { characteristic hyperdense lenticular } \\
\text { collection, typically localized in the } \\
\text { dorsal lateral spinal epidural space. } \\
\text { They felt that the surgical indication } \\
\text { is absolute. }\end{array}$ & $\begin{array}{l}\text { This case report in } 1987 \\
\text { is in contrast to the } \\
\text { one published in } 1989 \\
\text { which mandates surgical } \\
\text { intervention. }\end{array}$ \\
\hline $\begin{array}{l}\text { Zupruk \& } \\
\text { Mehta, } 1989 \\
\text { (203) }\end{array}$ & $\begin{array}{l}\text { Post traumatic cervical epidural hematoma is an uncommon } \\
\text { entity. This case report in } 1989 \text { presented post traumatic cervical } \\
\text { epidural hematoma manifesting as Brown-Séquard syndrome } \\
\text { which manifested after chiropractic manipulation of the neck. } \\
\text { Both are rarities, namely cervical epidural hematoma as well as } \\
\text { Brown-Séquard syndrome. The diagnosis was made with CT } \\
\text { scanning and surgical evaluation of the hematoma was followed } \\
\text { by full recovery. }\end{array}$ & $\begin{array}{l}\text { The authors concluded that it is a } \\
\text { rare phenomenon to have cervical } \\
\text { epidural hematoma after chiropractic } \\
\text { manipulation and at the same time } \\
\text { to present with Brown-Séquard } \\
\text { syndrome. }\end{array}$ & $\begin{array}{l}\text { Chiropractic manipulation } \\
\text { can cause cervical epidural } \\
\text { hematoma specifically } \\
\text { in patients with severe } \\
\text { cervical spondylosis. }\end{array}$ \\
\hline $\begin{array}{l}\text { Crabbe et al, } \\
1992(207)\end{array}$ & $\begin{array}{l}\text { A healthy } 20 \text {-year old male developed an extradural hematoma } \\
\text { in his cervical spinal canal after an episode of "disco dancing" } \\
\text { and "head banging." The following day he complained of neck } \\
\text { pain, and } 36 \text { hours after this, he presented to the hospital } \\
\text { complaining of weakness of his left arm and leg with sensory } \\
\text { loss in his right leg. CT scan of the cervical spine showed an } \\
\text { extradural hematoma located in the left side of the spinal canal } \\
\text { between the levels of C4 and C6. The patient had symptoms } \\
\text { of Brown-Séquard syndrome. The patient was treated with } \\
\text { intravenous steroids and improved without surgical intervention. }\end{array}$ & $\begin{array}{l}\text { The authors concluded that cervical } \\
\text { spinal extradural hematoma causing } \\
\text { a transient Brown-Séquard syndrome } \\
\text { resolved with steroid therapy. }\end{array}$ & $\begin{array}{l}\text { The study indicates either } \\
\text { spontaneous epidural } \\
\text { hematoma without needle } \\
\text { placement or surgery } \\
\text { with usual movements } \\
\text { in dancing resolved with } \\
\text { conservative management. }\end{array}$ \\
\hline $\begin{array}{l}\text { Whedon } \\
\text { et al, } 2006 \\
\text { (208) }\end{array}$ & $\begin{array}{l}\text { A 79-year-old man with a past medical history of polymyalgia } \\
\text { rheumatica, congestive heart failure, and atrial fibrillation, for } \\
\text { which he was undergoing long-term anticoagulant therapy and } \\
\text { underwent chiropractic manipulation. } \\
\text { Soon after his treatment, the patient developed signs of cord } \\
\text { compression. Investigations showed injury to the cord. The } \\
\text { patient was treated with fresh frozen plasma and vitamin K and } \\
\text { underwent C4/5 laminectomies. Postoperatively, the patient } \\
\text { slowly regained his strength; he was discharged to a rehabilitation } \\
\text { center on postoperative day } 5 \text {. At follow-up, several months after } \\
\text { discharge, he had nearly full strength. }\end{array}$ & $\begin{array}{l}\text { Authors concluded that practitioners } \\
\text { of spinal manipulative therapy } \\
\text { should be aware of spinal epidural } \\
\text { hematoma as a possible complication } \\
\text { of manipulation in patients at risk } \\
\text { and should exercise caution in } \\
\text { the care of patients undergoing } \\
\text { anticoagulant therapy. }\end{array}$ & $\begin{array}{l}\text { This case report shows } \\
\text { chiropractic manipulation } \\
\text { resulting in epidural } \\
\text { hematoma in a patient } \\
\text { with multiple cervical } \\
\text { spine abnormalities despite } \\
\text { appropriate diagnosis } \\
\text { and surgical intervention } \\
\text { the result was borderline } \\
\text { taking several months to } \\
\text { recover. }\end{array}$ \\
\hline $\begin{array}{l}\text { Nourbakhsh } \\
\text { \& Garges, } \\
2007 \text { (223) }\end{array}$ & $\begin{array}{l}\text { This is a case report of hematoma of the lumbar spinal synovial } \\
\text { joint in a } 67 \text {-year old man on anticoagulant therapy who } \\
\text { presented with progressive neurologic symptoms in the right } \\
\text { lower extremity. MRI revealed a lesion which was thought to be } \\
\text { a synovial joint cyst; however, during surgery, it was proven to } \\
\text { be epidural hematoma originating from the synovial joint. The } \\
\text { patient recovered completely with surgical decompression. }\end{array}$ & $\begin{array}{l}\text { The authors stated that this was } \\
\text { the first report of synovial cyst } \\
\text { hematoma due to anticoagulant } \\
\text { therapy but spontaneous without } \\
\text { trauma. }\end{array}$ & $\begin{array}{l}\text { The case report indicates } \\
\text { that epidural hematoma } \\
\text { can masquerade in } \\
\text { many forms occurring } \\
\text { without needle placement } \\
\text { or surgery and proper } \\
\text { diagnosis will yield } \\
\text { appropriate recovery. }\end{array}$ \\
\hline $\begin{array}{l}\text { Song \& Lee, } \\
2005 \text { (225) }\end{array}$ & $\begin{array}{l}\text { This report presents } 2 \text { patients who had acute paraplegia with } \\
\text { sensory loss due to spontaneous spinal epidural hematoma. } \\
\text { One had myocardial infarction and the other had deep vein } \\
\text { thrombosis and the former was treated with anticoagulants and } \\
\text { the latter was treated with thrombolytic agent. } \\
\text { Postoperatively, both showed no improvement of neurological } \\
\text { symptoms, and on follow-up of } 12 \text { months, one showed no } \\
\text { neurological improvement and the other showed insignificant } \\
\text { improvement of lower extremity muscle power. }\end{array}$ & $\begin{array}{l}\text { The authors thought that this } \\
\text { poor outcome was due to delayed } \\
\text { operation, which was done more } \\
\text { than } 24 \text { hours after symptom onset. } \\
\text { The outcome in spontaneous spinal } \\
\text { epidural hematoma is essentially } \\
\text { determined by the time taken } \\
\text { from symptom onset to operation, } \\
\text { therefore they concluded early and } \\
\text { precise diagnosis such as careful } \\
\text { history taking and MRI evaluation is } \\
\text { necessary. }\end{array}$ & $\begin{array}{l}\text { The authors emphasize the } \\
\text { prompt recognition and } \\
\text { surgical decompression of } \\
\text { epidural hematoma even } \\
\text { in case of spontaneous } \\
\text { epidural hematoma. }\end{array}$ \\
\hline
\end{tabular}


Table 2 (cont.). Descriptions of reports of spontaneous or traumatic bleeding.

\begin{tabular}{|c|c|c|c|}
\hline Study/Year & Case Report & Conclusions by the Study Authors & $\begin{array}{l}\text { Author Conclusions of } \\
\text { the Review }\end{array}$ \\
\hline $\begin{array}{l}\text { Heiner, } 2009 \\
(231)\end{array}$ & $\begin{array}{l}\text { Cervical epidural hematoma after chiropractic spinal manipulation } \\
\text { was reported in a healthy } 38 \text {-year old female } 4 \text { hours after the } \\
\text { short-term onset of numbness and pain in her neck and arms } \\
\text { during cervical spinal manipulation therapy by a chiropractor. } \\
\text { The diagnosis was made by MRI and MR angiography of the neck } \\
\text { without contrast. This showed a right-sided epidural hematoma } \\
\text { extending from the level of the foramen magnum to the C4 level } \\
\text { with associated mass effect upon the spinal cord. }\end{array}$ & $\begin{array}{l}\text { The patient was managed } \\
\text { conservatively and } 2 \text { weeks after } \\
\text { discharge, symptoms had completely } \\
\text { resolved with minimal residual } \\
\text { paraesthesias along the posterior part } \\
\text { of her neck. }\end{array}$ & $\begin{array}{l}\text { This case report illustrates } \\
\text { conservative management } \\
\text { in some cases is effective. }\end{array}$ \\
\hline $\begin{array}{l}\text { Abe et al, } \\
2009(232)\end{array}$ & $\begin{array}{l}\text { Spinal epidural hematoma after stretch exercise was reported } \\
\text { in a } 60 \text {-year old man with development of severe neck pain } \\
\text { and rapidly progressing weakness of left arm. Appropriate } \\
\text { diagnosis was made by MRI and the patient underwent surgical } \\
\text { intervention with evacuation of hematoma. However, upper } \\
\text { extremity weakness did not completely resolve. }\end{array}$ & $\begin{array}{l}\text { They concluded that early diagnosis } \\
\text { and treatment can confer a } \\
\text { significant prognostic advantage to } \\
\text { patients with spinal cord hematoma. }\end{array}$ & $\begin{array}{l}\text { Spontaneous epidural } \\
\text { hematoma successfully } \\
\text { treated with proper } \\
\text { diagnosis and appropriate } \\
\text { intervention. }\end{array}$ \\
\hline $\begin{array}{l}\text { Ohaegbulam } \\
\text { et al, } 2008 \\
(245)\end{array}$ & $\begin{array}{l}\text { Three cases were reported of lumbar epidural hematoma associated } \\
\text { with spondylolysis. The first case was a 15-year old athletic male } \\
\text { patient developing spontaneous epidural hematoma at the level } \\
\text { of pars fracture. Diagnosis was made by MRI and the patient was } \\
\text { managed conservatively, followed by physical therapy program for } \\
\text { strengthening. } \\
\text { The second patient was an } 18 \text {-year old male ice hockey player } \\
\text { who had experienced low back pain for } 2 \text { years prior to the onset. } \\
\text { The diagnosis of spontaneous hematoma was diagnosed by } \\
\text { MR imaging. It was managed conservatively with full recovery. } \\
\text { Hematoma was at the level of spondylolisthesis. } \\
\text { The third case was a 35-year old active male who experienced } \\
\text { onset of back tightness the morning after playing soccer. Epidural } \\
\text { hematoma was diagnosed. MR imaging obtained one month after } \\
\text { symptoms developed showed an epidural collection of dorsolateral } \\
\text { hematoma at L2/3 to the left with mild thecal sac compression. } \\
\text { A CT scan of his lumbar spine revealed bilateral pars defects but } \\
\text { no spondylolisthesis. The patient improved with conservative } \\
\text { management. }\end{array}$ & $\begin{array}{l}\text { The authors concluded that their } \\
\text { report described the clinical and } \\
\text { imaging findings in } 3 \text { cases of an } \\
\text { epidural hematoma associated with } \\
\text { spondylolysis. All cases resolved } \\
\text { without surgery and without } \\
\text { neurological deficit. This diagnostic } \\
\text { possibility should be considered } \\
\text { in the young active patient who } \\
\text { experiences new or increased } \\
\text { back and or leg pain and it may be } \\
\text { reasonable to avoid surgery in such } \\
\text { cases in which there is reasonable } \\
\text { certainty that the lesion noted on MR } \\
\text { imaging is a hematoma and there is } \\
\text { no progressive neurological deficit. }\end{array}$ & $\begin{array}{l}\text { This study once again } \\
\text { shows spontaneous } \\
\text { epidural hematoma which } \\
\text { can be resolved with } \\
\text { conservative management. }\end{array}$ \\
\hline $\begin{array}{l}\text { Borges et al, } \\
2000(260)\end{array}$ & $\begin{array}{l}\text { Acute cervical epidural hematoma was reported in a } 74 \text {-year } \\
\text { old patient with a nocturnal onset of neck and chest pain } \\
\text { which progressed to a flexed paralysis of the } 4 \text { extremities. } \\
\text { Initially lumbar puncture was performed. Subsequently CT } \\
\text { scan was done showing a large cervical epidural bleeding in the } \\
\text { posterolateral region of C4/5 extending from C7 to T1 along } \\
\text { with a C6 vertebral body hemangioma. A normal selective } \\
\text { angiography of multiple arteries was observed. Spontaneous } \\
\text { spinal epidural hematoma was diagnosed. The patient recovered } \\
\text { completely. }\end{array}$ & $\begin{array}{l}\text { The authors demonstrated that a rare } \\
\text { case of spinal cord decompression } \\
\text { and complete neurological } \\
\text { recovery may supervene when } \\
\text { the decompression is performed. } \\
\text { They concluded that spontaneous } \\
\text { spinal epidural hematoma is a rare } \\
\text { condition with a rather unfavorable } \\
\text { prognosis if left untreated. }\end{array}$ & $\begin{array}{l}\text { Even though authors } \\
\text { performed lumbar } \\
\text { puncture and symptoms } \\
\text { were relieved, MRI is the } \\
\text { choice of assessment for } \\
\text { the diagnosis. }\end{array}$ \\
\hline $\begin{array}{l}\text { Costabile } \\
\text { et al, } 1984 \\
(261)\end{array}$ & $\begin{array}{l}\text { The authors reported } 3 \text { cases of spinal epidural hematoma, one } \\
\text { lumbar, one cervical, and one thoracic. All were dorsolaterally } \\
\text { localized, the first and third were dependent on the anticoagulant } \\
\text { therapy and the second was spontaneous. The patients developed } \\
\text { sudden onset of spinal pain, flaccid paralysis, and loss of sphincter } \\
\text { control. The second case, with involvement of the cervical spine, } \\
\text { also had a cervical anterior spinal cord syndrome with preoperative } \\
\text { transient improvement, followed by the development of Brown } \\
\text { Séquard syndrome with subsequent deterioration. The postoperative } \\
\text { course was satisfactory in all patients with complete recovery in } 2 .\end{array}$ & $\begin{array}{l}\text { The authors opined that epidural } \\
\text { hematoma may develop with or } \\
\text { without anticoagulant therapy } \\
\text { spontaneously and the cervical } \\
\text { epidural hematoma may lead to } \\
\text { Brown Séquard syndrome with } \\
\text { subsequent deterioration. }\end{array}$ & $\begin{array}{l}\text { This reports } 3 \text { cases of } \\
\text { spontaneous epidural } \\
\text { hematoma in } 2 \text { patients } \\
\text { on anticoagulant therapy } \\
\text { and in one patient without } \\
\text { anticoagulant therapy. }\end{array}$ \\
\hline $\begin{array}{l}\text { Ng et al, } \\
2002(263)\end{array}$ & $\begin{array}{l}\text { The authors reported spinal epidural hematoma in a patient with } \\
\text { thrombocytopenia with traumatic epidural hematoma presenting } \\
\text { with right hemiparesis which progressed to complete tetraplegia. } \\
\text { Postoperatively the patient improved significantly. }\end{array}$ & $\begin{array}{l}\text { The authors opined that MRI } \\
\text { is an important modality in the } \\
\text { early diagnosis of spinal epidural } \\
\text { hematoma and can facilitate emergent } \\
\text { decompression surgery which offers } \\
\text { the best chance of neurological } \\
\text { improvement. }\end{array}$ & $\begin{array}{l}\text { This case shows } \\
\text { the importance of } \\
\text { early diagnosis and } \\
\text { decompression. The } \\
\text { epidural hematoma } \\
\text { developed without } \\
\text { interventional techniques, } \\
\text { but was related to trauma. }\end{array}$ \\
\hline
\end{tabular}


Table 2 (cont.). Descriptions of reports of spontaneous or traumatic bleeding.

\begin{tabular}{|c|c|c|c|}
\hline Study/Year & Case Report & Conclusions by the Study Authors & $\begin{array}{l}\text { Author Conclusions of } \\
\text { the Review }\end{array}$ \\
\hline & $\begin{array}{l}\text { A 19-year-old male who presented with a 2-month history of } \\
\text { neck pain and weakness of the upper and lower limbs without } \\
\text { sensory deficit was reported. MRI showed features of anteriorly } \\
\text { located cervical epidural hematoma. As the patient had started } \\
\text { improving by the time he sought neurosurgical consultation, } \\
\text { he was treated conservatively, and he improved over a period } \\
\text { of } 2 \text { months. This case illustrates that, though rare, chronic } \\
\text { spontaneous spinal epidural hematoma should be entertained in } \\
\text { the differential diagnosis of cervical cord compression. }\end{array}$ & $\begin{array}{l}\text { The authors concluded that chronic } \\
\text { spontaneous spinal epidural } \\
\text { hematoma is a rare cause of cervical } \\
\text { cord compression. However, } \\
\text { it should be entertained in the } \\
\text { differential diagnosis of chronic } \\
\text { cervical compressive myelopathy. } \\
\text { Since spontaneous spinal epidural } \\
\text { hematomas are known to resolve } \\
\text { spontaneously, in properly selected } \\
\text { cases, surgical intervention may not } \\
\text { always be necessary. }\end{array}$ & $\begin{array}{l}\text { Conservative management } \\
\text { was effective treatment in } \\
\text { this case. }\end{array}$ \\
\hline \multirow[t]{2}{*}{$\begin{array}{l}\text { Takano et al, } \\
1994 \text { (278) }\end{array}$} & $\begin{array}{l}\text { The authors reported a rare case of acute cervical epidural } \\
\text { hematoma caused by the hemorrhage from extradural arterio- } \\
\text { venous malformation. The patient was a } 74 \text {-year-old Japanese } \\
\text { man with a past history of total gastrectomy after being } \\
\text { diagnosed as having gastric cancer } 12 \text { years before. Six hours } \\
\text { prior to admission, the patient had experienced a sudden episode } \\
\text { of severe nuchal pain radiating to both scapular areas, followed } \\
\text { by rapid development of left-side Brown-Sequard Syndrome } \\
\text { below the C4 cord level, and urinary incontinence. Plain cervical } \\
\text { X-ray films did not show any destructive lesion suggesting } \\
\text { a metastatic tumor. T1 and T2 weighted images of MRI } \\
\text { demonstrated a high intensity mass lesion, suggesting an acute } \\
\text { epidural hematoma, extending from C3 to C6 and compressing } \\
\text { severely the left side spinal cord posteriorly. Twelve hours } \\
\text { after the onset of symptoms, an emergency laminectomy from } \\
\text { C3 to C6 was performed and a fresh epidural clot with small } \\
\text { vascular tissue was totally removed. Histological examination } \\
\text { of the small vascular tissue in the hematoma revealed arterio- } \\
\text { venous malformation. The postoperative recovery of the patient } \\
\text { was dramatic. He regained full muscle strength and there was } \\
\text { complete disappearance of sensory deficits } 2 \text { weeks after the } \\
\text { operation. }\end{array}$ & $\begin{array}{l}\text { The authors concluded that even } \\
\text { though acute spinal epidural } \\
\text { hematoma caused by extradural } \\
\text { arterio-venous malformation is a } \\
\text { rare clinical entity, MRI is the most } \\
\text { helpful diagnostic tool for this } \\
\text { condition. Further, they stressed that } \\
\text { accurate neuroradiological diagnosis } \\
\text { and prompt surgical decompression } \\
\text { of the spinal cord are essential to } \\
\text { obtain an excellent surgical outcome. }\end{array}$ & $\begin{array}{l}\text { The study emphasizes once } \\
\text { again that a high level of } \\
\text { suspicion with appropriate } \\
\text { diagnosis and rapid } \\
\text { intervention results in } \\
\text { avoidance of neurological } \\
\text { dysfunction in many cases. }\end{array}$ \\
\hline & $\begin{array}{l}\text { The authors present the case of an adult woman, otherwise in } \\
\text { good health, who developed Brown-Séquard syndrome after } \\
\text { cervical spinal manipulation therapy. Decompressive surgery } \\
\text { performed within } 8 \text { hours after the onset of symptoms allowed } \\
\text { for complete recovery of the patient's preoperative neurological } \\
\text { deficit. }\end{array}$ & $\begin{array}{l}\text { The unique feature of this case } \\
\text { was the MRI showing increased } \\
\text { signal intensity in the paraspinal } \\
\text { musculature consistent with a } \\
\text { contusion, which probably formed } \\
\text { after spinal manipulation therapy. }\end{array}$ & $\begin{array}{l}\text { Another case of epidural } \\
\text { hematoma after } \\
\text { manipulation shows } \\
\text { diagnosis could be } \\
\text { occasionally difficult such } \\
\text { as paraspinal musculature } \\
\text { contusion coincidental } \\
\text { with manipulative therapy. }\end{array}$ \\
\hline $\begin{array}{l}\text { Gundag } \\
\text { et al, 2012 } \\
(319)\end{array}$ & $\begin{array}{l}\text { The authors reported a spontaneous resolution of paraparesis } \\
\text { because of acute spontaneous thoracolumbar epidural } \\
\text { hematoma. The patient presented } 3 \text { days after sudden onset of } \\
\text { back pain, numbness, and weakness. MRI revealed a posterior } \\
\text { thoracolumbar epidural hematoma extending from the level of } \\
\text { T10 to L2 with significant cord compression. Decompression was } \\
\text { recommended, but patient refused surgery and was managed } \\
\text { conservatively. One month later, weakness totally disappeared } \\
\text { and hematoma was absent on MRI. }\end{array}$ & $\begin{array}{l}\text { Spontaneous epidural hematoma } \\
\text { may be resolved spontaneously } \\
\text { in some patients; however, these } \\
\text { should always be considered in } \\
\text { the differential diagnosis of other } \\
\text { conditions. Since this was mild } \\
\text { paralysis and he was recovering } \\
\text { gradually, conservative treatment was } \\
\text { a success. }\end{array}$ & $\begin{array}{l}\text { Conservative management } \\
\text { may be helpful in } \\
\text { managing spontaneous } \\
\text { epidural hematoma. }\end{array}$ \\
\hline $\begin{array}{l}\text { Kamo et al, } \\
2012 \text { (334) }\end{array}$ & $\begin{array}{l}\text { The authors reported a case of subdural hematoma in the } \\
\text { lumbar spine in a 75-year-old woman. MRI showed lesions of } \\
\text { homogeneous high intensity in the spinal canal, findings closely } \\
\text { resembling those for lipomatosis; however, epidural hematoma } \\
\text { was diagnosed and patient was managed conservatively with full } \\
\text { recovery after } 2 \text { weeks. }\end{array}$ & $\begin{array}{l}\text { Authors share their experience of } \\
\text { encountering of subacute phase } \\
\text { of spinal subdural hematoma that } \\
\text { mimicked spinal epidural lipomatosis } \\
\text { of MR imaging. Even though it is } \\
\text { extremely rare, authors caution } \\
\text { that, subdural hematoma should be } \\
\text { considered among the differential } \\
\text { diagnosis for progressive spinal } \\
\text { compressive syndrome. }\end{array}$ & $\begin{array}{l}\text { Lipomatosis may present } \\
\text { as spinal subdural } \\
\text { hematoma and in this case } \\
\text { improve with conservative } \\
\text { management only. }\end{array}$ \\
\hline
\end{tabular}


Table 2 (cont.). Descriptions of reports of spontaneous or traumatic bleeding.

\begin{tabular}{|c|c|c|c|}
\hline Study/Year & Case Report & Conclusions by the Study Authors & $\begin{array}{l}\text { Author Conclusions of } \\
\text { the Review }\end{array}$ \\
\hline $\begin{array}{l}\text { Matsumoto } \\
\text { et al, } 2012 \\
(335)\end{array}$ & $\begin{array}{l}\text { The authors reported } 2 \text { cases with spontaneous spinal epidural } \\
\text { hematoma with hemiparesis mimicking acute cerebral infarction. } \\
\text { In one case, the presentation was neck pain and in the other case, } \\
\text { it was Lhermitte's sign; brain MRI and MR angiography were } \\
\text { negative for signs of ischemic infarction, hemorrhage, or arterial } \\
\text { dissection. Cervical MRI was performed and demonstrated } \\
\text { spontaneous spinal epidural hematoma. }\end{array}$ & $\begin{array}{l}\text { The authors concluded that } \\
\text { clinicians who perform intravenous } \\
\text { thrombolytic treatment with } \\
\text { alteplase need to be aware of this } \\
\text { possible contraindication. }\end{array}$ & $\begin{array}{l}\text { It is essential to be cautious } \\
\text { and entertain various types } \\
\text { of diagnosis and manage } \\
\text { appropriately. }\end{array}$ \\
\hline $\begin{array}{l}\text { Lo et al, } \\
2012(337)\end{array}$ & $\begin{array}{l}\text { A 61-year old female after finishing worshipping Buddha } \\
\text { presented with sudden onset of severe neck and back pain } \\
\text { followed by quadriparesis, sensory deficits below C4 level, and } \\
\text { sphincter dysfunction. MRI demonstrated acute extensive } \\
\text { epidural hematoma of cervicothoracic spinal segments. } \\
\text { Idiopathic spontaneous spinal epidural hematoma was diagnosed } \\
\text { and emergency decompressive laminectomy with hematoma } \\
\text { evaluation was performed within } 12 \text { hours of symptom onset. } \\
\text { Good functional and neurological outcomes were obtained. }\end{array}$ & $\begin{array}{l}\text { The authors concluded that } \\
\text { spontaneous spinal epidural } \\
\text { hematoma is a rare but disabling } \\
\text { or even fatal entity. Early diagnosis } \\
\text { and prompt surgery improve the } \\
\text { neurological and functional outcome. }\end{array}$ & $\begin{array}{l}\text { A case of spontaneous } \\
\text { spinal epidural hematoma } \\
\text { with no risk factors with } \\
\text { full recovery with surgical } \\
\text { decompression. }\end{array}$ \\
\hline $\begin{array}{l}\text { Russman \& } \\
\text { Kazi, } 1971 \\
(343)\end{array}$ & $\begin{array}{l}\text { A 53-year old white female without trauma, but with } \\
\text { hypertension developed an epidural hematoma at C6. } \\
\text { Preoperative neurological lesion was on the left side at L5. } \\
\text { The diagnosis was performed by myelogram and the patient } \\
\text { deteriorated during myelogram. The patient developed residual } \\
\text { Brown-Séquard syndrome. }\end{array}$ & $\begin{array}{l}\text { The authors concluded that the } \\
\text { syndrome is most commonly } \\
\text { associated with penetrating trauma } \\
\text { of the spinal cord or intramedullary } \\
\text { lesions and in this case, its } \\
\text { occurrence was associated with } \\
\text { extramedullary lesion. }\end{array}$ & $\begin{array}{l}\text { The authors caution } \\
\text { that epidural hematoma } \\
\text { can be originating from } \\
\text { extramedullary lesion. } \\
\text { Even myelography can } \\
\text { deteriorate the patient's } \\
\text { condition manifesting in } \\
\text { fatal results. }\end{array}$ \\
\hline $\begin{array}{l}\text { Mustafa \& } \\
\text { Bernstein, } \\
1987(344)\end{array}$ & $\begin{array}{l}\text { A } 70 \text {-year old female with no history of trauma developed a } \\
\text { cervical spinal hematoma at C } 5 / 6 \text { with factor } 11 \text { deficiency. } \\
\text { Diagnosis was by myelogram with full recovery. }\end{array}$ & $\begin{array}{l}\text { Another case of cervical epidural } \\
\text { hematoma with Brown-Séquard } \\
\text { syndrome which was spontaneous } \\
\text { in nature. }\end{array}$ & $\begin{array}{l}\text { Another case of } \\
\text { spontaneous epidural } \\
\text { hematoma resulting in } \\
\text { Brown-Séquard syndrome. }\end{array}$ \\
\hline $\begin{array}{l}\text { Mattle et al, } \\
1987(345)\end{array}$ & $\begin{array}{l}\text { A 46-year old male with no history of trauma on anticoagulant } \\
\text { therapy after myocardial infarction developed a cervical epidural } \\
\text { hematoma at C7/T1 resulting in Brown-Séquard syndrome. The } \\
\text { diagnosis was made by myelogram with full ambulation. }\end{array}$ & $\begin{array}{l}\text { This is a case of anticoagulant } \\
\text { therapy leading to spontaneous } \\
\text { hematoma without trauma with } \\
\text { full ambulation with continued } \\
\text { deficiency. }\end{array}$ & $\begin{array}{l}\text { Epidural hematoma in a } \\
\text { patient with anticoagulant } \\
\text { therapy but no trauma with } \\
\text { significant recovery. }\end{array}$ \\
\hline $\begin{array}{l}\text { Yang et al, } \\
2012(348)\end{array}$ & $\begin{array}{l}\text { A case of spinal epidural hematoma during breath-hold diving } \\
\text { was reported in a 47-year old male who presented with severe } \\
\text { frontal headache and intense cervical pain which developed } \\
\text { during a protracted spear fishing session. A cervical spine MRI } \\
\text { performed } 12 \text { days after symptoms onset showed a small epidural } \\
\text { blood collection on the left side of the spinal canal at the C7/ } \\
\text { T1 level. One week later, blood was no longer present and the } \\
\text { asymptomatic patient was discharged. }\end{array}$ & $\begin{array}{l}\text { The authors concluded that } \\
\text { protracted minor trauma with } \\
\text { neck flexion and repeat Valsalva } \\
\text { maneuvers might have played a } \\
\text { role in the genesis of this event. The } \\
\text { role of decompression is important; } \\
\text { however, this patient improved with } \\
\text { conservative management. }\end{array}$ & $\begin{array}{l}\text { Spontaneous hematomas } \\
\text { can occur with any type } \\
\text { of activity without risk } \\
\text { factors and be managed } \\
\text { conservatively or surgically. }\end{array}$ \\
\hline $\begin{array}{l}\text { Tremolizzo } \\
\text { et al, } 2012 \\
(349)\end{array}$ & $\begin{array}{l}\text { This is a report of a case of non-traumatic spinal epidural } \\
\text { hematoma in a female after breath-hold diving. }\end{array}$ & $\begin{array}{l}\text { The authors postulated that } \\
\text { protracted minor trauma (neck } \\
\text { flexion) and repeated Valsalva } \\
\text { manoeuvres might have played a role } \\
\text { in the genesis of this event. }\end{array}$ & $\begin{array}{l}\text { This case illustrates } \\
\text { necessity for a high } \\
\text { level of suspicion and } \\
\text { proper diagnosis and } \\
\text { management. }\end{array}$ \\
\hline $\begin{array}{l}\text { Kim et al, } \\
2012(350)\end{array}$ & $\begin{array}{l}\text { A 51-year old man developed spontaneous spinal epidural } \\
\text { hematoma related to low dose aspirin use. The patient was } \\
\text { successfully treated with medical management. }\end{array}$ & $\begin{array}{l}\text { The authors concluded that this } \\
\text { indicates that low dose aspirin could } \\
\text { induce spontaneous spinal epidural } \\
\text { hematoma and that conservative } \\
\text { treatment with close observation and } \\
\text { repeated imaging studies should be } \\
\text { considered in cases with neurological } \\
\text { improvement or mild deficits. }\end{array}$ & $\begin{array}{l}\text { Even though the patient } \\
\text { was on low dose aspirin, } \\
\text { no causal relationship } \\
\text { could be established due } \\
\text { to spontaneous epidural } \\
\text { hematoma occurring in } \\
\text { many other cases. }\end{array}$ \\
\hline $\begin{array}{l}\text { Fuster et al, } \\
2012(351)\end{array}$ & $\begin{array}{l}\text { The authors reported a spontaneous chronic epidural hematoma } \\
\text { of the lumbar spine mimicking an extradural spine tumor. A } \\
61 \text {-year-old woman was evaluated after } 18 \text { month history of pain, } \\
\text { dysesthesias, and mild weakness in both lower extremities with } \\
\text { significant radicular symptoms on the right side associated to } \\
\text { neurogenic claudication. A CT scan revealed a nodular image of } \\
\text { soft tissue density located in the right anterolateral epidural space } \\
\text { at L4-L5 level. MRI studies revealed epidural hematoma. Patient } \\
\text { underwent surgery and recovered. }\end{array}$ & $\begin{array}{l}\text { The authors concluded that } \\
\text { spontaneous chronic epidural } \\
\text { hematomas are rare, even more when } \\
\text { they produce scalloping of bone } \\
\text { structures, a diagnostic challenger. } \\
\text { They should always be considered } \\
\text { as a differential diagnosis in patients } \\
\text { with extradural chronic compression } \\
\text { taking into account that also chronic } \\
\text { epidural hematomas can cause bone } \\
\text { involvement. }\end{array}$ & $\begin{array}{l}\text { Appropriate diagnosis and } \\
\text { proper management with } \\
\text { surgical decompression or } \\
\text { conservative management } \\
\text { is essential. }\end{array}$ \\
\hline
\end{tabular}


Pain Physician: April Special Issue 2013; 16:SE261-SE318

Table 2 (cont.). Descriptions of reports of spontaneous or traumatic bleeding.

\begin{tabular}{|c|c|c|c|}
\hline Study/Year & Case Report & Conclusions by the Study Authors & $\begin{array}{l}\text { Author Conclusions of } \\
\text { the Review }\end{array}$ \\
\hline $\begin{array}{l}\text { Yabe et al, } \\
2012(352)\end{array}$ & $\begin{array}{l}\text { The authors present a case report in an elderly patient who developed } \\
\text { spontaneous spinal epidural hematoma during warfarin therapy. Since } \\
\text { the patient was on warfarin laboratory testing was performed and } \\
\text { based on MRI findings of a space occupying lesion on the dorsal side } \\
\text { of the spinal canal, compression of spinal cord epidural hematoma } \\
\text { was suspected. Patient was treated with oral vitamin K to prevent } \\
\text { expansion of the hematoma. Surgical intervention was contraindicated } \\
\text { due to old age and delayed diagnosis. Consequently, conservative } \\
\text { management was carried out. Eventually he recovered to operate an } \\
\text { electric wheelchair and underwent rehabilitation. }\end{array}$ & $\begin{array}{l}\text { Spontaneous epidural hematoma } \\
\text { must be considered specifically } \\
\text { in patients with sudden onset of } \\
\text { unexplained cervical or back pain } \\
\text { or subsequent radicular symptoms } \\
\text { during anticoagulant therapy. } \\
\text { Immediate MRI is essential for early } \\
\text { diagnosis and treatment. }\end{array}$ & $\begin{array}{l}\text { High level of suspicion } \\
\text { with appropriate diagnosis } \\
\text { in patients who are } \\
\text { on warfarin therapy is } \\
\text { essential with proper } \\
\text { management when } \\
\text { indicated. }\end{array}$ \\
\hline $\begin{array}{l}\text { Shima et al, } \\
2012 \text { (357) }\end{array}$ & $\begin{array}{l}\text { The authors reported a case of a spinal epidural hematoma with } \\
\text { symptoms mimicking cerebral stroke in an } 84 \text {-year-old female } \\
\text { with nuchal pain and right hemiparesis. CT scan of the neck } \\
\text { demonstrated a spinal epidural hematoma. She was managed } \\
\text { conservatively and her symptoms improved significantly. }\end{array}$ & $\begin{array}{l}\text { The authors emphasized that cervical } \\
\text { spinal lesions should be considered in } \\
\text { the differential diagnosis for patients } \\
\text { with acute onset hemiparesis, when } \\
\text { they are associated with neck pain. } \\
\text { They also stated that even though } \\
\text { MRI is a gold standard, a CT scan } \\
\text { is also useful for quick screening } \\
\text { for spontaneous cervical epidural } \\
\text { hematoma. }\end{array}$ & $\begin{array}{l}\text { CT scan will be helpful } \\
\text { and patients may be } \\
\text { treated conservatively, } \\
\text { however, the differential } \\
\text { diagnosis and high level of } \\
\text { suspicion is of paramount } \\
\text { importance. }\end{array}$ \\
\hline $\begin{array}{l}\text { Gwyn \& } \\
\text { Shinton, } \\
2012(358)\end{array}$ & $\begin{array}{l}\text { The authors presented a case report of an } 80 \text {-year-old gentleman } \\
\text { presenting with right arm weakness with sudden onset of right- } \\
\text { sided neck pain at rest radiating to his right shoulder and back, } \\
\text { leading to immediate numbness and tingling down right arm and } \\
\text { associated heaviness, with no history of trauma. His medications } \\
\text { included aspirin, } 75 \text { mg once a day and dipyridamole sustained } \\
\text { release } 200 \mathrm{mg} \text { twice a day. MRI evaluation showed a right- } \\
\text { sided shallow fluid collection projecting into the spinal canal } \\
\text { from the posterolateral aspect of the canal, diagnosed either } \\
\text { as hematoma or abscess, without a known cause. Patient was } \\
\text { managed conservatively and was discharged with full recovery } \\
\text { and epidural hematoma resolved after } 3 \text { weeks. }\end{array}$ & $\begin{array}{l}\text { Authors concluded that this report } \\
\text { highlights the importance of } \\
\text { considering a spontaneous epidural } \\
\text { hematoma in any patient presenting } \\
\text { with neck pain and limb weakness. } \\
\text { They also emphasized that specific } \\
\text { attention must be paid to any } \\
\text { antiplatelet medication as this may } \\
\text { put the patient at higher risk. }\end{array}$ & $\begin{array}{l}\text { Even though patients may } \\
\text { need surgical intervention, } \\
\text { this patient responded } \\
\text { well to conservative } \\
\text { management. High level of } \\
\text { suspicion and differential } \\
\text { diagnosis are essential. }\end{array}$ \\
\hline $\begin{array}{l}\text { Schwartz } \\
\text { et al, } 2012 \\
(362)\end{array}$ & $\begin{array}{l}\text { The authors reported a spontaneous cervical epidural hematoma } \\
\text { associated with thunderclap headache in an } 80 \text {-year-old woman } \\
\text { who abruptly developed an explosive, severe headache in the } \\
\text { bilateral occipital and frontal regions associated with neck } \\
\text { pain/stiffness while sitting on her couch watching television. } \\
\text { After multiple evaluations involving the head, MRI of the } \\
\text { cervical spine was performed which showed cervical epidural } \\
\text { hematoma. Patient was on warfarin, aspirin, and clopidogrel, all } \\
3 \text { antithrombotic agents. The headache and neck pain resolved } \\
\text { several days after withholding anticoagulation and treating with } \\
\text { empiric intravenous antibiotics. }\end{array}$ & $\begin{array}{l}\text { The authors concluded that this, to } \\
\text { the best of their knowledge, is the } \\
\text { first reported case of spontaneous } \\
\text { cervical epidural hematoma } \\
\text { presenting with a thunderclap } \\
\text { headache. Thus, the recognition } \\
\text { of spinal epidural hematoma with } \\
\text { thunderclap headache has important } \\
\text { clinical implications. }\end{array}$ & $\begin{array}{l}\text { A high level of suspicion } \\
\text { in patients with headache } \\
\text { or cerebral symptoms, } \\
\text { associated neck } \\
\text { symptomatology with } \\
\text { assessment with MRI is } \\
\text { essential. }\end{array}$ \\
\hline $\begin{array}{l}\text { Yang et al, } \\
2011 \text { (365) }\end{array}$ & $\begin{array}{l}\text { The authors reported a case of spontaneous spinal epidural } \\
\text { hematoma associated with myocardial infarction treatment in a } \\
56 \text {-year-old man. Patient was treated with nitroglycerin, aspirin, } \\
\text { low molecular weight heparin, and clopidogrel. } \\
\text { MRI showed epidural hematoma despite emergent } \\
\text { decompressive surgery, paraplegia was not improved } 7 \text { months } \\
\text { after surgery. }\end{array}$ & $\begin{array}{l}\text { The authors concluded that a } \\
\text { spontaneous spinal epidural } \\
\text { hematoma should be considered } \\
\text { when patients complain of abrupt, } \\
\text { strong, and non-traumatic back and } \\
\text { neck pain, particularly if they have } \\
\text { not spinal pain history. }\end{array}$ & $\begin{array}{l}\text { Despite aggressive } \\
\text { intervention, prognosis } \\
\text { was poor. }\end{array}$ \\
\hline $\begin{array}{l}\text { Kim et al, } \\
2012(367)\end{array}$ & $\begin{array}{l}\text { The authors reported a chronic pure radiculopathy in a 52-year- } \\
\text { old male without antithrombotic therapy and without injury } \\
\text { with organizing epidural hematoma around C8 nerve root. } \\
\text { MRI scan showed small space-occupying lesion around eighth } \\
\text { cervical nerve root. After surgery, the authors confirmed chronic } \\
\text { organizing epidural hematoma. }\end{array}$ & $\begin{array}{l}\text { The authors concluded that this is } \\
\text { only the second reported case in } \\
\text { the worldwide literature of pure } \\
\text { radiculopathy in a patient with } \\
\text { chronic spontaneous cervical } \\
\text { epidural hematoma. }\end{array}$ & $\begin{array}{l}\text { Epidural hematomas can } \\
\text { present in many ways, } \\
\text { consequently, a high level } \\
\text { of suspicion is essential } \\
\text { along with appropriate } \\
\text { management. }\end{array}$ \\
\hline $\begin{array}{l}\text { Jacob et al, } \\
2012(368)\end{array}$ & $\begin{array}{l}\text { The authors presented a case report of acute epidural } \\
\text { spinal hemorrhage from vasculitis which resolved with } \\
\text { immunosuppression in a 61-year-old female presenting with } \\
\text { sudden onset of back pain and headache. }\end{array}$ & $\begin{array}{l}\text { Immunomodulating therapy should be } \\
\text { considered in the management of select } \\
\text { patients with spinal vasculitis which } \\
\text { may lead to improved clinical outcome } \\
\text { and potentially disease resolution. }\end{array}$ & $\begin{array}{l}\text { A difficult case } \\
\text { of epidural spinal } \\
\text { hemorrhage managed } \\
\text { with immunomodulating } \\
\text { therapy. }\end{array}$ \\
\hline $\begin{array}{l}\text { Nakanishi } \\
\text { et al, } 2011 \\
(373)\end{array}$ & $\begin{array}{l}\text { The authors reported } 3 \text { cases of hemiparesis caused by } \\
\text { spontaneous cervical spinal epidural hematoma in a } 73 \text {-year-old } \\
\text { woman, a } 62 \text {-year-old man, and a } 60 \text {-year-old woman with all of } \\
\text { them presenting with symptoms of hemiparesis and eventually } \\
\text { diagnosed with cervical spinal epidural hematoma. First } 2 \text { patients } \\
\text { were treated with surgical decompression, whereas, third patient } \\
\text { was treated with conservative management, with all of them } \\
\text { improving. }\end{array}$ & $\begin{array}{l}\text { The authors concluded that these } \\
\text { cases suggest that acute cervical } \\
\text { spinal epidural hematoma should be } \\
\text { considered as a differential diagnosis } \\
\text { in patients presenting with clinical } \\
\text { symptoms of sudden neck pain and } \\
\text { radicular pain with progression to } \\
\text { hemiparesis. }\end{array}$ & $\begin{array}{l}\text { A high level of suspicion } \\
\text { with appropriate diagnosis } \\
\text { and either surgical or } \\
\text { conservative management } \\
\text { is the mainstay of } \\
\text { management. }\end{array}$ \\
\hline
\end{tabular}


Table 2 (cont.). Descriptions of reports of spontaneous or traumatic bleeding.

\begin{tabular}{|c|c|c|c|}
\hline Study/Year & Case Report & Conclusions by the Study Authors & $\begin{array}{l}\text { Author Conclusions of } \\
\text { the Review }\end{array}$ \\
\hline $\begin{array}{l}\text { Puah et al, } \\
2012(376)\end{array}$ & $\begin{array}{l}\text { The authors reported a spontaneous cervical spinal epidural } \\
\text { hematoma in the postpartum period in a } 31 \text {-year-old Chinese } \\
\text { woman who underwent a lower segment cesarian section. } \\
\text { She presented with sudden onset of neck pain and lower limb } \\
\text { weakness with no trauma } 3 \text { weeks after discharge. MRI showed } \\
\text { cervical epidural hematoma. She was treated with intravenous } \\
\text { dexamethasone and an emergency cervicothoracic laminectomy } \\
\text { and evacuation of the hematoma. The patient recovered fully } \\
\text { after one year even though she required self-catheterization once } \\
\text { daily for bladder dysfunction. }\end{array}$ & $\begin{array}{l}\text { The authors concluded that early } \\
\text { recognition and intervention for } \\
\text { their patient allowed for neurological } \\
\text { recovery with a spontaneous cervical } \\
\text { spinal epidural hematoma in the } \\
\text { postpartum period. }\end{array}$ & $\begin{array}{l}\text { Sudden onset of neck } \\
\text { pain in the postpartum } \\
\text { period with neurological } \\
\text { dysfunction must be } \\
\text { treated with high suspicion. } \\
\text { Appropriate diagnosis and } \\
\text { treatment are essential. }\end{array}$ \\
\hline $\begin{array}{l}\text { Cai et al, } \\
2011 \text { (378) }\end{array}$ & $\begin{array}{l}\text { Authors described a case of spontaneous epidural hematoma } \\
\text { of the thoracic spine presenting as Brown-Séquard syndrome } \\
\text { in a healthy } 35 \text {-year-old male with insidious development of } \\
\text { intrascapular pain without trauma. } \\
\text { MRI identified spontaneous epidural hematoma and patient } \\
\text { was offered prompt surgical intervention. The patient opted for } \\
\text { conservative treatment which was followed by rapid resolution. }\end{array}$ & $\begin{array}{l}\text { Authors conclude that prompt } \\
\text { surgical decompression is an } \\
\text { absolute surgical indication widely } \\
\text { accepted for patients with progressive } \\
\text { neurological deficit. Successful } \\
\text { non-operative care in this case does } \\
\text { not make it a standard of care and } \\
\text { surgical decompression remains the } \\
\text { standard treatment for spontaneous } \\
\text { epidural hematoma. }\end{array}$ & $\begin{array}{l}\text { Even though case illustrates } \\
\text { a rare presentation and } \\
\text { spontaneous recovery, } \\
\text { surgical intervention must } \\
\text { always be considered. }\end{array}$ \\
\hline $\begin{array}{l}\text { Kim \& Kim, } \\
2011 \text { (379) }\end{array}$ & $\begin{array}{l}\text { This is a case report of an epidural hematoma in a } 63 \text {-year-old } \\
\text { man with a } 25 \text {-year history of ankylosing spondylitis. After a } \\
\text { minor fall, MRI showed a large posterior epidural hematoma } \\
\text { with cord compression. } \\
\text { Prompt surgical decompression was carried out, however, the } \\
\text { patient died. }\end{array}$ & $\begin{array}{l}\text { Authors concluded that a good } \\
\text { outcome depends on prompt } \\
\text { diagnosis and surgery, even though } \\
\text { outcome was poor in this patient. }\end{array}$ & $\begin{array}{l}\text { Prompt diagnosis and } \\
\text { treatment is essential in } \\
\text { epidural hematoma of any } \\
\text { origin. }\end{array}$ \\
\hline
\end{tabular}

Table 3. Reports of bleeding and epidural hematoma associated without antithrombotic therapy with interventional techniques.

\begin{tabular}{|l|l|l|l||}
\hline Study/Year & Case Report & Conclusions by the Study Authors & $\begin{array}{l}\text { Author Conclusions of } \\
\text { the Review }\end{array}$ \\
\hline $\begin{array}{l}\text { Williams et al, } \\
1990 \text { (178) }\end{array}$ & $\begin{array}{l}\text { A diagnosis of cervical epidural hematoma was made } \\
\text { and was confirmed by CT scan after a seventh epidural in } \\
\text { several years in a patient who was taking indomethacin. } \\
\text { Immediate surgery revealed an epidural hematoma. During } \\
\text { the operation blood results became available showing } \\
\text { that INR was 1.0, the clotting time was 41 seconds with a } \\
\text { control of 40 seconds, and the platelet count was within } \\
\text { normal limits. Bleeding time was not measured. }\end{array}$ & $\begin{array}{l}\text { Authors concluded that repeated epidural } \\
\text { steroid injections should preferably } \\
\text { be performed in centers equipped to } \\
\text { accurately to diagnose and promptly treat } \\
\text { this rare but serious complication. }\end{array}$ & $\begin{array}{l}\text { In this case there were no } \\
\text { major antithrombotics } \\
\text { utilized (except for } \\
\text { indomethacin), however, } \\
\text { patient suffered with } \\
\text { cervical spondylosis. All } \\
\text { the bleeding parameters } \\
\text { were appropriate. Even } \\
\text { then, patient developed } \\
\text { cervical epidural } \\
\text { hematoma. Further, there } \\
\text { are no recommendations } \\
\text { to stop indomethacin } \\
\text { in the majority of the } \\
\text { guidelines. }\end{array}$ \\
\hline
\end{tabular}


Pain Physician: April Special Issue 2013; 16:SE261-SE318

Table 3 (cont.). Reports of bleeding and epidural hematoma associated without antithrombotic therapy with interventional techniques.

\begin{tabular}{|c|c|c|c|}
\hline Study/Year & Case Report & Conclusions by the Study Authors & $\begin{array}{l}\text { Author Conclusions of } \\
\text { the Review }\end{array}$ \\
\hline $\begin{array}{l}\text { Stoll \& } \\
\text { Sanchez, } 2002 \\
(180)\end{array}$ & $\begin{array}{l}\text { A healthy } 34 \text {-year old man with no evidence of coagulopathy } \\
\text { and not taking antiplatelet medication suddenly had onset } \\
\text { of acute cervical myelopathy from a large cervical epidural } \\
\text { hematoma } 8 \text { days after cervical epidural steroid block. The } \\
\text { patient developed a Brown-Séquard type of myelopathy } \\
\text { manifesting by severe weakness of the left arm and leg and } \\
\text { right-sided numbness and loss of temperature appreciation. } \\
\text { The diagnosis was made by CT scan. Because of the severe } \\
\text { neurological deficit, the patient was directly taken to surgery } \\
\text { with MRI scan. The surgical exposure showed a large, discreet } \\
\text { sausage-shaped extradural hematoma, appearing darkish } \\
\text { and somewhat organized. There was no active bleeding nor } \\
\text { were any abnormal vessels seen. Following prompt surgical } \\
\text { evaluation of the clot, the patient made a near complete } \\
\text { recovery. }\end{array}$ & $\begin{array}{l}\text { The authors concluded that this case } \\
\text { illustrated that epidural hematoma may } \\
\text { occur in the absence of known risk } \\
\text { factors. The delayed onset and the absence } \\
\text { of risk factors have implications for the } \\
\text { use of epidural steroid injection in chronic } \\
\text { pain management. }\end{array}$ & $\begin{array}{l}\text { This case again illustrates } \\
\text { that epidural hematoma } \\
\text { can occur in patients } \\
\text { without antiplatelet } \\
\text { therapy (ibuprofen } \\
\text { discontinued). The size of } \\
\text { the needle, the technique, } \\
\text { and number of attempts } \\
\text { were not available. It is } \\
\text { unknown if vigorous } \\
\text { physical therapy or } \\
\text { epidural injection caused } \\
\text { the epidural hematoma. }\end{array}$ \\
\hline $\begin{array}{l}\text { Yagi et al, } \\
1998 \text { (187) }\end{array}$ & $\begin{array}{l}\text { The authors described a case of } 41 \text {-year old man with } \\
\text { prior anterior cervical fusion who underwent an epidural } \\
\text { block at C7/T1 for shoulder pain. Two hours after cervical } \\
\text { twisting, he had onset of severe neck pain and bilateral } \\
\text { shoulder pain. This was followed by asymmetrical } \\
\text { quadriparesis. An MRI showed an epidural hematoma } \\
\text { from C3 to C7. At operation, no active bleeding or vascular } \\
\text { abnormality was found and he made a good recovery. }\end{array}$ & $\begin{array}{l}\text { The authors of this case report attributed } \\
\text { the hematoma to cervical twisting, noting } \\
\text { the spinal puncture was not difficult and } \\
\text { no impairment of coagulation was found. }\end{array}$ & $\begin{array}{l}\text { Whatever the cause is, it } \\
\text { is essential to recognize } \\
\text { that epidural hematoma } \\
\text { can happen at any time, } \\
\text { even in the best hands, } \\
\text { and appropriate care must } \\
\text { be taken. }\end{array}$ \\
\hline $\begin{array}{l}\text { Lee et al, } 2011 \\
\text { (193) }\end{array}$ & $\begin{array}{l}\text { A 58-year old woman presented with quadriparesis and } \\
\text { neck pain after dry needling. MRI of the spine revealed a } \\
\text { hyperintense mass in the T2 weighted at C2-T2 level, which } \\
\text { proved to be an epidural hematoma. } \\
\text { The diagnosis was made with MRI and decompression was } \\
\text { carried out. The patient recovered completely. }\end{array}$ & $\begin{array}{l}\text { The authors concluded that even though } \\
\text { it is rare, epidural hematoma is a possible } \\
\text { complication in needling therapies. The } \\
\text { authors concluded the spinal hematoma } \\
\text { caused by dry needling in this case was } \\
\text { probably the result of unintentional } \\
\text { needling of the spinal canal, similar to } \\
\text { that caused by central neural blockade. } \\
\text { However, there were no risk factors and } \\
\text { the patient was not on antiplatelet therapy. }\end{array}$ & $\begin{array}{l}\text { The epidural hematoma } \\
\text { may develop following } \\
\text { dry needling without } \\
\text { major interventional } \\
\text { techniques and may be } \\
\text { treated appropriately with } \\
\text { prompt diagnosis. }\end{array}$ \\
\hline $\begin{array}{l}\text { Ozdemir et al, } \\
2007 \text { (204) }\end{array}$ & $\begin{array}{l}\text { A } 40 \text {-year old man was admitted with severe persistent } \\
\text { headache and vomiting after epidural steroid injection for } \\
\text { right leg pain. Epidural steroid injection was performed } \\
\text { with a } \# 18 \text { gauge Tuohy needle which revealed a dural } \\
\text { puncture. The second attempt at L3/4 level was successful. } \\
\text { It appears that epidural steroid injection was performed } \\
\text { without fluoroscopy. MRI showed a right frontal subdural } \\
\text { hematoma. His headache was relieved after strict bedrest, } \\
\text { intravenous hydration, and analgesics. The patient was } \\
\text { discharged with full recovery after one week without } \\
\text { neurological dysfunction. }\end{array}$ & $\begin{array}{l}\text { The authors concluded that intracranial } \\
\text { subdural hematoma for accidental dural } \\
\text { puncture during epidural steroid injection } \\
\text { is a rare complication, even though there } \\
\text { were no risk factors in this patient. }\end{array}$ & $\begin{array}{l}\text { Intracranial subdural } \\
\text { hematoma can develop in } \\
\text { patients without any risk } \\
\text { factors. }\end{array}$ \\
\hline $\begin{array}{l}\text { Lee et al, } 2007 \\
(222)\end{array}$ & $\begin{array}{l}\text { A healthy 38-year-old woman after motor vehicle injury } \\
\text { developed upper extremity radiculopathy. She underwent } \\
\text { a series of right transforaminal epidural injections at the } \\
\text { C7-T1 level. Approximately } 4 \text { days after the final injection, } \\
\text { she awakened with severe upper thoracic back pain and } \\
\text { progressive loss of sensation in the lower extremities. By late } \\
\text { that morning, patient had progressive neurological symptoms } \\
\text { and onset of weakness and she was promptly referred to } \\
\text { the emergency department for evaluation. MRI of the spine } \\
\text { showed a large hematoma extending from T1 to T5. The } \\
\text { patient underwent surgical decompression. Within } 6 \text { months } \\
\text { patient regained full strength and sensation in both lower } \\
\text { extremities. }\end{array}$ & $\begin{array}{l}\text { Authors concluded that interventional } \\
\text { pain physicians must appreciate the } \\
\text { possibility of catastrophic complications } \\
\text { and discuss with the patient prior to the } \\
\text { procedure. They also cautioned that the } \\
\text { physician should be aware that symptoms } \\
\text { from a slowly developing epidural } \\
\text { hematoma can present even days after an } \\
\text { injection. }\end{array}$ & $\begin{array}{l}\text { The study shows that } \\
\text { apart from various other } \\
\text { complications with } \\
\text { cervical transforaminal } \\
\text { epidural injections, a } \\
\text { spinal epidural hematoma, } \\
\text { even without risk factors, } \\
\text { is possible. Appropriate } \\
\text { management can address } \\
\text { these issues if patients do } \\
\text { develop complications. }\end{array}$ \\
\hline $\begin{array}{l}\text { Bose, } 2005 \\
\text { (276) }\end{array}$ & $\begin{array}{l}\text { This case report described severe adverse effects } \\
\text { (quadriplegia and respiratory arrest) associated with an } \\
\text { epidural injection into the C6-C7 space. Although the } \\
\text { patient's symptoms improved somewhat with supportive } \\
\text { care, quadriparesis appears irreversible. No reports of } \\
\text { quadriparesis after cervical epidural injection were found } \\
\text { in the literature, although other adverse effects have been } \\
\text { reported. }\end{array}$ & $\begin{array}{l}\text { The authors concluded that although } \\
\text { evidence is not conclusive, this patient } \\
\text { may have suffered a vascular event from a } \\
\text { cervical epidural injection. }\end{array}$ & $\begin{array}{l}\text { The study shows that } \\
\text { patients may suffer } \\
\text { with vascular events } \\
\text { from cervical epidural } \\
\text { injections, thus, a high } \\
\text { level of suspicion and } \\
\text { caution are essential. }\end{array}$ \\
\hline
\end{tabular}


techniques were identified $(178,180,187,193,204,222$, 276,391). In addition, the survey by Manchikanti et al (81) showed there were multiple cases of epidural hematoma in patients who were not on antiplatelet and warfarin therapy.

Table 4 shows the reports of bleeding and epidural hematoma related to the patients with discontinuation of antiplatelet and antithrombotic therapy in chronic pain with interventional techniques $(189,190,201)$. Manchikanti et al (81) also showed epidural hematoma in 29 patients with discontinuation of antiplatelet and warfarin therapy compared to 26 patients with continued antiplatelet therapy. However, they also showed the prevalence of thromboembolic events were 153 in patients with discontinuation of antiplatelet therapy compared to 9 in patients with continued antiplatelet therapy.

Table 5 shows the reports assessing bleeding complications and epidural hematoma in patients with continuation of antiplatelet therapy and interventional techniques. There were only 3 reports of bleeding complications when anticoagulant therapy was continued for interventional techniques $(176,177,388)$. However, there is an abundance of literature with complications related to anesthesia and surgery $(209,212-214,216,217,219,220,224,226$ $228,230,242,248,253,258,259,262)$. Further, Manchikanti et al (81), in assessing the frequency of adverse effects during interventional pain management techniques, showed bleeding complications with epidural hematoma in 26 instances compared to 29 instances where antiplatelet and warfarin therapy was discontinued. However, with continuation of antiplatelet therapy, thromboembolic events were only 9 compared to 153 with discontinuation of antiplatelet and warfarin therapy.

\subsection{Analysis of Evidence}

Based on the review of the comprehensive literature without methodological quality assessment of the presented studies and case reports, the evidence appears as follows:

- There is good evidence for the risk of thromboembolic phenomenon in patients who discontinue antithrombotic therapy.

- There is good evidence spontaneous epidural hematomas occur with or without traumatic injury in patients with or without anticoagulant therapy associated with stressors such chiropractic manipulation, diving, and anatomic abnormalities such as ankylosing spondylitis.

- There is good evidence for the lack of necessity of discontinuation of NSAIDs, including low dose aspirin, prior to performing interventional techniques.

- There is fair evidence that excessive bleeding, including epidural hematoma formation may occur with interventional techniques when antithrombotic therapy is continued.

- There is fair evidence that the risk of thromboembolic phenomenon is higher than the risk of epidural hematomas with discontinuation of antiplatelet therapy prior to interventional techniques, even though both risks are significant.

- There is fair evidence that anatomic conditions such as spondylosis, ankylosing spondylitis, and spinal stenosis, and procedures involving the cervical spine; multiple attempts; and large bore needles increase the risk of epidural hematoma.

- There is fair evidence that rapid assessment and surgical or nonsurgical intervention to manage patients with epidural hematoma can avoid permanent neurological complications.

- There is fair evidence of the lack of necessity of discontinuation of phosphodiesterase inhibitors (dipyridamole [Persantine], cilostazol [Pletal], and Aggrenox [dipyridamole plus aspirin]) prior to performing interventional techniques.

- There is limited evidence to discontinue antiplatelet therapy (clopidogrel [Plavix®], ticlopidine [Ticlid $\circledast$ ], and prasugrel [Effient $\circledast$ ]) to avoid bleeding and epidural hematomas.

- There is limited evidence to continue antiplatelet therapy during interventional techniques including epidural injections to avoid thromboembolic fatalities.

\subsection{Discussion}

This comprehensive review of the literature about the role of antithrombotic and antiplatelet therapy in interventional pain management assessed numerous manuscripts, without randomized trials. There is substantial literature, though mostly consisting of observational studies and case reports. There is no literature available in reference to monitoring platelet function under antiplatelet therapy in reference to interventional techniques or its application during intraoperative treatment (401-406).

The results of this assessment showed good evidence for increased risk of thromboembolic phenomenon in patients who discontinue antithrombotic 
Table 4. Reports of bleeding and epidural hematoma related to patients with discontinuation of antiplatelet and antithrombotic therapy with interventional techniques in chronic pain management.

\begin{tabular}{|c|c|c|c|}
\hline Study/Year & Case Report & $\begin{array}{l}\text { Conclusions by the Study } \\
\text { Authors }\end{array}$ & $\begin{array}{l}\text { Author Conclusions of the } \\
\text { Review }\end{array}$ \\
\hline $\begin{array}{l}\text { Xu et al, } 2009 \\
\text { (189) }\end{array}$ & $\begin{array}{l}\text { A 78-year-old woman with history of diabetes mellitus, atrial } \\
\text { fibrillation, myocardial infarction status after coronary stent } \\
\text { placement, and who was on a regimen of aspirin and warfarin, } \\
\text { stopped her warfarin and aspirin } 6 \text { days before the third } \\
\text { epidural procedure and was bridged over to enoxaparin } 1 \mathrm{mg} / \\
\text { kg twice daily. She received her last enoxaparin dose at } 7 \text { a.m. } \\
\text { one day before the procedure. } \\
\text { The lumbar epidural injection was performed atraumatically } \\
\text { by using the loss of resistance technique. She received her } \\
\text { usual warfarin dosing } 8 \text { hours after the procedure and initiated } \\
\text { her enoxaparin shots at } 7 \text { p.m. the following day, } 30 \text { hours after } \\
\text { the procedure, after an INR was found to be within normal } \\
\text { range. } \\
\text { The following morning after the second shot of enoxaparin, } \\
\text { she developed excruciating radicular pain and presented } \\
\text { to the emergency room. CT scan of the lumbar spine was } \\
\text { inconclusive. Subsequently, she underwent an MRI which } \\
\text { showed a lumbar epidural clot that spanned from L2 to L5 } \\
\text { causing severe thecal sac compression. } \\
\text { Patient underwent surgical decompression. She recovered } \\
\text { almost completely with rehabilitation. }\end{array}$ & $\begin{array}{l}\text { The authors concluded that } \\
\text { despite the overall low incidence } \\
\text { of hemorrhagic complications } \\
\text { associated with epidural steroid } \\
\text { injections, because of the } \\
\text { potential catastrophic outcome } \\
\text { of epidural hematomas, it } \\
\text { is extremely important to } \\
\text { watch for these complications, } \\
\text { specifically in patients on } \\
\text { anticoagulants prior to } \\
\text { procedure. They believe that } \\
\text { early reintroduction of warfarin } \\
\text { may have been responsible in } \\
\text { this patient. }\end{array}$ & $\begin{array}{l}\text { Even though all anticoagulants } \\
\text { were discontinued prior to } \\
\text { procedure resulting in normal } \\
\text { INR, early reintroduction of } \\
\text { warfarin may have resulted in } \\
\text { lumbar epidural hematoma.. }\end{array}$ \\
\hline $\begin{array}{l}\text { Ain \& Vance, } \\
2005 \text { (190) }\end{array}$ & $\begin{array}{l}\text { An } 85 \text {-year-old woman underwent epidural steroid injection. } \\
\text { She was on enoxaparin which was withheld per guidelines. } \\
\text { Prior to that she was taking warfarin for chronic atrial } \\
\text { fibrillation and a St. Jude aortic valve. Warfarin was withheld } 6 \\
\text { days before the epidural steroid injection and patient received } \\
1 \mathrm{mg} / \text { kg subcutaneous enoxaparin every } 12 \text { hours for } 4 \text { days } \\
\text { before her appointment. On the day before her appointment, } \\
\text { she received only her morning dose. At the time of the } \\
\text { injection, it was more than } 24 \text { hours since her last dose. Her } \\
\text { INR was } 1.2 \text {. } \\
\text { Epidural steroid injection was performed atraumatically } \\
\text { with use of 18-gauge Tuohy needle and the loss of resistance } \\
\text { technique into the L4-L5 interspace. The vertebral level of the } \\
\text { injection was not confirmed radiologically, thus it is possible } \\
\text { that the injection was performed at the L3-L4 interspace. } \\
\text { No paresthesias or blood were encountered during needle } \\
\text { placement. Methylprednisolone, } 80 \text { mg, was injected into the } \\
\text { epidural space. Enoxaparin regimen was reinstated } 24 \text { hours } \\
\text { after the procedure. The patient had received a total of } 3 \text { doses } \\
\text { when, } 48 \text { hours after the procedure, she reported intractable } \\
\text { back pain at the location of the epidural steroid injection. } \\
\text { MRI showed epidural hematoma. Repeat MRI showed } \\
\text { increasing size of the epidural hematoma. Patient underwent } \\
\text { decompressive laminectomy and intravenous steroids were } \\
\text { continued. Patient recovered completely. }\end{array}$ & $\begin{array}{l}\text { The authors concluded that } \\
\text { this case emphasized that } \\
\text { even a low dose of enoxaparin } \\
\text { administered over the course of } \\
\text { days could produce a very long } \\
\text { prolonged anticoagulation effect } \\
\text { such as that even } 36 \text { hours after } \\
\text { its discontinuation the patient } \\
\text { may remain anticoagulated. } \\
\text { Patient's renal insufficiency } \\
\text { may have been a factor. Thus, } \\
\text { authors concluded that current } \\
\text { ASRA recommendations for } \\
\text { treatment of patients receiving } \\
\text { low molecular weight heparin } \\
\text { may not apply to patients with } \\
\text { renal insufficiency. }\end{array}$ & $\begin{array}{l}\text { Epidural hematoma occurred } \\
\text { despite appropriate precautions } \\
\text { and the results with full recovery } \\
\text { after surgical decompression. }\end{array}$ \\
\hline $\begin{array}{l}\text { Reitman \& } \\
\text { Watters, } 2002 \\
\text { (201) }\end{array}$ & $\begin{array}{l}\text { A } 62 \text {-year old woman underwent cervical epidural steroid } \\
\text { injection by an experienced anesthesiologist. She responded } \\
\text { well to the first injection. Consequently, she underwent a } \\
\text { second injection. She was on Fiorinal on a regular basis for } \\
\text { headaches; this was discontinued for a week prior to epidural } \\
\text { steroid injection. } \\
\text { She developed acute onset of axial pain followed by } \\
\text { progressive quadriparesis within a matter of } 8 \text { hours. She } \\
\text { underwent a CT scan which showed anterior spinal hematoma } \\
\text { from C } 3 \text { to C5. After surgery the patient was initially } \\
\text { quadriplegic, but rapidly gained full function in the left upper } \\
\text { and lower extremities. She was making steady progress, but } \\
\text { she developed meningitis, about } 8 \text { days after the surgery. } \\
\text { Subsequently, she suffered a cardiopulmonary arrest. The first } \\
\text { time she was successfully resuscitated, but remained critically } \\
\text { ill with no evidence of neurological function. Six days later she } \\
\text { had a second cardiac arrest and could not be resuscitated. }\end{array}$ & $\begin{array}{l}\text { Authors concluded that } \\
\text { spinal hematoma can occur } \\
\text { after cervical epidural steroid } \\
\text { injection. Prompt recognition } \\
\text { and treatment could improve } \\
\text { the prognosis for recovery. The } \\
\text { patient suffered devastating } \\
\text { complications in this study; } \\
\text { however, there were no risk } \\
\text { factors in this patient. The } \\
\text { only remote risk factor was } \\
\text { Fiorinal therapy which was } \\
\text { discontinued. }\end{array}$ & $\begin{array}{l}\text { The devastating complications } \\
\text { of epidural hematoma can occur } \\
\text { even without known risk factors } \\
\text { or anticoagulant therapy.. }\end{array}$ \\
\hline
\end{tabular}


Table 5. Reports assessing bleeding complications and epidural hematoma in patients with continuation of antiplatelet therapy with interventional techniques.

\begin{tabular}{|c|c|c|c|}
\hline Study/Year & Case Report & $\begin{array}{l}\text { Conclusions by the Study } \\
\text { Authors }\end{array}$ & $\begin{array}{l}\text { Author Conclusions } \\
\text { of the Review }\end{array}$ \\
\hline $\begin{array}{l}\text { Maier et al, } \\
2002(176)\end{array}$ & $\begin{array}{l}\text { Two cases were presented with lumbar sympathetic blockade in } \\
2 \text { patients under medication with irreversible platelet aggregation } \\
\text { inhibitors. } \\
\text { The first patient was a 71-year-old male patient with intermittent } \\
\text { claudication and a trophic leg ulcer due to progressive peripheral } \\
\text { arterial disease. He was on ticlopidine } 500 \text { mg/day for stroke } \\
\text { prevention in the presence of carotid artery stenosis. Patient } \\
\text { underwent left-sided lumbar sympathetic block under fluoroscopy. } \\
\text { There was no known vascular puncture. } \\
\text { Two days later, a widespread skin hematoma was recognized. } \\
\text { Four days later a second block was performed under fluoroscopic } \\
\text { visualization which involved intravascular needle penetration. That } \\
\text { is } 6 \text { days after the first block. Following this, the patient developed a } \\
\text { large retroperitoneal hematoma. He was managed conservatively. } \\
\text { The second case involved a 79-year-old female patient with } \\
\text { generalized peripheral arterial disease, polyneuropathy, coronary } \\
\text { artery sclerosis, and a history of stroke with treatment with } 75 \text { mg } \\
\text { per day of clopidogrel. Clopidogrel was discontinued } 3 \text { days prior to } \\
\text { lumbar sympathetic block. } 72 \text { hours later, the coagulation parameters, } \\
\text { including bleeding time, were within normal limits. Lumbar } \\
\text { sympathetic blocks were performed at L3 level with attempts with no } \\
\text { intravascular injection. } \\
\text { She complained of burning groin and medial thigh pain. Her pain } \\
\text { was improved with opioid. She was walking on the ward without } \\
\text { complaints. An hour later she was found pulseless and resuscitation } \\
\text { attempts were unsuccessful. The autopsy revealed a massive } \\
\text { coagulated hematoma beneath the left psoas muscle with enlarged } \\
\text { retroperitoneal hemorrhage. There were no visible puncture lesions } \\
\text { in larger vessels. }\end{array}$ & $\begin{array}{l}\text { The authors concluded that } \\
\text { irreversible platelet inhibitors } \\
\text { should be discontinued for at } \\
\text { least } 7 \text { days prior to any invasive } \\
\text { technique, and any hemorrhage } \\
\text { is not controllable by external } \\
\text { compression. They also concluded } \\
\text { that in case of high thrombotic } \\
\text { risk, patients should be switched } \\
\text { to a different therapeutic regimen } \\
\text { with heparin up to } 6 \text { hours prior } \\
\text { to blockade. They believe that } \\
\text { groin pain and, particularly, } \\
\text { pain at the medial side of the } \\
\text { thigh, seem to be early signs of } \\
\text { bleeding complications of lumbar } \\
\text { sympathetic block. }\end{array}$ & $\begin{array}{l}\text { In the first case } \\
\text { report, ticlopidine } \\
\text { was not stopped, } \\
\text { and a retroperitoneal } \\
\text { hematoma was } \\
\text { observed. Nonetheless, } \\
\text { conservative } \\
\text { management was } \\
\text { appropriate without } \\
\text { fatal complications. } \\
\text { In the second } \\
\text { case, even though } \\
\text { clopidogrel was } \\
\text { discontinued prior to } \\
\text { lumbar sympathetic } \\
\text { block, coagulation } \\
\text { parameters were } \\
\text { appropriate, and } \\
\text { bleeding time was } \\
\text { appropriate, the result } \\
\text { was fatal. Thus, no } \\
\text { conclusions could be } \\
\text { reached. }\end{array}$ \\
\hline $\begin{array}{l}\text { Benzon et al, } \\
1999(177)\end{array}$ & $\begin{array}{l}\text { This case report describes a patient with acute onset of quadriparesis } \\
\text { admitted to a teaching hospital with a large cervical epidural } \\
\text { hematoma, developing numbness and weakness of his arms and legs } \\
\text { within } 30 \text { minutes after the performance of the cervical epidural } \\
\text { steroid injection. At the time of injection, he was taking several } \\
\text { clopidogrel, possibly aspirin, and diclofenac that had been started } \\
\text { after a prior coronary angioplasty. He also had a prior uneventful } \\
\text { cervical epidural steroid injection } 11 \text { days before the incident in } \\
\text { question, but it is not clear if he was taking these antiplatelet drugs } \\
\text { then. His PT, INR, and PPT were within normal limits. His platelet } \\
\text { count was appropriate. The last doses of antiplatelet drugs were } \\
\text { unclear. } \\
\text { He underwent an emergency C3-T3 laminectomy and evacuation } \\
\text { of cervical epidural hematoma. Approximately } 14 \text { hours after } \\
\text { the epidural injection postoperatively upper extremity strength } \\
\text { improved, but his lower extremities remained paralyzed. Three } \\
\text { months after the surgery he had regained his strength in his upper } \\
\text { extremities, but the paralysis of his lower extremities remained. }\end{array}$ & $\begin{array}{l}\text { The authors of this case report } \\
\text { cautioned that these drugs inhibit } \\
\text { platelet adhesion to the vascular } \\
\text { endothelium and shear stress- } \\
\text { induced platelet aggregation and } \\
\text { section. After discontinuation } \\
\text { of clopidogrel therapy, platelet } \\
\text { aggregation and bleeding time } \\
\text { returned to baseline within } 5 \\
\text { days. Authors stated that there } \\
\text { has been no case report of spinal } \\
\text { hematoma after neuraxial block } \\
\text { in patients receiving clopidogrel; } \\
\text { however, there was a case } \\
\text { report with ticlopidine. They } \\
\text { recommended that neuraxial } \\
\text { blocks be postponed for } 5 \text { - } 7 \\
\text { days in patients who are receiving } \\
\text { several antiplatelet drugs. }\end{array}$ & $\begin{array}{l}\text { This is another case } \\
\text { report showing } \\
\text { risks of antiplatelet } \\
\text { therapy with multiple } \\
\text { antiplatelet drugs. Even } \\
\text { with prompt surgical } \\
\text { intervention results } \\
\text { were poor. }\end{array}$ \\
\hline
\end{tabular}


therapy; fair evidence for excessive bleeding, including epidural hematoma formation, may occur with interventional techniques when antithrombotic therapy is continued; good evidence that spontaneous epidural hematomas occur with or without traumatic injury in patients with or without anticoagulant therapy. These spontaneous epidural hematomas are more likely associated with stressors such as chiropractic manipulation, diving, and anatomic abnormalities such as ankylosing spondylitis. There is fair evidence that the risk of thromboembolic phenomenon is higher than the risk of epidural hematomas with discontinuation of antiplatelet therapy prior to interventional techniques, even though both risks are significant.

In addition, there is good evidence that discontinuation of NSAIDs, including low dose aspirin, prior to performing interventional techniques does not reduce bleeding risk; fair evidence that continuation of phosphodiesterase inhibitors (dipyridamole [Persantine], cilostazol [Pletal], and Aggrenox [aspirin and dipyridamole]) prior to performing interventional techniques does not increase bleeding risk; limited evidence that discontinuing antiplatelet therapy with clopidogrel (Plavix), ticlopidine (Ticlid), or prasugrel (Effient) reduces risks of bleeding and epidural hematomas during interventional procedures but increases the risk of cerebrovascular and cardiovascular thromboembolic fatalities.

Further, there is fair evidence that anatomic conditions such as spondylosis, ankylosing spondylitis, spinal stenosis, and procedures involving the cervical spine; multiple attempts, and large bore needles increase the risk of epidural hematoma; and rapid assessment and surgical or nonsurgical intervention to manage patients with epidural hematoma can avoid permanent neurological complications.

There is limited evidence in reference to newer antithrombotic agents dabigatran (Pradaxa) and rivaroxaban (Xarelto) to discontinue to avoid bleeding and epidural hematomas and are continued during interventional techniques to avoid cerebrovascular and cardiovascular thromboembolic events.

While the preparation of guidelines for interventional pain management $(73-77,79,80)$ has been difficult, the question of whether or not to continue antithrombotic and antiplatelet therapy for interventional procedures is especially difficult to answer. Recommendations are made based on observational studies and case reports. Thus, the Institute of Medicine (IOM) considers most guidelines as not based on evidence (407).
The IOM has released methodology standards for clinical guidelines, which when followed, result in guidelines that can be trusted (407). In this manuscript the IOM describes multiple challenges in developing guidelines. The IOM states that the literature assessing the best methods for guideline development have evolved dramatically in the 20 years since the IOM's first report on the subject.

The issue of conflicting guidelines is a major issue in the era of comparative effectiveness research and evidence-based medicine (408-414). A publication, based on IOM standards, on adverse events in hospitals showed they were not accurately measured (415). In fact, they developed a new standard and illustrated that many years and much expense, due to the extensive measures proposed by IOM standards, have not improved care by reducing the number of adverse events in hospitals, but that adverse events in hospitals may be 10 times greater than previously measured (415). Multiple issues related to various regulations and guidelines since the enactment of the American Recovery and Reinvestment Act (ARRA) (416) and the Patient Protection and Affordable Care Act (ACA) $(43,44,46-49,417)$ along with various guidelines $(72,73,79,80)$ have been questioned. These guidelines are not only related to subjects such as infection control, but also to mammography, prostate cancer screening, fraud and abuse, and even the administering sedation during procedures, as issues affecting medical practices in the modern era $(38,418-460)$.

Our literature search showed a large number of spontaneous occurrences of hematoma. In addition, there have been some case reports of epidural hematoma during interventional techniques (majority with regional anesthesia) whether antiplatelet therapy was continued or discontinued $(80-98,171$ $398,461,462)$. Spontaneous spinal epidural hematoma is a rare, but recognized, entity. The causes of spontaneous spinal epidural hematoma vary but may be higher in patients with bleeding disorders, therapy with anticoagulants following thrombolysis for $\mathrm{MI}$ and spinal arteriovenous malformation, chiropractic manipulation, diving, hypertension, Paget's disease, and ankylosing spondylitis $(181,185,202,203,207,208,223$, $225,231,232,245,260,275,278,295,297,319,343-345,348-$ $352,357,358,362,365,368,373,376,378-380,463-481)$. Even when thromboembolic or hematoma events occur and are temporally related to an interventional procedure, a spontaneous event cannot be ruled out.

Groen and van Alphen (471), in 1996, reviewed 
333 cases of spontaneous spinal epidural hematoma reported in the literature, including 3 of their own patients. Since then, multiple other case reports have been published. From their analysis it was evident that, among the 333 cases, the majority were in the posterior and posterolateral spinal epidural space. Due to the anatomical characteristics of the internal vertebral plexus, they postulated that the spinal epidural venous network was the major source of epidural hematoma.

Spontaneous spinal epidural hematoma usually presents with acute onset of spinal pain, which may rapidly progress to quadriparesis or paraparesis (265). However, several cases of Brown-Séquard syndrome due to cervical spontaneous spinal epidural hematoma have been reported $(180,203,207,278,295,343-345,378,474)$. However, occasionally the pain produced by cervical spontaneous spinal epidural hematoma may be attributed to cardiac disease (277), which may result in a double jeopardy as these patients might receive thrombolytic therapy, which might aggravate the spontaneous spinal epidural hematoma. Symptoms may also mimic stroke (357). The majority of the cases report (471) reveal a classic clinical picture consisting of acute onset of severe, often radiating, back pain, followed by signs and symptoms of a rapidly evolving nerve root and/or spinal cord compression. Only 9 of 333 cases presented in a chronic manner. Among these 9 patients, only one had a lesion in the cervical region (471). The best diagnostic tool for spontaneous epidural hematoma is MRI. Resolution of spontaneous spinal epidural hematoma is well known $(181,319,378,398,469,471-481)$. In fact, some cases have improved within a few hours of onset of the symptomatology (398). Even then, among the 333 cases reported (471), surgery was performed in 327 patients. The authors concluded that in patients who underwent surgery, the factors that determined the outcome were interval between the onset of the symptoms and the extent of preoperative neurological deficit. In patients with complete sensory motor loss, the results were better if surgery was performed less than 36 hours after onset of neurological deficit. In patients with incomplete sensory motor deficit, favorable outcomes correlated highly with surgery carried out less than 48 hours following onset.

The development of epidural hematoma with or without anticoagulant or antithrombotic therapy is a grave complication even though it is extremely rare in interventional pain management. Spinal hematoma is relatively more common complication associated with regional anesthesia. In fact, Wulf (229) reported 51 confirmed spinal hematomas associated with epidural anesthesia in 1996. However, Horlocker et al (85), in American Society of Regional Anesthesia and Pain Medicine (ASRA) guidelines for regional anesthesia, described that while these complications may be common, the actual incidence of neurologic dysfunction resulting from hemorrhagic complications associated with central neural blockade is unknown. In an extensive review of the literature, Tryba (482), in 1993, identified 13 cases of spinal hematoma after 850,000 epidural anesthetics and 7 cases among 650,000 spinal techniques. Consequently, on the basis of these observations, the calculated incidence has been estimated to be approximately less than 1 in 150,000 epidural and less than one in 220,000 spinal anesthetics (97). However, these estimates represent the upper limit of the $95 \%$ confidence interval $(\mathrm{Cl})$, the actual frequency should be much less. The series involved in these calculations were conducted before the implementation of routine perioperative thromboprophylaxis. Further, later case series and epidemiologic surveys suggest that the risk has increased $(262,396,397)$.

Hemorrhaging to the spinal canal most commonly occurs in the epidural space, most likely because of the prominent epidural venous plexus, even though variables such as needle size, catheter placement, number of attempts, the type and volume of injectate, may also affect the site of clinically significant bleeding (83$85,96,296)$. In a literature review between 1906 and 1994, Vandermeulen et al (262) reported 61 cases of spinal hematoma associated with epidural or spinal anesthesia; $60 \%$ of the cases occurred in the last decade of the study period. In 42 (68\%) of the 61 patients, the spinal hematomas associated with central neural blockade occurred in patients with evidence of hemostatic abnormality. The review by Wulf (229) included an additional 16 cases. Vandermeulen et al (262) showed that 25 of the 61 patients in their report had received intravenous or subcutaneous unfractionated or $\mathrm{LMWH}$, whereas an additional 5 patients were presumably administered heparin because they were undergoing a vascular surgical procedure. However, only 12 of 61 patients had evidence of coagulopathy or thrombocytopenia or were treated with antiplatelet medications such as aspirin, indomethacin, ticlopidine, oral anticoagulants, thrombolytics (urokinase), or dextran 70 immediately before or after the spinal or epidural anesthetic. In $25 \%$ of the patients, needle or catheter placement was reported to be difficult. All in all, in $87 \%$ of the 61 cases, either a clotting abnormality or needle placement difficulty was 
present. Consequently, only $13 \%$ of the patients were without any coagulopathy or placement difficulties.

In our assessment, we found multiple cases of epidural hematoma in patients undergoing interventional techniques. In addition, 2 studies assessing bleeding risk of interventional techniques in chronic pain $(82,96)$ showed the lack of increased risk with continued administration of antiplatelet therapy. However, multiple surveys of interventional techniques $(81,83-85)$ have uniformly illustrated that in the majority of the patients, antiplatelet therapy is discontinued. Cases have been reported despite proper adherence to guidelines of antiplatelet therapy $(175,176,178,180,187,189,190$ ,193,201,204,222,276) and also in patients who have never had antiplatelet therapy. Further, it is also important to remember that the majority of these cases are related to spontaneous occurrence.

Multiple factors described include anatomy of the epidural space, spinal anatomy, coexisting pathology, coagulation status, needle placement, and injectate. A meta-analysis of over 600 spinal hematoma including both spontaneous and iatrogenic cases, revealed anticoagulation to be the second most common underlying etiology for spontaneous hematoma formation, following idiopathic occurrence with no readily identifiable cause (483). In this meta-analysis, spinal and epidural anesthetic procedures in combination with anticoagulation were the fifth highest cause of epidural hematomas. However, among this group of patients, spinal hematomas were most commonly encountered in those receiving continuous and not single-shot epidural anesthesia $(70,71)$.

Consequently, the majority of the interventionalists believe that the relative contribution of anticoagulation to hemorrhagic risk for patients receiving epidural steroid injections or other interventional techniques is unknown. Xu et al (189) in a 2009 publication reported that there were 8 cases ever published based on the English language literature in PubMed and MedWatch $(177,178,180,190,391,396)$. Their review showed that excluding one case in which the location of the hematoma was unknown, 4 cases involved the cervical spine. Interestingly, all 4 cases were associated with NSAID usage (199). However, current concepts and guidelines conclude that there is not a significantly increased risk for hemorrhage complications in patients on NSAIDs receiving neuraxial anesthesia, even though NSAID usage may increase the likelihood of developing minor complications or prolonging existing side effects $(83-85,96,97,199,201,218,396,405,461,462,484-495)$.
$\mathrm{Xu}$ et al (189) postulated that the evidence for such guidelines is based on studies such as that conducted by Horlocker et al (96), which were limited in patient population size and quantity of NSAID coverage, the only study published until 2011. In 2011, Manchikanti et al (82) published a larger study with 12,000 encounters which included all types of interventional techniques. However, this will also be considered a smaller sample size. However, $\mathrm{Xu}$ et al (189) considered these studies provided skewed results as smaller number of patients are on antiplatelet medications, specifically drugs such as indomethacin. Consequently, as they state, the relative contribution of each medication to the risk of spinal hematoma may be variable, especially for a relatively rare complication. However, a retrospective assessment of complications by Manchikanti et al $(82,461,462)$ revealed no epidural hematomas or major bleeding incidents in 120,000 interventional techniques performed in patients without antiplatelet therapy, with continued antiplatelet therapy, and discontinued antiplatelet therapy. Nevertheless, it is important to acknowledge that prospective well controlled long-term studies are essential and other factors may also contribute to the epidural hematomas. In the case report by Benzon et al (177), the patient had therapeutic doses of diclofenac, clopidogrel, and possibly aspirin during the epidural steroid injection, and there exists no study that examines whether multiple NSAIDs or antiplatelet drugs may elevate the risk of hemorrhage. The patients reported by Ghaly (391), Stoll and Sanchez (180), and Williams et al (178) only received one NSAID each (diclofenac, ibuprofen, and indomethacin, respectively). Cervical epidural steroid injections, in general, are potentially associated with a higher risk of complications due to anatomical considerations $(88,201,262,485-488)$. In fact, an in vitro study of 10 cadavers revealed that cervical epidural steroid injections were at particularly high risk for hemorrhagic complications due to the anatomical variation in the location of arteries within the spinal canal $(461,462,489,490)$. In addition, the anatomy of the ligamentum flavum varies significantly with its absence and extensive vasculature in the cervical spine (496-517).

$\mathrm{Xu}$ et al (189) also described that among the 3 epidural steroid injections in patients on a regimen of anticoagulation therapy that resulted in lumbar or thoracolumbar epidural hematomas, the case report by Snarr (392) documented a dural puncture, suggesting an increased likelihood of trauma in the spinal canal during the procedure. The patient also had a history of 
receiving several epidural steroid injections in the area in addition to being on warfarin therapy, both of which are known risk factors for hematoma development after epidural analgesia (85). Repeated epidural steroid injections, along with anatomical variations including post surgery syndrome, are major issues in interventional pain management. Many of the patients present with spinal stenosis, spondylosis, facet arthrosis, and post surgery syndrome often with multiple surgical interventions. These patients also suffer with comorbid medical disorders requiring antiplatelet therapy and many of the patients in interventional pain management settings are obese. Xu et al (189) also discussed that the case reported by Horlocker and Wedel (396) involved a patient taking enoxaparin and aspirin, but there is no additional information on dosage, timing, or injection technique to evaluate the risk factors for hematoma development. The case by Ain and Vance (190) was considered most similar to the case by Xu et al (189). The patient was an 85-year old woman who was taking warfarin for atrial fibrillation and aortic valve replacement (190). Warfarin was withheld 6 days before the epidural steroid injection, and the patient received $1 \mathrm{mg}$ per $\mathrm{kg}$ enoxaparin every 12 hours for 4 days before her appointment. A traumatic epidural steroid injection was performed greater than 24 hours after her last enoxaparin dose. The patient resumed her warfarin treatment on the evening of the injection and continued to take $1 \mathrm{mg} / \mathrm{kg}$ subcutaneous enoxaparin every 12 hours starting the second day after the procedure. Two days later, she experienced excruciating back pain, which was revealed to be an L2/4 hematoma on MR imaging. Similarly, Xu et al's (189) patient developed an epidural hematoma after epidural steroid injections, despite having following the ASRA's most current guidelines for patients receiving neuraxial anesthesia who are on a regimen of LMWH. These guidelines state that patients should discontinue warfarin for 4 - 5 days before neuraxial procedures, and recommend performing the procedure later than 24 hours after the last dose of bridging LMWH. If needle placement is traumatic or if blood is encountered during needle placement, a 24-hour delay is recommended before restarting LMWH.

The debate also continues with ophthalmic surgeries $(165,253,518-526)$. Research in ophthalmic surgery is based on perioperative management focusing on cataract surgery (527-536). However, cataract surgery has been described to be of lower risk of hemorrhage by virtue of small incision techniques and the use of topical anesthesia when compared to glaucoma surgery $(165,253)$. Patients undergoing glaucoma surgery often start with high intraocular pressure, experience a sudden drop in intraocular pressure or a period of hypotony, and may require an iridectomy. Consequently, these factors post an increased risk of intraoperative or delayed bleeding in the form of hyphema, vitreous or retinal hemorrhage, or choroidal hemorrhage $(513,534,535)$. In addition, complications may also be related to the type of anesthesia (536). A study of 347 patients (eyes) who were on anticoagulant therapy or antiplatelet therapy prior to glaucoma surgery (253) showed a higher rate of hemorrhagic complications than 347 control patients with hemorrhagic complications of $10.1 \%$ versus $3.7 \%$. Patients on coagulant therapy had a higher rate of hemorrhagic complications than patients on antiplatelet therapy (22.9\% versus $8 \%)$.

The risk of thromboembolic phenomenon may be even more significant than the risk of epidural hematoma. The regional anesthesia and interventional pain management literature has only focused on the risks of epidural hematoma paying scant attention to thromboembolic events. However, multiple guidelines of other specialties have described continuation of antiplatelet therapy during surgical interventions including peripheral vascular surgery with exceptions (108-130,141-143,146,151-165,253).

In a systematic review and meta-analysis of the hazards of discontinuing or not adhering to aspirin among patients at risk for coronary artery disease (14), noncompliance or withdrawal of aspirin treatment was illustrated with ominous prognostic implications in those at moderate-to-high risk for coronary artery disease. This study showed aspirin nonadherence or withdrawal being associated with a 3-fold higher risk of major adverse cardiac events which was magnified in patients with intracoronary stents with the conclusion that aspirin discontinuation in such patients should be advocated only when bleeding risk clearly overwhelms that of atherothrombotic events. In a study of the evaluation of incidence of death and acute $\mathrm{MI}$ associated with discontinuation of clopidogrel (Plavix) after acute coronary syndrome (19), the authors observed a clustering of adverse events in the initial 90 days after discontinuation among both medically treated and percutaneous coronary intervention treated patients with acute coronary syndrome, supporting the possibility of a clopidogrel rebound effect.

It has been shown that approximately $5 \%$ of patients who have undergone percutaneous coronary 
interventions will undergo noncardiac surgery within the first year after stenting (537). However, the proportion of patients undergoing other invasive procedures such as interventional techniques may be even higher (37-41,43-78,81-88,92,97,98,390,537). The physicians managing such patients are confronted with the complex issue of the risk of hemorrhagic complications when continuing the antiplatelet agents in the perioperative period and the risk of cerebral and cardiovascular events if the drugs are discontinued abruptly (14,37-41,43-78,81-88,92,97,98,143,390,537-561).

The data suggest the traditional attitude of discontinuing the medication 10 days before interventions poses considerable danger (108-130,139-146,537). Multiple guidelines recommend discontinuation and this has been a general practice to discontinue these drugs (85). Thus, despite the lack of evidence of significant risk of bleeding during interventional techniques in patients with antithrombotic therapy $(83-85,96)$, they are routinely discontinued. However, neither the continuation or discontinuation of antithrombotic therapy are without risk $(85,86,172-177,296,397)$. While most of the reports are related to regional anesthesia for surgical procedures, there have also been multiple reports of epidural hematoma in patients undergoing interventional techniques for chronic pain with or without antithrombotic therapy - continued or discontinued (81-96,176178, 180, 187, 189, 190,193,201,204,222,276,388,391).

Appropriate diagnosis and prompt conservative or surgical intervention is of paramount importance in any type of epidural hematoma. At present, surgical intervention is considered the most appropriate treatment if neurological compromise is evident; however, the literature illustrating improvement with conservative management raises additional questions. Thus, appropriate discussion with the patient, surgical team, and consideration of the degree of neurological deficit and progression, stability, or regression with shared decision-making is essential.

Multiple guidelines have been published with differing recommendations not only based on different regional practice approaches, but also on different specialties such as regional anesthesia versus interventional pain management $(85,492-495,537-541)$. All these guidelines are prepared based on case reports and observational studies with inadequate sample sizes. Raj et al (86) have described specific protocols for interventional pain management with risk stratification. However, it seems that the interventional pain management community continues to focus on the guidelines developed by ASRA (85). Due to the lack of guidelines prepared for interventional pain management with specific concerns, regional anesthesia guidelines are discussed herewith. The most commonly used guideline is the one prepared by ASRA. These guidelines are described as evidence-based guidelines with appropriate strength and grade of recommendations. However, these are based on observational studies and case reports. In fact, the process and validity of these guidelines has been questioned $(405,491)$. It is universally accepted that warfarin has to be stopped 3 to 5 days prior to interventional techniques, unless the INR is at an acceptable level, antiplatelet therapy and bridging have been described with variable opinions in multiple guidelines $(85,492-495,537-541)$. ASRA guidelines by Horlocker et al (85) recommend the following on perioperative management of patients on antiplatelet therapy:

- For patients with coronary stents, elective surgery is to be postponed for aspirin and clopidogrel therapy, therapy is continued for 4 to 6 weeks for baremetal stents and 12 months for drug eluting stents $(85,492,493)$.

- If surgery cannot be postponed, continue aspirin throughout perioperative period.

- Patients at highest risk for cardiac events exclusive of coronary stents.

- Continue aspirin throughout the perioperative period. Discontinue clopidogrel at least 5 days and preferably 10 days before surgery. Resume clopidogrel 24 hours postoperatively.

- Patients at low risk of cardiac events.

- Discontinue antiplatelet therapy 7 to 10 days before surgery. Resume antiplatelet therapy 24 hours postoperatively.

Horlocker (494) in a manuscript published in 2011 in reference to regional anesthesia and the patient receiving antithrombotic and antiplatelet therapy provided the same guidance as described in the guidelines (85).

- The concurrent use of medications that affect other components of clotting mechanisms, such as oral anticoagulants, standard heparin, and LMWH, increases the risk of bleeding complications for patients receiving antiplatelet agents.

- NSAIDS, by themselves, represent no significant risk for the development of spinal hematoma in patients having epidural or spinal injections.

- Allow platelet function to recover before neuraxial block after administration of ticlopidine, clopido- 
grel, and platelet glycoprotein IIb/llla receptor antagonist.

- The time to normal platelet aggregation after discontinuation of therapy is 14 days for ticlopidine, 5 to 7 days for clopidogrel, and 7 to 10 days for Prasugrel (Effient).

- For the platelet glycoprotein Ilb/llla inhibitors, the duration ranges from 8 hours for eptifibatide and tirofiban and 48 hours after abciximab administration.

Nordic guidelines for neuraxial blocks in disturbed hemostasis from the Scandinavian Society of Anesthesiology and Intensive Care Medicine were published in 2010 (538). These guidelines were developed by a task force of experts to establish consensus on recommendations for best clinical practice in providing effective and safe central neuraxial blocks in patients with an increased risk of bleeding. They performed a literature search and expert evaluation of the evidence which included risks of spinal bleeding from hereditary and acquired bleeding disorders and antihemostatic drugs used for thromboprophylaxis, risk evaluation in published case reports, and recommendations in published national guidelines. In reference to platelet inhibitors, they recommended the following.

1. Aspirin

- In patients on aspirin for secondary prevention after coronary event or stroke, aspirin is continued up to the day of central neuraxial block. (Recommendation grade $C$; evidence category III)

- In patients on aspirin for primary prevention of arterial thrombotic events, aspirin is interrupted 3 days before a planned central neuraxial block. (Recommendation grade D; evidence category IV)

- In patients on higher doses of aspirin treatment for its analgesic or anti-inflammatory effects (greater than $1 \mathrm{gm}$ per day), 7 days should be allowed to elapse between the last aspirin dose and central neuraxial block. (Recommendation grade D; evidence category IV)

2. NSAIDs other than aspirin

- In patients treated with NSAIDs, they recommended that the treatment is discontinued before a central neuraxial block. The drug-free intervals should be no less than 12 hours for Diclofenac, ibuprofen, ketoprofen; 24 hours for indomethacin, Ketoralac, Lornoxicam; 48 hours for naproxen; and 2 weeks for piroxicam and tenoxicam. (Recommendation grade D; evidence category IV)

- In patients planned for central neuraxial blockade, they recommended that a non-selective NSAID be replaced by another analgesic in the immediate perioperative period. (Recommendation grade D; evidence category IV)

3. Dipyridamole

- The consensus of these guidelines was that dipyridamole was a weak platelet inhibitor without any clinical important antihemostatic effect. Consequently, they recommended that there is no need for discontinuation before a central neuraxial blockade.

4. Thienopyridine-adenosine phosphate (ADP) blockers. These include clopidogrel, ticlopidine, prasugrel (Effient), and other novel antiplatelet drugs.

- In patients treated with clopidogrel or ticlopidine alone for primary prevention of thrombotic events, the treatment is discontinued no less than 5 days before an intended central neuraxial block. (Recommendation grade C; evidence category IV)

- In patients treated with dual antiplatelet medication with a thienopyridine and aspirin, after coronary stent implantation, the antiplatelet medication should not be interrupted and central neuraxial block is contraindicated. (Recommendation grade C; evidence category III)

Recommendations of the European Society of Anesthesiology (ESA) for regional anesthesia and antithrombotic agents (539) were published in 2010 by the ESA. They arrived at the guidelines by extensive review of the literature and consensus. Their results and conclusions included that in order to minimize bleeding complications during regional anesthetic techniques, care should be taken to avoid traumatic puncture. They also concluded:

- Regional anesthesia in patients receiving full anticoagulation treatment continues to be contraindicated.

- Aspirin and other NSAIDs may be continued.

- Clopidogrel be discontinued 7 days prior to central neuraxial block, ticlopidine 10 days, prasugrel (Effient) 10 days.

Green and Machin (540) in 2010 described the management of anticoagulant patients during neuraxial anesthesia. They summarized the results that performing a central neuraxial block in patients on anticoagulant therapy is a complex decision that should take into account the twin risks of bleeding and venous/arterial thrombosis if anticoagulation therapies were to be stopped. They felt that various guidelines issued to achieve normal hemostasis and thus allow safe admin- 
istration of central neuraxial block are weak based on the evidence which is observational studies and mainly case reports. Thus, they recommended that it is crucial to fully assess individual risk factors and understand anticoagulant pharmacokinetics in order to appropriately provide central neuraxial blockade. They described multiple patient-related risk factors associated with spinal epidural hematoma which included patient related factors such as elderly, female gender, acquired coagulopathy (liver/renal failure, malignancy, HELLP syndrome, DIC, etc.), thrombocytopenia, spinal abnormalities such as spina bifida, spinal stenosis, spinal tumors, ankylosing spondylitis, and osteoporosis. They also described procedure-related risk factors including a traumatic procedure with multiple attempts, presence of blood in the needle or the catheter, indwelling epidural catheter compared to a single shot epidural, and catheter removal. Drug related factors included anticoagulant therapy, and dual anticoagulant and antiplatelet therapies. They reported 9 cases of epidural hematomas $(98,175,189,190,283,386-389)$.

Vandermeulen (541) in a 2010 manuscript described various issues related to regional anesthesia and anticoagulation. He summarized the recommendations from various guidelines.

- Clopidogrel has to be stopped 7 days prior, ticlopidine 10 days, eptifibatide/tirofiban 8 to 10 hours, and prasugrel (Effient) for at least 7 days before intervention.

- Low-dose aspirin and dipyridamole may be continued except in cases with concomitant administration of other drugs.

\section{Non-steroidal Antiinflammatory Drugs (NSAIDS)}

NSAIDs inhibit cyclooxygenase and thus platelet aggregation in a reversible manner in proportion to the half-life of the agent used. For selective COX-2 inhibitors, there is no evidence of any relevant effects on platelet aggregation capacity or an increased bleeding tendency (542). The nonopioid analgesics, acetaminophen and dipyrone, have not been linked to spinal epidural hematomas. In contrast, aspirin, even after a single-dose, leads to irreversible inhibition of platelet function as a result of cyclooxygenase inhibition. Due to the lack of a nucleus, platelets are not able to synthesize new cyclooxygenase, so that the effect persists for the entire lifetime of the platelets, usually 7 to 10 days. However, healthy bone marrow will replace more than $30 \%$ of the irreversibly inhibited platelets within 3 to 4 days $(543,544)$. Bleeding effects of aspirin appear to be dose dependent, with more adverse events observed in patients receiving more than $100 \mathrm{mg}$ daily (545). Even though spontaneous bleeding in those taking aspirin is doubled, the risk remains generally very low, with a requirement of 800 patients annually to be treated for one additional bleeding event to occur (546). In a meta-analysis of noncardiac surgical procedures, 1.5-fold higher bleeding rates were reported in patients receiving aspirin (539). With the exception of intracranial procedures, prosthetic resections, and tonsillectomies, no severe cases of bleeding were observed (143). Multiple studies considered the safety of neuraxial interventions during aspirin administration (82-85,89,96,461,462). The Collaborative Low-Dose Aspirin Study in Pregnancy (CLASP) (557) included a total of 9,364 pregnant women, only 2,783 of the women underwent epidural analgesia. Overall, only 700 women were available for analysis. None of the women in this study experienced a problem related to aspirin. Pregnancy was associated with a general low grade activation of coagulation, and aspirin was taken alone rather than in combination with other thromboprophylaxis. These 2 factors would have reduced the risk of epidural hematoma in this cohort. Horlocker et al $(83,84,96)$ included a number of patients not only for surgery, but also for interventional techniques with epidural steroids. A small proportion of patients received concurrent thromboprophylaxis with heparin, a significant proportion received multiple antiplatelet drugs, and no epidural hematomas were observed. Manchikanti et al $(82,461,462)$ evaluated 12,000 encounters with 18,000 procedures which included over 1,500 patients on aspirin undergoing epidural injections with 1,050 of them continuing their aspirin therapy during the procedures and 500 discontinuing it, with no incidence of epidural hematoma or major bleeding episodes for any interventions.

Multiple adverse cardiovascular events have been described with discontinuation of aspirin. Aspirin is known to reduce the risk of a recurrent cardiovascular event by around $30 \%$, and mortality by approximately $15 \%$, in patients with a history of acute coronary syndrome, stroke, or peripheral arterial occlusive disease (547). The risk of discontinuing aspirin in patients with implanted coronary stents or unstable coronary syndromes has been described, along with a rebound phenomenon. Consequently, the preoperative withdrawal of aspirin is unnecessary in most cases and is associated with a high risk of acute thrombosis (539). However, it should be noted that concurrent intake of ibuprofen 
may lead to a reduction in the efficacy of aspirin (542) and that NSAIDs increase the risk of adverse cardiovascular events. The American College of Chest Physicians (ACCP) does not currently recommend assessment of platelet function before invasive procedures because there is no apparent correlation with the bleeding (492).

Thus, based on the previous guidelines and comprehensive evaluation of the literature, NSAIDs, including low-dose aspirin, specifically when given in isolation, do not increase the risk of spinal epidural hematoma and are not a contraindication for interventional techniques.

\section{Platelet Aggregation Inhibitors:}

Ticlopidine and clopidogrel are the most commonly utilized platelet aggregation inhibitors belonging to the thienopyridine group (560-562). Prasugrel (or Effient) is also a platelet aggregation inhibitor (563-569). They act by antagonizing adenosine diphosphate (ADP) at the platelet's purine receptors. ADP-induced aggregation is noncompetitively and irreversibly inhibited whereas arachidonic acid metabolism is unaffected. They undergo hepatic conversion into active metabolites in vivo. Consequently, several days are required before full effect is reached, and the process is dose dependent. The active metabolites are eliminated by the kidneys (548). A reduction in ADP-dependent activation of the glycoprotein $2 \mathrm{~B} / 3 \mathrm{~A}$ receptor takes place, causing a reduction in fibrinogen fixation and platelet cross-linking. On a $500 \mathrm{mg}$ per day regimen, the maximum aggregation inhibiting effect is achieved after 8 to 11 days on ticlopidine. The elimination half-life is 24 to 32 hours, but because platelet function inhibition is irreversible, the effect is still in evidence more than 72 hours after its withdrawal (549). However, with long-term administration, the elimination half-life increases to over 90 hours, and following cessation, 10 days should be allowed before normalization can be expected (550). In contrast to clopidogrel, ticlopidine can lead to neutropenia in up to $1 \%$ of the patients, limiting widespread use of the drug and making regular blood count checks necessary in the initial weeks.

Prasugrel or Effient is a thienopyridine which is a prodrug that requires conversion to an active metabolite before binding to the platelet P2Y2 receptor to develop antiplatelet activity (563-569).

Prasugrel, or Effient, is given as a $60 \mathrm{mg}$ loading dose producing at least $50 \%$ inhibition of platelet aggregation by one hour in $90 \%$ of patients. Mean steady- state inhibition of platelet aggregation was about $70 \%$ following 3 to 5 days of dosing at $10 \mathrm{mg}$ daily after $60 \mathrm{mg}$ loading dose of Effient (563-569). Platelet aggregation gradually returns to baseline values over 5 to 9 days after discontinuation of prasugrel, which is a reflection of new platelet production rather than the pharmacokinetics of prasugrel. However, the relationship between inhibition of platelet aggregation and clinical activity of Prasugrel has not been established (563). Prasugrel is a prodrug and is rapidly metabolized to a pharmacological active metabolite and inactive metabolites. The active metabolite has an elimination half-life of about 7 hours ranging from 2 to 15 hours. In addition, healthy subjects, patients with stable atherosclerosis, and patients undergoing percutaneous coronary intervention show similar pharmacokinetics. A large phase 3 study randomly assigned 13,608 patients with moderate to high risk acute coronary syndromes scheduled for percutaneous and coronary intervention to receive prasugrel (Effient) or clopidogrel for 6 to 15 months. Prasugrel (Effient) therapy was associated with significantly reduced rates of ischemic events, including stent thrombosis, but with an increased risk of major hemorrhage that was occasionally fatal (570). Thus far, no data are available in reference to use of this drug prior to interventional techniques. The antiplatelet effects last for the platelet lifespan and pretreatment levels of platelet function are achieved 7 to 10 days after discontinuation.

Adverse events of prasugrel included hypertension, hypotension, atrial fibrillation, brachycardia, noncardiac chest pain, and peripheral edema in 3\% to $8 \%$ of the patients; headache, dizziness, fatigue, fever, extremity pain in $3 \%$ to $6 \%$ of the patients; and hypercholesterolemia and hyperlipidemia in $7 \%$ of the patients. Epistaxis, dyspnea, and cough also have been reported. Surprisingly, back pain was reported in $5 \%$ of the patients (551-557).

The maximum platelet function inhibiting effect is observed after 3 to 7 days or approximately 12 to 24 hours following oral administration of clopidogrel 75 mg, 6 to 7 days after following oral administration of clopidogrel $75 \mathrm{mg}$, or in approximately 12 to 24 hours following initial bolus administration of 300 to $600 \mathrm{mg}$. Recovery of platelet function occurs only 6 to 7 days after clopidogrel administration (558).

Risk of bleeding with thienopyridines has been reported to be more frequent than with aspirin. The incidence of severe bleeding is increased by simultaneous treatment with vitamin $\mathrm{K}$ antagonists, dextrans, 
or heparins (548). Clopidogrel treatment in patients undergoing cardiac surgery may cause severe surgical bleeding, with a 2.5-fold increase in the need for transfusion and a 5- to 10-fold increase in the risk of repeat surgery, as well as prolonged course of intensive therapy (559-561). Immediate improvement of hemostasis is only possible by administering platelets. There have been reports of spinal epidural hematoma following neuraxial blockade during clopidogrel administration. However, spinal epidural hematoma following discontinuation of clopidogrel administration also has been described $(81,176,177)$. In the study by Manchikanti et al (82), with over 265 patients on clopidogrel and an additional 265 patients on combination of aspirin and clopidogrel, with continued therapy during interventional procedures in over 200 patients and discontinuation of at least 7 days in 330 patients, there were no differences noted in outcomes with no major bleeding or epidural hematoma.

In reference to the thromboembolic events, compared to aspirin, clopidogrel and ticlopidine are better at preventing ischemic cerebral infarction (562), $\mathrm{MI}$, and vascular deaths in general $(555,558,560,562)$. Prasugrel has been shown to be more effective than ticlopidine and clopidogrel in reducing the combined rate of death from cardiovascular causes, nonfatal MI, or nonfatal stroke (552). However, an increased rate of serious bleedings and fatal bleedings was also observed (565-570). However, the overall mortality did not differ between the 2 treatment groups. Overall, it has been suggested that acute coronary syndrome patients can be safely switched from clopidogrel to prasugrel and that doing so results in a further reduction in platelet function after one week (567). Another study of high risk patients also produced similar results with clopidogrel and prasugrel (569).

Thus, patients with unstable coronary syndromes, previous percutaneous coronary interventions, and stent implantations, benefit from long-term dual platelet aggregation inhibitors with aspirin and clopidogrel $(562,571)$. The premature withdrawal of this treatment following coronary interventions increases the risk of stent thrombosis and MI with high mortality (572). Patients with a drug eluting stent are at risk for a particularly long period, due to late and incomplete endothelialization (573). Consequently, the American Heart Association (AHA) currently recommends drug eluting stents are used only provided no surgery is planned within the following 12 months, and the patients show a high degree of compliance (574). Thus, with multiple other risk factors in interventional pain management settings, a cardiologist should be consulted before an interruption of platelet aggregation inhibition, and clopidogrel with aspirin should be administered during the perioperative period. However, with bare-metal stents, dual platelet aggregation inhibition should be administered for at least 4 to 6 weeks and with both types of stents, the administration of aspirin should be continued on a lifelong basis and perioperative interruption should be avoided (574).

It is also important to consider that selective serotonin reuptake inhibitors (SSRIs) are often used to treat depression and also deplete serotonin in platelets by blocking reuptake and can produce a range of disorders through a decreased platelet binding affinity, blockade of platelet calcium mobilization, and reduced platelet secretion (575-577). A slight bleeding tendency may be evident during the perioperative period (578-580) and one study found blood transfusion requirements to be higher in patients on SSRIs (581). However, others have failed to find increased perioperative bleeding in patients undergoing coronary artery bypass grafting $(582,583)$. Thus, the use of SSRIs with other drugs have an influence on coagulation, such as aspirin, thienopyridines, NSAIDs, vitamin K antagonists, or even LMWH which seem to increase the bleeding tendency (584586). However, there are no reports of spinal hematoma following neuraxial block during the use of SSRIs.

Platelet function after cessation of therapy was assessed in some studies, and clopidogrel therapy showed variable results $(401,587)$. Perakis et al $(587)$ examined the change in platelet function after the common clinical scenario of discontinuing chronic clopidogrel therapy in those patients preparing to undergo an elective surgery and the time course of platelet function recovery after clopidogrel discontinuation. Platelet inhibition was evaluated at baseline before clopidogrel discontinuation, and subsequently every other day in the week before their scheduled procedure, utilizing a VerifyNow P2Y12 device (Accumetrics, San Diego, CA). Mean platelet inhibition was $32.1 \%$ on day 0 before clopidogrel discontinuation, decreasing to $3.7 \%$ on day 4. Platelet inhibition decreased significantly after discontinuation of clopidogrel in a time-dependent manner, even though a considerable interindividual variability was observed over the study period. Patients on concomitant proton pump inhibitors and clopidogrel demonstrated a decreased effect of clopidogrel. In another study, Benzon et al (401) determined residual antiplatelet activity of clopidogrel before neuraxial in- 
jections. They assessed residual platelet activity in 13 patients at baseline and 3, 5, and 7 days after discontinuation of clopidogrel. On day 3 after clopidogrel discontinuation, 2 patients had greater than 30\%, 7 patients had $11 \%$ to $29 \%$, and 4 patients had less than $10 \%$ platelet inhibition. On day 5 , none of the patients had greater than $30 \%, 3$ patients had $11 \%$ to $29 \%$ and 10 patients had less than $10 \%$ platelet inhibition. There were no differences between the platelet inhibition groups between days 5 and 7 . The authors concluded that their findings support the recommendation that discontinuation of clopidogrel for 5 days allows greater than $70 \%$ of platelet function and might be adequate before a neuraxial injection is performed. This is an extremely small study. Consequently, it is difficult to draw conclusions on which to base patient care decisions.

Glenn et al (588) also described safe removal of an epidural catheter 72 hours after clopidogrel and aspirin administrations guided by platelet function analysis and thromboelastography. In addition, the influence of proton pump inhibitors on the antiplatelet potency of clopidogrel was evaluated by 5 different platelet functions concluding that concomitant treatment with proton pump inhibitors did not attenuate the antiplatelet effect of clopidogrel in patients on dual antiplatelet therapy irrespective of the type of proton pump inhibitor and the used test system (589). In contrast, increased platelet inhibition by enhancement of CYP3A4 metabolic activity was demonstrated by St. John's wort (590). Similarly, the addition of polyunsaturated Omega-3 ethyl esters to the combination of aspirin and clopidogrel significantly potentiated platelet response to clopidogrel after percutaneous coronary intervention (591).

Based on previous guidelines and comprehensive literature review with the existent case reports of epidural hematomas and thromboembolic events, there is limited evidence either to continue or discontinue clopidogrel and ticlopidine prior to interventional techniques. The current recommendations are that they may be discontinued for 7 days with clopidogrel and prasugrel and/or 10 to 15 days with ticlopidine, based on the consideration of the individual patient, risk factors, and the planned procedure in consultation with the treating cardiologist.

\section{Phosphodiesterase Inhibitors:}

Cilostazol, or Pletal, and dipyridamole or Persantine, produces a selective inhibition of phosphodiesterase, thereby increasing the intracellular level or cyclic adenosine monophosphate and causing a weak revers- ible inhibition of platelet aggregation (592-605). However, dipyridamole is used for inhibition of thrombus formation for chronic use, whereas it is used for vasodilation in high doses over a short-term period (594). Cilostazol, or Pletal with similar profile, is used in the alleviation of the symptoms of intermittent claudication in individuals with peripheral vascular disease $(600,601)$.

Dipyridamole blocks the thromboxane synthase as well as the thromboxane receptor. It inhibits the cellular reuptake of adenosine into platelets, red blood cells, and endothelial cells leading to increased extracellular concentration of adenosine. Dipyridamole has also been shown to lower pulmonary hypertension without significant drop of systemic blood pressure. Dipyridamole inhibits formation of proinflammatory cytokines in vitro and proliferation of smooth muscle cells in vivo. Dipyridamole has been shown to increase myocardial profusion and left ventricular function in patients with ischemic cardiomyopathy. It has been shown to inhibit the replication of Mengovirus RNA (606) and can be used for myocardial stress testing as an alternative to exercise-induced stress methods. In fact, modified release dipyridamole, or Aggrenox, is used in conjunction with aspirin in the secondary prevention of stroke and transient ischemic attack (596). Dipyridamole absorption is $\mathrm{pH}$ dependent and concomitant treatment with gastric acid suppressors such as proton pump inhibitors will inhibit the absorption of liquid and plain tablets $(597,598)$. However, modified-release preparations are buffered and absorption may not be affected $(596,597,607,608)$. However, it is not approved as monotherapy for stroke prophylaxis, even though a Cochrane review has suggested that dipyridamole may reduce the risk of a further vascular event in patients presenting after cerebral ischemia (599).

Vascular smooth muscle contains PDE3A (phosphodiesterase 3A), thus, cilostazol also produces direct arterial vasodilatation. Consequently it is most commonly used for peripheral vascular disease. It has been approved for treatment of chronic peripheral arterial disease and recently, the ACCP recommended it for intermittent claudication in patients who do not respond to exercise therapy and are not candidates for revascularization (595). In addition, investigators also found that adding cilostazol to a dual antiplatelet treatment with aspirin and clopidogrel was superior in the prevention of coronary artery stenosis and cardiac death after primary percutaneous coronary intervention with drug eluting stents, without increasing the incidence of bleeding $(609,610)$. Cilostazol is used orally at a dose 
of $100 \mathrm{mg}$ twice daily reaching maximum plasma levels after 2.7 to 3.6 hours. The compound is eliminated predominantly by hepatic metabolism and subsequent urinary excretion of the metabolites (593). The total pharmacological activity of cilostazol and its metabolites in mild hepatic or mild to moderate renal impairment was similar to that of healthy individuals. However, due to renal excretion of metabolites, cilostazol is contraindicated in patients with severe renal insufficiency and also moderate to severe hepatic impairment.

Aggrenox is a combination antiplatelet agent in a gelatin capsule format containing $200 \mathrm{mg}$ of dipyridamole in an extended-release form and $25 \mathrm{mg}$ of aspirin, as an immediate-release sugar-coated tablet. Their combination has been used in prevention of stroke and transient ischemic attack.

There has been one case report of a hematoma following epidural catheter removal during treatment with cilostazol (400), but in general, any prospective data on the perioperative use of the drug are lacking and the effect on the incidence of bleeding is currently unknown. In fact, Vandermeulen (541) after reviewing various guidelines concluded that dipyridamole may be continued except in cases with concomitant administration of other drugs. The Nordic guidelines (538) also recommended not to stop dipyridamole.

Based on the available guidelines and comprehensive review of the literature, there is limited evidence in reference to discontinue or continue these drugs during interventional techniques. Thus, considering the individual patient, risk factors, the planned procedure, and in consultation with the treating physician, dipyridamole (Persantine), Aggrenox (aspirin and dipyridamole), and Cilostazol (Pletal) may be continued.

\section{Glycoprotein Inhibitors:}

Glycoprotein Ilb/llla inhibitors block the glycoprotein Ilb/llla receptor, the final common pathway of platelet aggregation, which represents the most potent form of platelet inhibition, though it is reversible (539). Abciximab inhibits over $80 \%$ of ADP-induced platelet aggregation and reduces thrombin generation after intravenous administration. Additional antithrombotic properties that distinguish it from other agents in this group include binding to platelets very quickly with its presence observed 2 weeks after the last administration, with no significant renal elimination. If severe bleeding occurs, transfusion of platelet concentrates is required, although redistribution of abciximab among the freshly infused platelets can also partly inhibit these. There is approximately $50 \%$ to $80 \%$ platelet aggregation capacity 4 hours after intravenous administration with eptifibatide and tirofiban (611).

The most frequent side effects are severe bleeding and thrombocytopenia (612), which after abciximab occurs in $0.3 \%$ to $1.0 \%$ (611). Thrombocytopenia is most likely to have an immunological cause and occurs within the first 24 hours, so platelet count is required at this time $(539,613)$. In acute coronary intervention, glycoprotein IIb/llla inhibitors reduce the incidences of $\mathrm{MI}$ and mortality. Abciximab is more effective than tirofiban or eptifibatide (614). In contrast to the acute effects of intravenous glycoprotein Ilb/llla inhibitors, long-term administration of oral preparations does not appear to reduce cardiovascular complications; instead, an increased tendency to bleed and an increased mortality rate were observed (611).

As glycoprotein IIb/llla inhibitors are used only in acute coronary syndromes, in combination with anticoagulants and aspirin, and as cardiac surgery procedures are usually conducted as emergencies with continuing anticoagulation, neuraxial blockade is contraindicated (Class III, level C) (539). If a catheter has to be removed after their administration, most guidelines recommend waiting at least 48 hours after abciximab, and 8 to 10 hours after tirofiban or eptifibatide (615). At this time, a platelet count should always be obtained to exclude thrombocytopenia. In addition, their use has been restricted significantly $(611,616-620)$.

\section{Heparins:}

Patients on unfractionated heparin as well as LMWH for thromboprophylaxis may present for interventional techniques. Thromboprophylaxis with low dose heparin does not lead to an increased risk of bleeding after neuraxial blockade, provided that a time interval of 4 to 6 hours is observed between heparin administration and puncture or catheter manipulation and withdraw (539). However, additional administration of low dose heparin should be delayed for at least one hour after the block (Evidence Class Ilb, Level C evidence) (539). Generally, doses of low dose heparin used for venous thromboprophylaxis are relatively safe, an increased risk of bleeding occurs at therapeutic doses when neuraxial techniques are performed. Thus, they are contraindicated at therapeutic doses. Thus, a neuraxial block should be considered only after interrupting heparin administration for at least 4 hours and a normal activated partial thromboplastin time (aPTT) and/or anti-Xa activity be assessed. (Evidence Class: Ila, Level C) (539). However, coagulation 
studies are not required during prophylaxis with unfractionated heparin, except when treatment has lasted 5 days or more, when a platelet count is needed to exclude heparin induced thrombocytopenia.

LMWHs are used for both prophylaxis and treatment of venous thromboembolism (621). The anticoagulated effect of LMWH is assessed by measuring plasma antifactor Xa activity. (Evidence Class I, Level A) (539). The described advantages of $\mathrm{LMWH}$ are related to its high bioavailability (approximately 100\% after subcutaneous administration) and their longer half-life of 4 to 7 hours, which together make once daily administration feasible. For thromboprophylaxis, LMWHs are considered superior to unfractionated heparins and are the treatment of choice $(622,623)$. With subcutaneous administration of $\mathrm{LMWH}$, maximum efficacy levels are observed in approximately 3 to 4 hours, and the terminal elimination half-life in patients with normal renal function is approximately 4 to 6 hours $(624,625)$. However, in patients with severe renal insufficiency, anti-Xa activity reaches a higher maximum level and the elimination half-life can increase by up to 16 hours (626). Thus to avoid any bleeding complications, there should be a time interval of at least 12 hours between subcutaneous administration of LMWH at prophylactic doses and neuraxial blockade $(262,619,627)$. (Evidence Class Ila, Level C). If LMWH is prescribed on a twice daily schedule (e.g., enoxaparin $30 \mathrm{mg}$ per day), compared to a once daily regimen, the risk of epidural hematoma may be increased because the trough levels of anti-Xa activity are higher (628). Consequently, when patients are receiving a twice daily schedule, at least one dose of LMWH should be omitted creating a 24 hour time interval before an interventional procedure and the subsequent dose. (Evidence Class Ilb, Level C). However, when the risk of thrombosis is high in settings such as mitral or double mechanical valve replacement, neuraxial blockade is contraindicated. In addition, epidural hematomas with surgical anesthesia or spontaneously have been reported with LMWH (629-633).

Based on the available literature and guidelines with the risk of epidural hematomas, bleeding events, and thromboembolic events, there is limited evidence either to continue or discontinue unfractionated heparin or LMWH prior to interventional techniques. The current recommendations are that they may be discontinued approximately 12 hours to providing interventional techniques based on consideration of the individual patient, risk factors, the planned procedure in consultation with the treating cardiologist.

\section{Vitamin K Antagonists:}

Vitamin $\mathrm{K}$ antagonists, specifically warfarin have been utilized for therapeutic anticoagulation which is considered an absolute contraindication to neuraxial blockade unless INR is below the considered safe limits for the specific interventional technique. It can take several days after these drugs have been withdrawn before coagulation returns to normal; however, the process can be accelerated by administering vitamin $\mathrm{K}$, prothrombin complex concentrates (PCC), or if PCC is unavailable, fresh frozen plasma. However, it requires an appropriate indication and should follow an individual risk-benefit analysis. Further, new oral anticoagulants such as Xa inhibitors, rivaroxaban (634), and apixaban or the thrombin inhibitor dabigatran have been utilized and also have been described to lack some of the limitations of the well known vitamin $\mathrm{K}$ antagonists (634). Multiple instances of bleeding or epidural hematoma have been reported with warfarin administration.

Oral anticoagulants, including warfarin, exert their anticoagulant effect indirectly by interfering with the synthesis of the vitamin K-dependent clotting factors, factor II (thrombin), VII, IX, and X. The effects of warfarin are not apparent until a significant amount of biologically inactive factors are synthesized and are dependent on factor half-life $(405,635,636)$. The half-life of factor VII is 6 to 8 hours, factor IX is 24 hours, factor X is 25 to 60 hours, and factor II is 50 to 80 hours. The prothrombin time (PT) is the test used most commonly to monitor therapy with vitamin K antagonists (405). The PT response to reduction of 3 of the 4 vitamin K-dependent procoagulant clotting factors II, VII, and X (635). The lack of reliability of the PT led to the use of the INR, the ratio of patient's PT to that of a control sample (635). The INR represents the activities of several coagulation factors during the onset and steady-state of warfarin therapy. Clinical experience with patients who, congenitally, are deficient in factors II, IX, or X suggests that a factor activity level of $40 \%$ for each factor is adequate for normal or near normal hemostasis (637). Bleeding may occur if the level of any clotting factor is decreased to $20 \%$ to $40 \%$ of baseline. During the first few days of therapy, the PT reflects primarily a reduction of factor VII, the half-life of which is approximately 6 hours $(85,405,638)$. Prolongation of the INR greater than 1.2 occurs when factor VII activity is reduced to approximately $55 \%$ of baseline, whereas an INR of 1.5 is associated with a factor VII activity of $40 \%$ (636).

Multiple factors affecting warfarin response include patient variables such as age, female sex, and 
preexisting medical conditions (lower patient weight, hepatic, cardiac, and renal disease) that are associated with an enhanced response to warfarin and/or a lower dose requirement for maintenance anticoagulation (85), Asian patients requiring lower doses than white patients during long-term therapy $(85,635,639)$, and concomitant administration of various drugs with anticoagulant effects. Warfarin is a drug with a narrow therapeutic range. Consequently, attention to the individual patient's response to warfarin therapy and maintenance of a consistent level of anticoagulation is of paramount importance. Multiple dietary ingredients may affect clotting levels. Patients are advised to avoid grapefruit and cranberry products, to eat a consistent amount a week to week of spinach, turnip greens, other leafy greens, broccoli, brussel sprouts, kale, parsley, natto, liver, or green tea; herbal supplements such as garlic, ginger, gingko biloba ginseng, fish oil, tumeric, St. John's wort, chondroitin sulfate; vitamin supplements including vitamin A, C, or E over the $100 \%$ of the recommended doses; and chronic heavy drinking of beverages containing alcohol. Further, patients are recommended to drink black tea, which is not high in vitamin $\mathrm{K}$ and also choose vegetables which are not high in vitamin $\mathrm{K}$ such as corn, squash, potatoes, onions, carrots, cucumbers, celery, peppers, pumpkin, and tomatoes.

There are no studies directly examining the risk of procedure-related bleeding and INR in patients recently discontinued from warfarin. Consequently, careful consideration should be given before performing neuraxial interventional techniques in these patients. Labeling of warfarin in the United States specifically lists spinal puncture and lumbar block anesthesia as contraindicated during warfarin therapy that is not interrupted before surgery. ASRA limitations provide timing of neuraxial catheter removal during warfarin thromboprophylaxis.

Administration of PCC or fresh frozen plasma is associated with high risk and has been considered inappropriate to normalize coagulation before neuraxial procedures (640-656). Vitamin K supplementation may be considered in some patients (640-666). A literature review by Holbrook et al (640) found a weak recommendation for vitamin $\mathrm{k}$ supplementation along with a multitude of other factors. However, the anticoagulation management guidelines by Holbrook et al (640) provided a strong recommendation to target an INR ratio of 2.0 to 3.0 for patients on vitamin $\mathrm{K}$ antagonist therapy. Gebuis et al (659) showed variability in INR with vitamin $\mathrm{K} 1$ supplementation resulting in an improvement of time that anticoagulation was within the therapeutic range. Vitamin $\mathrm{K} 1$ and $\mathrm{K} 2$ are capable of reversing the anticoagulant activity of warfarin. Supplemental vitamin $\mathrm{K}$, for which oral dosing is often more active than injectable dosing in human adults, reverses the vitamin $\mathrm{K}$ deficiency caused by warfarin, and therefore modulates or totally reverses the intended anticoagulant action of warfarin and related drugs. Foods containing high amounts of vitamin $\mathrm{K}$ like green leafy vegetables may reverse anticoagulant action of warfarin; however, occasionally small amounts of vitamin K (1 mg per day) are given orally to patients taking warfarin to facilitate more predictable action of warfarin. However, similar to warfarin, oral administration of vitamin $K$ requires 2 to 5 days after dosing to have maximum effect while there is minimum effect in the first 24 hours after they are given. Vitamin $\mathrm{K}$ injection is administered most commonly in newborns (667). Vitamin $\mathrm{K}$ is also administered as an antidote for poisoning by vitamin $\mathrm{K}$ antagonists. In fact, multiple benefits of vitamin $\mathrm{K}$ have been demonstrated in animal studies (668-670). Dentali et al (671), in a systematic review of treatment of coumarin-associated coagulopathy, showed that vitamin $\mathrm{K}$ therapy is an effective treatment for INR prolongation in patients with Coumadin-associated coagulopathy. However, they showed that clinical trials powered to detect differences in rates of bleeding and thrombosis are now required to determine if vitamin $K$ reduces the risk of bleeding without causing thrombosis in nonbleeding patients. Others $(672,673)$ have also shown that vitamin $K$ therapy is an effective treatment in patients with vitamin K-associated therapy in patients who have been anticoagulated. However, it was shown that oral vitamin $\mathrm{K}$ lowers the INR more rapidly than subcutaneous vitamin $\mathrm{K}$ in the treatment of warfarinassociated coagulopathy in a randomized trial (673). This study showed that 15 of 26 patients receiving oral vitamin $\mathrm{K}$ and 6 of 26 patients receiving subcutaneous vitamin $\mathrm{K}$ had therapeutic INRs on the day after study drug administration in patients with an INR between 4.5 and 10.0. In a systematic review, Ansell et al (635) also recommended oral vitamin $\mathrm{K}$ rather than subcutaneous administration to reverse a mildly elevated INR. In contrast, in a systematic review and meta-analysis, Dezee et al (674), with inclusion of 21 studies of which 10 were randomized and 10 were prospective, concluded that there was limited evidence to suggest that oral and intravenous vitamin $\mathrm{K}$ are equivalent and more effective for excessive anticoagulation than sim- 
ply withholding warfarin sodium. They also concluded that subcutaneous vitamin $\mathrm{K}$ is inferior to oral and intravenous vitamin $\mathrm{K}$ for this indication and is similar to placebo. They were unable to establish if treatment with vitamin $\mathrm{K}$ decreases hemorrhagic events from the published literature. Thus, the literature is conflicting in reference to the efficacy of vitamin $\mathrm{K}$ to reverse the anticoagulant effect of warfarin (575-592). Vitamin K supplements may be used either intravenously or orally based on the emergence of the situation in low doses with caution and understanding of adverse effects and risk of thromboembolism.

Warfarin may be stopped 3 days or longer based on risk factors, the planned procedure, individual patient, in consultation with the treating cardiologist. If the INR is higher than the desired level or 1.4 for epidural injections and somewhat higher for facet joint nerve blocks, etc., individual consideration must be given.

\section{Thrombin Inhibitors}

Dabigatran, or Pradaxa $®$, is an oral anticoagulant, which has been used more frequently to reduce thromboembolic phenomenon in stroke, as well as non-valvular atrial fibrillation. Dabigatran etexilate is an inactive pro-drug, which is converted to dabigatran in plasma. It is a direct thrombin inhibitor. After an oral dose, the peak effect is reached within 2 to 4 hours and the plasma half-life ranges from 11 to 22 (mean 13) hours after multiple dose administration (675). The dose recommendations are $150 \mathrm{mg}$ taken orally twice daily for patients with creatinine clearance of greater than 30 $\mathrm{mL}$ per minute. However, for patients with severe renal impairment, the recommended dose is $75 \mathrm{mg}$ twice daily. Many of the patients are converted from warfarin to dabigatran. Since dabigatran is an oral direct thrombin inhibitor, anticoagulant effect is through direct clotting factor inhibition and not clotting factor depletion. Thus, the administration of clotting factors is not anticipated to be wholly effective in reversing the effects of dabigatran. However, dabigatran is not highly protein bound and is mostly cleared by the kidneys. Administration in the setting of renal failure will lead to a half-life in excess of 24 hours. Consequently, the primary means of reversing the effects of dabigatran is through natural renal elimination. Hemodialysis may be effective in removing approximately $60 \%$ of dabigatran.

There is no data correlating any lab tests of dabigatran levels to any clinical outcome. In the absence of such a test, measurements are very difficult. Essentially a normal thrombin time means that the drug is dissi- pated, which may take several days to occur even in patients with normal creatinine clearance. There have not been any major prospective studies.

Dabigatran or Pradaxa may be stopped for procedures with standard risk of bleeding for 24 hours in patients with creatinine function over $50 \mathrm{~mL}$ per minute or for 2 to 5 days for those with reduced renal function for interventional techniques with high risk of bleeding entering the epidural space or spinal canal for patients with normal renal function with creatinine clearance of 50 to $80 \mathrm{~mL}$. They may be stopped for 2 to 4 days. In patients undergoing spinal interventional techniques entering the epidural space, with low renal function below $50 \mathrm{~mL}$ creatinine clearance per minute, they should be stopped for at least 4 days or longer.

\section{Anti-Xa Agents}

Among the multiple factor $\mathrm{Xa}$ inhibitors, rivaroxaban, or Xarelto ${ }^{\circledR}$, has been utilized commonly in the United States by oral administration. Its renal elimination and hepatic clearance is dabigatran $33 \%$ active drug with each route. The hepatic elimination make accumulation less likely than with other anticoagulants which are exclusively eliminated through the kidney. Rivaroxaban prolongs the PT time in a dose-dependent manner (680). Its half-life is 5.7 to 9.2 hours. Plasma protein binding of rivaroxaban is approximately $92 \%$ to $95 \%$ with albumin being the main binding component in humans. Following oral administration, approximately one-third of the absorbed dose is excreted and changed in the urine, with the remaining two-thirds excreted as inactive metabolites in both the urine and feces. Compared to healthy subjects with normal creatinine clearance, rivaroxaban exposure increases in subjects with renal impairment, with increased pharmacodynamic effects. Similarly, with hepatic impairment, compared to patients with normal liver function, significant increases in rivaroxaban exposure were observed, along with increased pharmacodynamic effects.

There have not been any major prospective studies in assessment of laboratory tests for dabigatran prior to surgery or interventional techniques. However, some laboratory coagulation tests can be used as qualitative assessment to determine if dabigatran is significantly contributing to bleeding event. Activated partial thromboplastin time, or aPTT, can be used but is relatively insensitive to the effects of direct thrombin inhibitors. The expected median peak aPTT level is approximately 2 times control values and median trough aPTT is approximately 1.5 times control values. The 
utility of aPTT assessment is primarily for its negative predictive value. Consequently, aPTT indicates a little anticoagulant activity. However, even a mildly elevated aPTT can still be associated with clinically important levels of dabigatran and aPTT becomes increasingly insensitive at higher dabigatran levels as could be seen in an overdose (676). Thrombin time (TT) or aPTT is a sensitive test to assess the effects of therapeutic dabigatran levels and a normal TT excludes the presence of significant dabigatran levels. Further, TT is also subject to influence of concomitant administration of other coagulants.

Ecarin clotting time (ECT) is a test which shows strong linear relationship between dabigatran levels and ECT a normal ECT generally excludes the presence of significant dabigatran levels. Moreover, the ECT is not influenced by the concomitant administration of other anticoagulants. However, ECT is not an easily available test.

In most patients with normal kidney function, dabigatran is excreted within one to 2 days after the last dose has been taken. Since the half-life of dabigatran is considered as 13 hours, due to its renal excretion, 50\% of dabigatran is excreted within 13 hours, with another $25 \%$ excreted in the next 13 hours and $87.5 \%$ in the next 13 hours. Thus, in patients with standard risk of bleeding, discontinuation for 24 hours and those with high risk of bleeding for 2 to 4 days with renal function with creatinine clearance above $50 \mathrm{~mL}$ per minute is advised. In patients with creatinine clearance of 30 to $50 \mathrm{~mL}$, half-life is considered as 18 hours with discontinuation for 48 hours in patients with standard risk of bleeding and over 4 days for high risk bleeding is applicable. In patients with creatinine clearance of less than $30 \mathrm{~mL}$ where half-life is expected to be 27 hours with a range of 22 to 35 hours, in patients with standard risk of bleeding, it may be discontinued for 48 to 120 hours, whereas in patients with high risk of bleeding, it should be discontinued a minimum of 5 days. The examples of high risk of bleeding include surgical intervention such as heart surgery, neurosurgery, abdominal or major organ surgery. Further, patients with low blood platelets, bleeding disorders, and previous major bleeding, etc., are also considered as high risk. Finally, spinal anesthesia is considered as high risk. Consequently, spinal interventional techniques involving epidural or spinal modalities are considered as high risk. Extraspinal techniques such as facet joint nerve blocks may fall into standard risk of bleeding category (677-679).

The potential for drug interactions include CYP3A4 and P-glycoprotein inhibitors. It may be monitored by assessing PT and there are no antidotes available. Con- sequently, there is no absolute data correlating any lab tests of rivaroxaban levels to any clinical outcome, either thrombosis or bleeding. PT time goes up to 13 to 25 seconds, 2 to 4 hours after the dose, then returns to normal, before the drug is fully dissipated. There has not been INR correlation. Thus, an abnormal PT means rivaroxaban has been taken recently (680). There are various other tests in consideration. There is no specific antidote for rivaroxaban (680). In addition, because of high plasma protein binding, it is not expected to be dialyzable. Protamine sulfate and vitamin $\mathrm{K}$ are not expected to affect anticoagulant activity of rivaroxaban. There is no experience with antifibrinolytic agents in individuals receiving rivaroxaban.

Available experience with neuraxial blockade or interventional techniques is very limited, thus, extreme caution is recommended when performing interventional techniques in the presence of rivaroxaban. However, it is clearly noted that epidural or spinal hematomas have occurred in patients treated with rivaroxaban in patients undergoing either neuraxial anesthesia, spinal puncture, or spinal interventional techniques. Concomitant use of other drugs that affect hemostasis such as NSAIDs, platelet inhibitors, and other anticoagulants, a history of traumatic or repeated epidural or spinal puncture, a history of spinal deformity, or a spinal surgery are important correlates for increased levels of risk. A time interval of 22 to 26 between the last dose of rivaroxaban of $10 \mathrm{mg}$ and catheter withdrawal has been required (539). Further, rivaroxaban dose is not to be administered earlier than 6 hours after the removal of a catheter and it may be delayed for 24 hours if traumatic puncture occurs.

If anticoagulation must be discontinued to reduce the risk of bleeding with surgical or other procedures, rivaroxaban may be stopped at least 24 hours before the procedure to reduce the risk of bleeding. Rivaroxaban may be restarted after the surgical or other procedures as soon as adequate hemostasis have been established noting that the onset of therapeutic effect is short. Based on the current literature, rivaroxaban may be discontinued 24 hours prior to performing interventional techniques based on risk factors, the planned procedure, individual patient, in consultation with the treating cardiologist.

\section{Recommendations:}

This comprehensive review with extensive literature search and analysis of various guidelines and the literature has provided recommendations specific for interventional techniques (Table 6). The recommenda- 
Table 6. Antithrombotic/antiplatelet therapy and interventional techniques guidelines.

\begin{tabular}{|c|c|c|c|c|c|c|}
\hline \multirow[b]{2}{*}{ Medication } & \multicolumn{2}{|c|}{ ASIPP Guidance } & \multirow[b]{2}{*}{$\begin{array}{c}\text { ASRA } \\
\text { Guidelines } \\
(\mathbf{8 5 , 4 9 4 )}\end{array}$} & \multirow[b]{2}{*}{$\begin{array}{c}\text { Nordic } \\
\text { Guidelines (538) }\end{array}$} & \multirow[b]{2}{*}{$\begin{array}{c}\text { European } \\
\text { Guidelines } \\
\text { (539) }\end{array}$} & \multirow[b]{2}{*}{$\begin{array}{c}\text { Belgium } \\
\text { Guidelines } \\
\quad(541)\end{array}$} \\
\hline & $\begin{array}{c}\text { Time to Wait } \\
\text { After Last Dose } \\
\text { of Medication } \\
\text { Before High Risk } \\
\text { Interventional } \\
\text { Techniques Are } \\
\text { Performed }\end{array}$ & $\begin{array}{c}\text { Time to Wait } \\
\text { After Last Dose } \\
\text { of Medication } \\
\text { Before Caudal } \\
\text { or Paravertebral } \\
\text { Interventional } \\
\text { Techniques are } \\
\text { Performed }\end{array}$ & & & & \\
\hline NSAIDS & Do not stop & Do not stop & Do not stop & 12 hours to 2 weeks & Do not stop & Do not stop \\
\hline \multicolumn{7}{|l|}{ Aspirin } \\
\hline Low dose aspirin & Do not stop & Do not stop & Do not stop & None to 12 hours & Do not stop & Do not stop \\
\hline High dose aspirin & May stop for 7 days & May stop for 7 days & 7 days & 3 days & Do not stop & NA \\
\hline \multicolumn{7}{|l|}{ Antiplatelet Agents } \\
\hline \multicolumn{7}{|c|}{ Phosphodiesterase Inhibitors } \\
\hline $\begin{array}{l}\text { Dipyridamole } \\
\text { (Persantine) }\end{array}$ & Do not stop & Do not stop & Do not stop & Do not stop & NA & NA \\
\hline Cilostazol (Pletal) & Do not stop & Do not stop & NA & NA & $42 \mathrm{hrs}$ & NA \\
\hline $\begin{array}{l}\text { Aggrenox (dipyridamole } \\
\text { plus aspirin) }\end{array}$ & Do not stop & Do not stop & NA & NA & NA & NA \\
\hline \multicolumn{7}{|c|}{ Platelet Aggregation Inhibitors } \\
\hline Clopidogrel (Plavix) & May stop for 7 days & May stop for 7 days & 5-10 days & 5 days & 7 days & 7 days \\
\hline Prasugrel (Effient) & May stop for 7 days & May stop for 7 days & 7-10 days & 5 days & $7-10$ days & 7 days \\
\hline Ticlopidine (Ticlid) & May stop for 14 days & May stop for 14 days & 5-10 days & 5 days & 10 days & 10 days \\
\hline \multicolumn{7}{|l|}{ Vitamin K Antagonists } \\
\hline Warfarin & $\begin{array}{l}\text { When INR is } 1.4 \text { or } \\
\text { less, both warfarin } \\
\text { may be stopped for } \\
1-5 \text { days. }\end{array}$ & $\begin{array}{l}\text { When INR is } 2.0 \text { or } \\
\text { less, both warfarin } \\
\text { may be stopped for } \\
1-5 \text { days. }\end{array}$ & $\begin{array}{c}\text { When INR } \\
\text { is } 1.4 \text { or less, } \\
\text { stop for at least } \\
5 \text { days. }\end{array}$ & $\begin{array}{l}\text { When INR is below } \\
1.4-2.2 \text { stop for } 1-4 \\
\text { days }\end{array}$ & $\begin{array}{l}\text { When INR is } \\
1.4 \text { or below }\end{array}$ & $\begin{array}{l}\text { When INR } \\
\text { is less than } \\
\text { 1.4. Stop for } \\
\text { 4-10 days }\end{array}$ \\
\hline \multicolumn{7}{|l|}{ Thrombin Inhibitors } \\
\hline Dabigatran (Pradaxa) ${ }^{*}$ & $\begin{array}{l}\text { Normal renal } \\
\text { function } 2-4 \text { days } \\
\text { Impaired renal } \\
\text { function (creatinine } \\
\text { clearance }<50 \mathrm{~mL} / \\
\text { min) at least } 5 \text { days }\end{array}$ & $\begin{array}{l}\text { Normal renal } \\
\text { function } 24 \mathrm{hrs} \text {. } \\
\text { Impaired renal } \\
\text { function (creatinine } \\
\text { clearance }<50 \mathrm{~mL} / \\
\text { min) at least } 5 \text { days }\end{array}$ & NA & NA & NA & NA \\
\hline \multicolumn{7}{|l|}{ Anti-Xa Agents } \\
\hline Rivaroxaban (Xarelto) & $24 \mathrm{hrs}$ & $24 \mathrm{hrs}$ & NA & NA & NA & NA \\
\hline \multicolumn{7}{|l|}{ Heparins } \\
\hline $\begin{array}{l}\text { Heparin (treatment) } \\
\text {-IV }\end{array}$ & $\begin{array}{l}6 \mathrm{hrs} \text { and a PTT } \\
\text { within normal limits }\end{array}$ & $\begin{array}{c}6 \mathrm{hrs} \text { and a PTT } \\
\text { within normal limits }\end{array}$ & $\begin{array}{l}10-12 \text { hrs and } \\
\text { a PTT within } \\
\text { normal limits }\end{array}$ & $\begin{array}{l}4 \text { hrs and a PTT } \\
\text { within normal } \\
\text { limits }\end{array}$ & $\begin{array}{l}\text { 4-6 hrs and a } \\
\text { PTT within } \\
\text { normal limits }\end{array}$ & $\begin{array}{l}6 \text { hrs and a } \\
\text { PTT within } \\
\text { normal } \\
\text { limits }\end{array}$ \\
\hline $\begin{array}{l}\text { Heparin (treatment) } \\
\text { - SC }\end{array}$ & $\begin{array}{c}12 \mathrm{hrs} \text { and aPTT } \\
\text { within norm al limits }\end{array}$ & $\begin{array}{c}12 \mathrm{hrs} \text { and aPTT } \\
\text { within normal limits }\end{array}$ & $\begin{array}{l}10-12 \text { hrs and } \\
\text { a PTT within } \\
\text { normal limits }\end{array}$ & $\begin{array}{l}4 \text { hrs and a PTT } \\
\text { within normal } \\
\text { limits }\end{array}$ & $\begin{array}{l}\text { 4-6 hrs and a } \\
\text { PTT within } \\
\text { normal limits }\end{array}$ & $\begin{array}{l}12 \text { hrs and a } \\
\text { PTT within } \\
\text { normal } \\
\text { limits }\end{array}$ \\
\hline LMWH & $12 \mathrm{hrs}$ & $12 \mathrm{hrs}$ & $10 \mathrm{hrs}$ & $10-24 \mathrm{hrs}$ & $12 \mathrm{hrs}$ & $12-24 \mathrm{hrs}$ \\
\hline
\end{tabular}

${ }^{*}$ These recommendations are dependant on multiple factors including the individual patient, risk factors, and cardiologist opinion.

LMWH = Low Molecular Weight Heparin; PTT = Partial Thromboplastin Time; NSAID = Nonsteroidal Anti-inflammatory Drugs; INR = International Normalized Ratio; hrs = Hours 
tions for various agents are dependent on multiple factors including the individual patient, risk factors, and cardiologist's opinion. This must be a shared decision. The risks of thromboembolic phenomenon and bleeding with hematoma formation must be considered equally. The recommendations provided here are based on previous guidelines and comprehensive literature reviews.

- NSAIDS, including low dose aspirin, do not increase the risk of spinal epidural hematoma and are not a contraindication for interventional techniques (evidence-good).

- However, high dose aspirin and combination of multiple drugs should be taken into consideration and may or may not be discontinued based on clinical judgment of individual risk and benefits assessment. In this regard, the simultaneous use of multiple agents that possess anticoagulant properties (e.g. NSAIDs or aspirin along with SSRIs, fish oil, etc.) will increase the risk of morbidity and/or mortality.

- Phosphodiesterase inhibitors including dipyridamole (Persantine), Aggrenox (dipyridamole plus aspirin), and cilostazol (Pletal) do not appear to increase the risk of spinal epidural hematoma and are not a contraindication for interventional techniques (evidence - fair).

- $\quad$ They may or may not be discontinued prior to interventional techniques.

- Platelet aggregation inhibitors including ticlopidine (Ticlid), clopidogrel (Plavix), and prasugrel (Effient) may be continued or discontinued prior to interventional techniques (evidence - fair).

- Based on patient factors and managing cardiologist's opinion, if a decision is made to discontinue, the current recommendations are that they may be discontinued for 7 days with clopidogrel and prasugrel and/or 10 to 15 days with ticlopidine (evidence - fair).

- $\quad$ There is also emerging evidence that discontinuation of 3 days may be effective (evidence - limited).

- Warfarin may be continued or discontinued based on INR achieved during therapy (evidence - good).

- For high risk interventional techniques including interlaminar epidural injections, percutaneous adhesiolysis, disc decompression, sympathetic blocks, and placement of implantables, warfarin should be discontinued for an appropriate period of time and INR of 1.4 or less must be achieved (evidence - good).
- For intermediate risk procedures such as caudal epidural injection, paravertebral interventional techniques, and peripheral joint injections, warfarin should be continued for an appropriate period of time and INR of 2 or less may be considered (evidence - limited).

- Unfractionated heparin or LMWH may be discontinued approximately 12 hours prior to providing interventional techniques (evidence - limited).

- Dabigatran (Pradaxa) may be stopped 2 to 4 days for major interventional techniques with high risk of bleeding in patients with creatinine clearance greater than $50 \mathrm{~mL}$ per minute. For low risk or paravertebral interventional techniques and caudal, it may be stopped for one day in patients with normal renal function. May be stopped at least 4 to 5 days for those with creatinine less than $50 \mathrm{~mL}$ per minute. (evidence - limited)

- Rivaroxaban (Xarelto) may be stopped for one day or longer (evidence-limited).

\subsection{Conclusion}

Based on the available literature including guidelines, the recommendations in patients with antithrombotic therapy for therapy prior to interventional techniques are provided.

\section{Acknowledgments}

The authors wish to thank Vidyasagar Pampati, MSc, for statistical assistance; Sekar Edem for assistance in the search of the literature; Alvaro F. Gómez, MA and Laurie Swick, BS for manuscript review; and Tonie M. Hatton and Diane E. Neihoff, transcriptionists, for their assistance in preparation of this manuscript. We would like to thank the editorial board of Pain Physician for review and criticism in improving the manuscript.

\section{Author Affiliations}

Dr. Manchikanti is Medical Director of the Pain Management Center of Paducah, Paducah, KY, and Clinical Professor, Anesthesiology and Perioperative Medicine, University of Louisville, Louisville, KY.

Dr. Falco is Medical Director of Mid Atlantic Spine \& Pain Physicians, Newark, DE; Director, Pain Medicine Fellowship Program, Temple University Hospital, Philadelphia, PA; and Associate Professor, Department of PM\&R, Temple University Medical School, Philadelphia, PA.

Dr. Benyamin is the Medical Director, Millennium Pain Center, Bloomington, IL, and Clinical Assistant Pro- 
fessor of Surgery, College of Medicine, University of IIlinois, Urbana-Champaign, IL.

Dr. Caraway, St. Mary's Pain Relief Center, Huntington, WV.

Dr. Alan D. Kaye is Chairman and Professor, Department of Anesthesia, LSU Health Science Center, New Orleans, LA.

Dr. Helm is Medical Director, The Helm Center for Pain Management, Laguna Hills, CA.

Dr. Wargo is an Interventional Pain Physician at the McFarland Clinic, Mary Greeley Medical Center, Ames, IA.

Dr. Hansen is Medical Director, Pain Relief Centers, Conover, NC.

Dr. Parr is Medical Director, Premier Pain Center, Covington, LA.

Dr. Singh is Medical Director, Spine Pain Diagnostics Associates, Niagara, WI.

Dr. Swicegood is Medical Director, Advanced Interventional Pain and Diagnostics of Western Arkansas, Fort Smith, AR

Dr. Smith is Professor and Director of Pain Management for Albany Medical College, Department of Anesthesiology, Albany, NY.

Dr. Schultz is the Medical Director of MAPS Medical Pain Clinics, Minneapolis, MN.

Dr. Malla is an Interventional Pain Physician at the Pain Management Center of Paducah, Paducah, KY.

Dr. Hirsch is Vice Chief of Interventional Care, Chief of Minimally Invasive Spine Surgery, Service Line Chief of Interventional Radiology, Director of Endovascular Neurosurgery and Neuroendovascular Program, Massachusetts General Hospital; and Associate Professor, Harvard Medical School, Boston, MA.

\section{Conflict of Interest:}

Dr. Falco is a consultant for St. Jude Medical Inc. and Joimax Inc.

Dr. Benyamin is a consultant with Bioness and Nevro; serves on the advisory boards of Vertos Medical and Nuvo Pharma; teaches/lectures for Vertos Medical, Boston Scientific, Neurotherm, and Bioness; and receives research/grants from Alfred Mann Foundation, Teknon Foundation, Spinal Restoration, Inc., Bioness, Boston Scientific, Vertos Medical, Medtronic, Kimberly Clarke, Epimed, BioDelivery Sciences International, Inc., Theravance, Mundipharma Research, Cephalon/Teva, AstraZeneca, and Purdue Pharma, LP.

Dr. Caraway is a consultant for Medtronic, Inc., Spinal Modulation, Inc., and Vertos, Inc.

Dr. Kaye is a speaker for Depomed, Inc.

Dr. Helm is a clinical investigator with Epimed and receives research support from Cephalon/Teva, AstraZeneca, and Purdue Pharma, LP. He has attended an advisory group meeting for Activas.

Dr. Schultz is a paid consultant for Medtronic.

Dr. Hirsch has received fees from CareFusion in the past 12 months. He participated in an Aetrium focus group and received compensation.

\section{References}

1. Thom T, Haase N, Rosamond W, Howard VJ, Rumsfeld J, Manolio T, Zheng ZJ, Flegal K, O'Donnell C, Kittner S, LloydJones D, Goff DC Jr, Hong Y, Adams R, Friday G, Furie K, Gorelick P, Kissela B, Marler J, Meigs J, Roger V, Sidney S, Sorlie P, Steinberger J, Wasserthiel-Smoller $S$, Wilson M, Wolf P. Heart Disease and Stroke Statistics-2006 Update: A report from the American Heart Association Statistics Committee and Stroke Statistics Subcommittee. Circulation 2006; 113:E85-E151.

2. Mendis S, Puska P, Norrving B (eds). Global Atlas on Cardiovascular Disease Prevention and Control. Word Health Organization, Geneva, 2011.

3. World Health Organization. Cardiovascular disease (CVDs) Fact sheet. September 2012. www.who.int/mediacentre/ factsheets/fs317/en/index.html

4. Schiller JS, Lucas JW, Ward BW, Peregoy JA. Summary health statistics for U.S. adults: National Health Interview Survey, 2010. Vital Health Stat 2012; 252:1-207.

5. Kochanek KD, Xu J, Murphy SL, Miniño AM, Kung HS; Division of Vital Statistics. Deaths: Final data for 2009. Natl Vital Stat Rep 2011; 60:1-167.

6. Institute of Medicine (IOM). Relieving Pain in America: A Blueprint for Transforming Prevention, Care, Education, and Research. The National Academies Press, Washington, DC, June 29, 2011.

7. Freburger JK, Holmes GM, Agans RP, Jackman AM, Darter JD, Wallace AS, Castel LD, Kalsbeek WD, Carey TS. The rising prevalence of chronic low back pain. Arch Intern Med 2009; 169:251-258.
8. Hoy D, Brooks P, Blyth F, Buchbinder R. The epidemiology of low back pain. Best Pract Res Clin Rheumatol 2010; 24:769781.

9. Hoy DG, Protani M, De R, Buchbinder R. The epidemiology of neck pain. Best Pract Res Clin Rheumatol 2010; 24:783792.

10. Hoy DG, Bain C, Williams G, March L, Brooks P, Blyth F, Woolf A, Vos T, Buchbinder R. A systematic review of the global prevalence of low back pain. Arthritis Rheum 2012 Jan 9. [Epub ahead of print].

11. Reid KJ, Harker J, Bala MM, Truyers C, Kellen E, Bekkering GE, Kleijnen J. Epidemiology of chronic non-cancer pain in Europe: Narrative review of prevalence, pain treatments and pain impact. Curr Med Res Opin 2011; 27:449-462. 


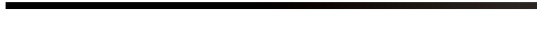 \\ 12. Bekkering GE, Bala MM, Reid K, Kel- len E, Harker J, Riemsma R, Huygen FJ, Kleijnen J. Epidemiology of chronic pain and its treatment in The Netherlands. Neth J Med 2011; 69:141-153. \\ 13. Pizzo PA, Clark NM. Alleviating suffer- ing 101 - Pain relief in the United States. N Engl J Med 2012; 367:197-198. \\ 14. Biondi-Zoccai GG, Lotrionte M, Agos- toni P, Abbate A, Fusaro M, Burzotta F, Testa L, Sheiban I, Sangiorgi G. A sys- tematic review and meta-analysis on the hazards of discontinuing or not adher- ing to aspirin among 50,279 patients at risk for coronary artery disease. Eur Heart ] 2006; 27:2667-2674. \\ 15. Gurbel PA, Bliden KP, Hiatt BL, O'Connor CM. Clopidogrel for coro- nary stenting: Response variability, drug resistance, and the effect of pretreat- ment platelet reactivity. Circulation 2003; 107:2908-2913.}

16. Geurts WH, Bergqvist D, Pineo GF, Heit JA, Samama CM, Lassen MR, Colwell CW; American College of Chest Physicians. Prevention of venous thromboembolism: American College of Chest Physicians evidence-based clinical practice guidelines (8th edition). Chest 2008; 133:381S-453S.

17. lakovou I, Schmidt T, Bonizzoni E, Ge L, Sangiorgi GM, Stankovic G, Airold F, Chieffo A, Montorfano M, Carlino M, Michev I, Corvaja N, Briguori C, Gerckens U, Grube E, Colombo A. Incidence, predictors, and outcome of thrombosis after successful implantation of drugeluting stents. JAMA 2005; 293:2126-2130.

18. Price MJ, Berger PB, Teirstein PS, Tanguay JF, Angiolillo DJ, Spriggs D, Puri S, Robbins M, Garratt KN, Bertrand OF, Stillablower ME, Aragon JR, Kandzari DE, Stinis CT, Lee MS, Manoukian SV, Cannon CP, Schork NJ, Topol EJ; GRAVITAS Investigators. Standard- vs high dose clopidogrel based on platelet function testing after percutaneous coronary intervention: The GRAVITAS randomized trial. JAMA 2011; 305:1097-1105.

19. Ho PM, Peterson ED, Wang L, Magid DJ, Fihn SD, Larsen GC, Jesse RA, Rumsfeld JS. Incidence of death and acute myocardial infarction associated with stopping clopidogrel after acute coronary syndrome. JAMA 2008; 299:532-539. Erratum in: JAMA 2008; 299:2390.

20. Trivedi NA. A meta-analysis of low-dose aspirin for prevention of preeclampsia. ] Postgrad Med 2011; 57-91-95.

21. Johnson SG, Rogers K, Delate T, Witt DM. Outcomes associated with combined antiplatelet and anticoagulant therapy. Chest 2008; 133:948-954.

22. Marso SP, Amin AP, House JA, Kennedy KF, Spertus JA, Rao SV, Cohen DJ, Messenger JC, Rumsfeld JS; National Cardiovascular Data Registry. Association between use of bleeding avoidance strategies and risk of periprocedural bleeding among patients undergoing percutaneous coronary intervention. JAMA 2010; 303:2156-2164.

23. Chan AT, Giovannucci EL, Meyerhardt JA, Schernhammer ES, Curhan GC, Fuchs CS. Long-term use of aspirin and nonsteroidal anti-inflammatory drugs and risk of colorectal cancer. JAMA 2005; 294:914-923.

24. Berger JS, Roncaglioni MC, Avanzini F, Pangrazzi I, Tognoni G, Brown DL. Aspirin for the primary prevention of cardiovascular events in women and men: A sex-specific meta-analysis of randomized controlled trials. JAMA 2006; 295:306-313.

25. McDermott MM, Criqui MH. Aspirin and secondary prevention in peripheral artery disease: A perspective for the early 21st century. JAMA 2009; 301:1927-1928.

26. Berger JS, Krantz MJ, Kittelson JM, Hiatt WR. Aspirin for the prevention of cardiovascular events in patients with peripheral artery disease: A meta-analysis of randomized trials. JAMA 2009; 301:1909-1919.

27. Howard-Alpe GM, de Bono J, Hudsmith L, Orr WP, Foex P, Sear JW. Coronary artery stents and non-cardiac surgery. $\mathrm{Br}$ ] Anaesth 2007; 98:560-574.

28. Eisenstein EL, Anstrom KJ, Kong DF, Shaw LK, Tuttle RH, Mark DB, Kramer JM, Harrington RA, Matchar DB, Kandzari DE, Peterson ED, Schulman KA, Califf RM. Clopidogrel use and longterm clinical outcomes after drug-eluting stent implantation. JAMA 2007; 297:159-168.

29. Nicolucci A. Aspirin for primary prevention of cardiovascular events in diabetes: Still an open question. JAMA 2008; 300:2180-2181.

30. Ogawa $H$, Nakayama $M$, Morimoto $T$, Uemura S, Kanauchi M, Doi N, Jinnouchi H, Sugiyama S, Saito Y; Japanese Primary Prevention of Atherosclerosis With Aspirin for Diabetes (JPAD) Trial Investigators. Low-dose aspirin for primary prevention of atherosclerotic events in patients with type 2 diabetes: A randomized controlled trial. JAMA 2008; 300:2134-2141. Erratum in: JAMA 2009; 301:1882.

31. Bhatt DL, Fox KA, Hacke W, Berger PB, Black HR, Boden WE, Cacoub P, Cohen EA, Creager MA, Easton JD, Flather MD, Haffner SM, Hamm CW, Hankey GJ, Johnston SC, Mak KH, Mas JL, Montale- scot G, Pearson TA, Steg PG, Steinhubl SR, Weber MA, Brennan DM, FabryRibaudo L, Booth J, Topol EJ; CHARISMA Investigators. Clopidogrel and aspirin versus aspirin alone for the prevention of atherothrombotic events. $N$ Engl J Med 2006; 354:1706-1717.

32. Paikin JS, Wright DS, Eikelboom JW. Effectiveness and safety of combined antiplatelet and anticoagulant therapy: A critical review of the evidence from randomized controlled trials. Blood Rev 2011; 25:123-129.

33. Sprigg N, Gray LJ, England T, Willmot MR, Zhao L, Sare GM, Bath PM. A randomised controlled trial of triple antiplatelet therapy (aspirin, clopidogrel and dipyridamole) in the secondary prevention of stroke: Safety, tolerability and feasibility. PLoS One 2008; 3:e2852.

34. Walker CW, Dawley CA, Fletcher SF. Aspirin combined with clopidogrel (Plavix) decreases cardiovascular events in patients with acute coronary syndrome. Am Fam Physician 2007; 76:1643-1645.

35. Jackowski L, Stocks N, Rowett D. Reducing the risk of adverse thrombotic events -- The role of aspirin and clopidogrel. Aust Fam Physicians 2008; 37:721723, 725-726.

36. Adesanya AO, de Lemos JA, Greilich NB, Whitten $\mathrm{CW}$. Management of perioperative myocardial infarction in noncardiac surgical patients. Chest 2006; 130:584-596.

37. Manchikanti L, Falco FJE, Singh V, Pampati V, Parr AT, Benyamin RM, Fellows B, Hirsch JA. Utilization of interventional techniques in managing chronic pain in the Medicare population: Analysis of growth from 2000 to 2011. Pain Physician 2012; 15:E969-E982.

38. Manchikanti L, Falco FJE, Benyamin RM, Caraway DL, Helm II, S, Wargo BW, Hansen H, Parr AT, Singh S, Hirsch JA. Assessment of infection control practices for interventional techniques: $A$ best evidence synthesis of safe injection practices and use of single-dose medication vials. Pain Physician 2012; 15:E573E614.

39. Manchikanti L, Falco FJE, Singh V, Benyamin RM, Hirsch JA. The Independent Payment Advisory Board. Pain Physician 2011; 14:E313-E342.

40. Abbott ZI, Nair KV, Allen RR, Akuthota VR. Utilization characteristics of spinal interventions. Spine ] 2012; 1:35-43.

41. Manchikanti L, Pampati V, Falco FJE, Hirsch JA. Growth of spinal interventional pain management techniques: Analysis of utilization trends and medicare expenditures 2000 to 2008. Spine (Phila Pa 1976) 2013; 38:157-168.

42. White AP, Arnold PM, Norvell DC, Eck- 
er E, Fehlings MG. Pharmacologic management of chronic low back pain: Synthesis of the evidence. Spine (Phila Pa 1976) 2011; 36:S131-S143.

43. Manchikanti L, Singh V, Caraway DL, Benyamin RM, Hirsch JA. Medicare physician payment systems: Impact of 2011 schedule on interventional pain management. Pain Physician 2011; 14:E5-E33.

44. Manchikanti L, Parr AT, Singh V, Fellows B. Ambulatory surgery centers and interventional techniques: A look at long-term survival. Pain Physician 2011; 14:E177-E215.

45. Ivanova JI, Birnbaum HG, Schiller M, Kantor E, Johnstone BM, Swindle RW. Real-world practice patterns, healthcare utilization, and costs in patients with low back pain: The long road to guideline-concordant care. Spine ] 2011; 11:622-632.

46. Manchikanti L, Hirsch JA. Obamacare 2012: Prognosis unclear for interventional pain management. Pain Physician 2012; 15:E629-E640.

47. Manchikanti L, Singh V, Hirsch JA. Saga of payment systems of ambulatory surgery centers for interventional techniques: An update. Pain Physician 2012; 15:109-130.

48. Manchikanti L, Falco FJ, Benyamin RM, Helm II S, Parr AT, Hirsch JA. The impact of comparative effectiveness research on interventional pain management: Evolution from Medicare Modernization Act to Patient Protection and Affordable Care Act and the Patient-Centered Outcomes Research Institute. Pain Physician 2011; 14:E249-E282.

49. Manchikanti L, Pampati V, Hirsch JA. Analysis of utilization patterns of vertebroplasty and kyphoplasty in the Medicare population. J Neurointervent Surg 2012; 0:1-6.

50. Deyo RA, Mirza SK, Turner JA, Martin BI. Overtreating chronic back pain: Time to back off? J Am Board Fam Med 2009; 22:62-68.

51. Manchikanti L, Buenaventura RM, Manchikanti KN, Ruan X, Gupta S, Smith HS, Christo PJ, Ward SP. Effectiveness of therapeutic lumbar transforaminal epidural steroid injections in managing lumbar spinal pain. Pain Physician 2012; 15:E199-E245.

52. Parr AT, Manchikanti L, Hameed $\mathrm{H}$, Conn A, Manchikanti KN, Benyamin RM, Diwan S, Singh V, Abdi S. Caudal epidural injections in the management of chronic low back pain: A systematic appraisal of the literature. Pain Physician 2012; 15:E159-E198.

53. Simopoulos TT, Manchikanti L, Singh V, Gupta S, Hameed H, Diwan S, Cohen SP. A systematic evaluation of prevalence and diagnostic accuracy of sacroiliac joint interventions. Pain Physician 2012; 15:E305-E344.

54. Hansen H, Manchikanti L, Simopoulous TT, Christo PJ, Gupta S, Smith HS, Hameed $\mathrm{H}$, Cohen SP. A systematic evaluation of the therapeutic effectiveness of sacroiliac joint interventions. Pain Physician 2012; 15:E247-E278.

55. Helm S II, Deer TR, Manchikanti L, Datta S, Chopra P, Singh V, Hirsch JA. Effectiveness of thermal annular procedures in treating discogenic low back pain. Pain Physician 2012; 15:E279-E304.

56. Benyamin RM, Manchikanti L, Parr AT, Diwan SA, Singh V, Falco FJE, Datta S, Abdi S, Hirsch JA. The effectiveness of lumbar interlaminar epidural injections in managing chronic low back and lower extremity pain. Pain Physician 2012; 15: $\mathrm{E}_{3} 63-\mathrm{E}_{4} 04$

57. Diwan SA, Manchikant L, Benyamin RM, Bryce DA, Geffert S, Hameed H, Sharma ML, Abdi S, Falco FJE. Effectiveness of cervical epidural injections in the management of chronic neck and upper extremity pain. Pain Physician 2012; 15:E405-E434.

58. Benyamin RM, Wang VC, Vallejo R, Singh V, Helm S II. A systematic evaluation of thoracic interlaminar epidural injections. Pain Physician 2012; 15:E497E514.

59. Manchikanti KN, Atluri S, Singh V, Geffert S, Sehgal N, Falco FJE. An update of evaluation of therapeutic thoracic facet joint interventions. Pain Physician 2012; 15: $\mathrm{E}_{463}-\mathrm{E}_{4} 81$.

6o. Helm S II, Benyamin RM, Chopra P, Deer TR, Justiz R. Percutaneous adhesiolysis in the management of chronic low back pain in post lumbar surgery syndrome and spinal stenosis: $\mathrm{A}$ systematic review. Pain Physician 2012; 15:E435-E462.

61. Manchikanti L, Cash KA, McManus CD, Pampati V, Smith HS. One year results of a randomized, double-blind, active controlled trial of fluoroscopic caudal epidural injections with or without steroids in managing chronic discogenic low back pain without disc herniation or radiculitis. Pain Physician 2011; 14:25-36.

62. Manchikanti L, Singh V, Cash KA, Pampati V, Damron KS, Boswell MV. A randomized, controlled, double-blind tri- al of fluoroscopic caudal epidural injections in the treatment of lumbar disc herniation and radiculitis. Spine (Phila Pa 1976) 2011; 36:1897-1905.

63. Manchikanti L, Singh V, Cash KA, Pampati V, Datta S. Fluoroscopic caudal epidural injections in managing post lumbar surgery syndrome: Two-year results of a randomized, double-blind, activecontrol trial. Int J Med Sci 2012; 9:582591.

64. Manchikanti L, Cash RA, McManus CD, Pampati V, Fellows B. Fluoroscopic caudal epidural injections with or without steroids in managing pain of lumbar spinal stenosis: One year results of randomized, double-blind, active-controlled trial. J Spinal Disord Tech 2012; 25:226-234.

65. Manchikanti L, Cash KA, Pampati V, Malla Y. Fluoroscopic cervical epidural injections in chronic axial or disc-related neck pain without disc herniation, facet joint pain, or radiculitis. J Pain Res 2012; 5:227-236.

66. Manchikanti L, Cash KA, Pampati V, Wargo BW, Malla Y. Management of chronic pain of cervical disc herniation and radiculitis with fluoroscopic cervical interlaminar epidural injections. Int J Med Sci 2012; 9:424-434.

67. Manchikanti L, Singh V, Cash KA, Pampati V, Falco FJE. The role of fluoroscopic interlaminar epidural injections in managing chronic pain of lumbar disc herniation or radiculitis: A randomized, double-blind trial. Pain Pract 2012 Dec. 27. [Epub ahead of print]

68. Manchikanti L, Cash KA, McManus CD, Pampati V, Benyamin R. Fluoroscopic lumbar interlaminar epidural injections in managing chronic lumbar axial or discogenic pain. J Pain Res 2012; 5:301311.

69. Manchikanti L, Cash KA, McManus CD, Pampati V, Benyamin RM. A preliminary report of a randomized double-blind, active controlled trial of fluoroscopic thoracic interlaminar epidural injections in managing chronic thoracic pain. Pain Physician 2010; 13:E357-E369.

70. Manchikanti L, Singh V, Falco FJE, Cash KA, Pampati V. Evaluation of lumbar facet joint nerve blocks in managing chronic low back pain: A randomized, doubleblind, controlled trial with a 2-year follow-up. Int J Med Sci 2010; 7:124-135.

71. Manchikanti L, Singh V, Falco FJE, Cash KA, Fellows B. Comparative outcomes of a 2-year follow-up of cervical medial branch blocks in management of 
chronic neck pain: A randomized, double-blind controlled trial. Pain Physician 2010; 13:437-450.

72. Pinto RZ, Maher CG, Ferreria ML, Hancock M, Oliveira VC, McLachlan AJ, Koes $\mathrm{B}$, Ferreira PH. Epidural corticosteroid injections in the management of sciatica: A systematic review and meta-analysis. Ann Intern Med 2012; 344:e497.

73. Chou R, Huffman L. Guideline for the Evaluation and Management of Low Back Pain: Evidence Review. American Pain Society, Glenview, IL, 2009.

www.ampainsoc.org/pub/pdf/LBPEvidRev.pdf

74. Kloth DS, Calodney AK, Derby R, Lagattuta FP, O'Neill C, Yurth E, Miller LE, Block JE. Improving the safety of transforaminal epidural steroid injections in the treatment of cervical radiculopathy. Pain Physician 2011; 14:285-293.

75. Zhu J, Falco FJ, Formoso F, Onyewu O, Irwin FL. Alternative approach for lumbar transforaminal epidural steroid injections. Pain Physician 2011; 14:331-341.

76. Park $\mathrm{CH}$, Lee SH, Park HS. Lumbar retrodiscal versus post-ganglionic transforaminal epidural steroid injection for the treatment of lumbar intervertebral disc herniations. Pain Physician 2011; 14:353-36o.

77. Amr YM. Effect of addition of epidural ketamine to steroid in lumbar radiculitis: One-year follow-up. Pain Physician 2011; 14:475-481.

78. Gharibo CG, Varlotta GP, Rhame EE, Liu EC, Bendo JA, Perloff MD. Interlaminar versus transforaminal epidural steroids for the treatment of subacute lumbar radicular pain: a randomized, blinded, prospective outcome study. Pain Physician 2011; 14:499-511.

79. Chou R, Atlas SJ, Loeser JD, Rosenquist RW, Stanos SP. Guideline warfare over interventional therapies for low back pain: Can we raise the level of discourse? J Pain 2011; 12:833-839.

8o. Manchikanti L, Benyamin RM, Falco FJE, Caraway DL, Datta S, Hirsch JA. Guidelines warfare over interventional techniques: Is there a lack of discourse or straw man? Pain Physician 2012; 15:E1E26.

81. Manchikanti L, Benyamin RM, Swicegood JR, Falco FJE, Datta S, Pampati V, Fellows B, Hirsch JA. Assessment of practice patterns of perioperative management of antiplatelet and anticoagulant therapy in interventional pain management. Pain Physician 2012; 15:E955E968.
82. Manchikanti L, Malla Y, Wargo BW, Cash KA, McManus CD, Damron KS, Jackson SD, Pampati V, Fellows B. A prospective evaluation of bleeding risk of interventional techniques in chronic pain. Pain Physician 2011; 14:317-329.

83. Horlocker TT, Wedel DJ, Schroeder DR, Rose SH, Elliott BA, McGregor DG, Wong GY. Preoperative antiplatelet therapy does not increase the risk of spinal hematoma associated with regional anesthesia. Anesth Analg 1995; 80:303309.

84. Horlocker TT, Wedel DJ, Offord KP. Does preoperative antiplatelet therapy increase the risk of hemorrhagic complications associated with regional anesthesia? Anesth Analg 1990; 70:631-634.

85. Horlocker TT, Wedel DJ, Rowlingson JC, Enneking FK, Kopp SL, Benzon HT, Brown DL, Heit JA, Mulroy MF, Rosenquist RW, Tryba M, Yuan CS. Regional anesthesia in the patient receiving antithrombotic or thrombolytic therapy: American Society of Regional Anesthesia and Pain Medicine evidence-based guidelines (third edition). Reg Anesth Pain Med 2010; 35:64-101.

86. Raj PP, Shah RV, Kaye AD, Denaro $S$, Hoover JM. Bleeding risk in interventional pain practice: Assessment, management, and review of the literature. Pain Physician 2004; 7:3-51.

87. Ahmed SU, Tonidandel W, Trella J, Martin NM, Chang Y. Peri-procedural protocols for interventional pain management techniques: a survey of US pain centers. Pain Physician 2005; 8:181-185.

88. Araujo M, Patel N, More-O'Ferrall D. Complications of interventional techniques. In: Manchikanti L, Christo PJ, Trescot AM, Falco FJE (eds). Clinical Aspects of Pain Medicine and Interventional Pain Management: A Comprehensive Review. ASIPP Publishing, Paducah, KY, 2011, pp 673-686.

89. Gogarten W, Van Aken H, Buttner J, Riess $\mathrm{H}$, Wulf $\mathrm{H}$, Buerkle $\mathrm{H}$. Neuraxial blockade and thromboembolism prophylaxis/antithrombotic therapy: Revised recommendations of the German Society of Anaesthesiology and Intensive Care. Anaesth Intensivmed 2003; 44:218-230.

90. Llau JV, de Andrés J, Gomar C, Gómez A, Hidalgo F, Sahagún J, Torres LM. Drugs that alter hemostasis and regional anesthetic techniques: Safety guidelines. Consensus Conference. Rev Esp Anestesiol Reanim 2001; 48:270-278.

91. Bugada D, Massimo A, Nicola Z, Anto- nio B, Battista B, Paolo G. Regional anesthesia and anticoagulant drugs: A survey of current Italian practice. Eur J Pain Suppl 2011; 5:335-343.

92. Gogarten W, Buerkle $H$, Van Aken $H$. The use of concomitant antiplatelet drugs during neuraxial anethesia is contraindicated in Germany. Reg Anesth Pain Med 2003; 28:585-586; author reply 586.

93. Llau Pitarch JV, De Andrés Ibáñez J, Gomar Sancho C, Gómez Luque Z, Hidalgo Martínez F, Torres Morera LM. Hemostasis-altering drugs and techniques for regional anesthesia and analgesia: Safety recommendations. Rev Esp Anestesiol Reanim 2005; 52:248-250.

94. Kozek-Langenecker SA, Fries D, Gütl $M$, Hofmann $N$, Innerhofer $P$, Knei$f f$, Neuner L, Perger P, Pernerstorfer T, Pfanner G, Schöchl H; Task Force on Perioperative Coagulation of the Austrian Society for Anesthesiology and Intensive Care Medicine. Locoregional anesthesia and coagulation inhibitors. Recommendations of the Task Force on Perioperative Coagulation of the Austrian Society for Anesthesiology and Intensive Care Medicine. Anaesthesist 2005; 54:476-484.

95. Vandermeulen E, Singelyn F, Vercauteren $M$, Brichant JF, Ickx BE, Gautier P; Belgian Association for Regional Anesthesia Working Party on anticoagulants and; central nerve blocks. Belgian guidelines concerning central neural blockade in patients with drug-induced alteration of coagulation: An update. Acta Anaesthesiol Belg 2005; 56:139-146.

96. Horlocker TT, Bajwa ZH, Ashraf Z, Khan $S$, Wilson JL, Sami N, Peeters-Asdourian C, Powers CA, Schroeder DR, Decker PA, Warfield CA. Risk assessment of hemorrhagic complications associated with nonsteroidal antiinflammatory medications in ambulatory pain clinic patients undergoing epidural steroid injection. Anesth Analg 2002; 95:1691-1697.

97. Horlocker TT, Wedel DJ. Anticoagulation and neuraxial block: Historical perspective, anesthetic implications, and risk management. Reg Anesth Pain Med 1998; 23:129-134.

98. Cameron CM, Scott DA, McDonald WM, Davies MJ. A review of neuraxial epidural morbidity: Experience of more than 8,000 cases at a single teaching hospital. Anesthesiology 2007; 106:9971002.

99. Chassot PG, Delabays A, Spahn DR. Perioperative antiplatelet therapy: The 
case for continuing therapy in patients at risk of myocardial infarction. $\mathrm{Br}$ ] Anaesth 2007; 99:316-328.

100. Giroud D, Li JM, Urban P, Meier B, Rutishauer W. Relation of the site of acute myocardial infarction to the most severe coronary arterial stenosis at prior angiography. Am J Cardiol 1992; 69:729-732.

101. Yusuf S, Zhao F, Mehta SR, Chrolavicius S, Tognoni G, Fox KK; Clopidogrel in Unstable Angina to Prevent Recurrent Events Trial Investigators. CURE Trial Investigators. Effects of clopidogrel in addition to aspirin in patients with acute coronary syndromes without STsegment elevation. N Engl J Med 2001; 345:494-502.

102. Dawood MM, Gutpa DK, Southern J, Walia A, Atkinson JB, Eagle KA. Pathology of fatal perioperative myocardial infarction: Implications regarding physiopathology and prevention. Int J Cardiol 1996; 57:37-44.

103. Landesberg G. The pathophysiology of perioperative myocardial infarction: Facts and perspectives. J Cardiothorac Vasc Anesth 2003; 17:90-100.

104. Priebe HJ. Triggers of perioperative myocardial ischaemia and infarction. $\mathrm{Br}$ J Anaesth 2004; 93:9-20.

105. Priebe HJ. Perioperative myocardial infarction-aetiology and prevention. $\mathrm{Br}$ ] Anaesth 2005; 95:3-19.

106. Hoffmeister HM, Heller W, Seipel L. Activation markers of coagulation and fibrinolysis: Alterations and predictive value in acute coronary syndrome. Thromb Haemostasis 1999; 82:76-79.

107. Blake GJ, Ridker PM. Inflammatory biomarkers and cardiovascular risk prediction. J Intern Med 2002; 252:283-294.

108. Laffey JG, Boylan JF, Cheng DC. The systemic inflammatory response to cardiac surgery. Anesthesiology 2002; 97:215-252.

109. Savonitto S, D'Urbano M, Caracciolo M, Barlocco F, Mariani G, Nichelatti M, Klugmann S, De Servi S. Urgent surgery in patients with a recently implanted coronary drug-eluting stent: A phase II study of 'bridging' antiplatelet therapy with tirofiban during temporary withdrawal of clopidogrel. $\mathrm{Br}$ J Anaesth 2010; 104:285-291.

110. Eberli D, Chassot PG, Sulser T, Samama CM, Mantz J, Delabays A, Spahn DR. Urological surgery and antiplatelet drugs after cardiac and cerebrovascular accidents. J Urol 2010; 183:2128-2136.

111. Mariscalco G, Bruno VD, Cottini M, Borsani P, Banach M, Piffaretti G, Dominici C, Beghi C, Sala A. Optimal tim- ing of discontinuation of clopidogrel and risk of blood transfusion after coronary surgery. Propensity score analysis. Circ J 2011; 75:2805-2812.

112. Di Minno MN, Prisco D, Ruocco AL, Mastronardi P, Massa S, Di Minno G. Perioperative handling of patients on antiplatelet therapy with need for surgery. Intern Emerg Med 2009; 4:279-288.

113. Johansen $M$, Afshari $A$, Kristensen $B B$. Discontinuation of treatment with platelet aggregation inhibitors in surgical patients with cardiac stents. Ugeskr Laeger 2010; 172:852-857.

114. Wiviott SD, Braunwald E, McCabe $\mathrm{CH}$, Horvath I, Keltai M, Herrman JP, Van de Werf F, Downey WE, Scirica BM, Murphy SA, Antman EM; TRITON-TIMI 38 Investigators. Intensive oral antiplatelet therapy for reduction of ischaemic events including stent thrombosis in patients with acute coronary syndromes treated with percutaneous coronary intervention and stenting in the TRITON-TIMI 38 trial: A subanalysis of a randomised trial. Lancet 2008; 371:13531363.

115. Chassot PG, Marcucci C, Delabays A, Spahn DR. Perioperative antiplatelet therapy. Am Fam Physician 2010; 82:1484-1489.

116. Chou S, Eshaghian S, Lamer A, Tran H, Dohad S, Kaul S. Bridging therapy in the perioperative management of patients with drug-eluting stents. Rev Cardiovasc Med 2009; 10:209-218.

117. Rottbauer W, Katus HA. Patients with coronary artery stents: When and how should operations be carried out? Chirurg 2009; 80:515-518.

118. Korte W, Cattaneo M, Chassot PG, Eichinger $S$, von Heymann $C$, Hofmann $N$, Rickli H, Spannagl M, Ziegler B, Verheugt $F$, Huber K. Peri-operative management of antiplatelet therapy in patients with coronary artery disease: Joint position paper by members of the working group on Perioperative Haemostasis of the Society on Thrombosis and Haemostasis Research (GTH), the working group on Perioperative Coagulation of the Austrian Society for Anesthesiology, Resuscitation and Intensive Care (ÖGARI) and the Working Group Thrombosis of the European Society for Cardiology (ESC). Thromb Haemost 2011; 105:743-749.

119. Savonitto S, Caracciolo M, Cattaneo M, DE Servi S. Management of patients with recently implanted coronary stents on dual antiplatelet therapy who need to undergo major surgery. J Thromb Haemost 2011; 9:2133-2142.

120. Metzler H, Kozek-Langenecker S, Huber K. Antiplatelet therapy and coronary stents in perioperative medicine--the two sides of the coin. Best Pract Res Clin Anaesthesiol 2008; 22:81-94.

121. Llau JV, Ferrandis R, Sierra P, GómezLuque A. Prevention of the renarrowing of coronary arteries using drug-eluting stents in the perioperative period: An update. Vasc Health Risk Manag 2010; 6:855-867.

122. Bell B, Layland J, Poon K, Spaulding C, Walters D. Focused clinical review: Periprocedural management of antiplatelet therapy in patients with coronary stents. Heart Lung Circ 2011; 20:438-445.

123. Tan VP, Yan BP, Kiernan TJ, Ajani AE. Risk and management of upper gastrointestinal bleeding associated with prolonged dual-antiplatelet therapy after percutaneous coronary intervention. Cardiovasc Revasc Med 2009; 10:36-44.

124. Grines $\mathrm{CL}$, Bonow RO, Casey DE Jr, Gardner TJ, Lockhart PB, Moliterno DJ, O'Gara P, Whitlow P; American Heart Association; American College of Cardiology; Society for Cardiovascular Angiography and Interventions; American College of Surgeons; American Dental Association; American College of Physicians. Prevention of premature discontinuation of dual antiplatelet therapy in patients with coronary artery stents: A science advisory from the American Heart Association, American College of Cardiology, Society for Cardiovascular Angiography and Interventions, American College of Surgeons, and American Dental Association, with representation from the American College of Physicians. J Am Dent Assoc 2007; 138:652-655.

125. Douketis JD, Spyropoulos AC, Spencer FA, Mayr M, Jaffer AK, Eckman MH, Dunn AS, Kunz R; American College of Chest Physicians. Perioperative management of antithrombotic therapy: Antithrombotic Therapy and Prevention of Thrombosis, 9th ed: American College of Chest Physicians Evidence-Based Clinical Practice Guidelines. Chest 2012; 141:e326S-50S. Erratum in: Chest 2012; 141:1129.

126. Chassot PG, Delabays A, Spahn DR. Perioperative use of anti-platelet drugs. Best Pract Res Clin Anaesthesiol 2007; 21:241-256.

127. Toth PP. The potential role of prasugrel in secondary prevention of ischemic events in patients with acute coronary 
syndromes. Postgrad Med 2009; 121:5972.

128. O’Riordan JM, Margey RJ, Blake G, O'Connell PR. Antiplatelet agents in the perioperative period. Arch Surg 2009; 144:69-76; discussion 76.

129. Hall R, Mazer CD. Antiplatelet drugs: A review of their pharmacology and management in the perioperative period. Anesth Analg 2011; 112:292-318.

130. Vial JH, McLeod LJ, Roberts MS. Rebound elevation in urinary thromboxane $\mathrm{B} 2$ and 6-keto-PFFr alpha exacerbation after aspirin withdrawal. Adv Prostaglandin Thromboxane Leukot Res 1991; 21A:157-160.

131. Lordkipanidzé M, Diodati JG, Pharand C. Possibility of a rebound phenomenon following antiplatelet therapy withdrawal: A look at the clinical and pharmacological evidence. Pharmacol Ther 2009; 123:178-186.

132. Weber AA, Braun $M$, Hohlfeld $T$, Schwippert B, Tschöpe D, Schrör K. Recovery of platelet function after discontinuation of clopidogrel treatment in healthy volunteers. $\mathrm{Br}$ J Clin Pharmacol 2001; 52:333-336.

133. Vial JH, McLeod LJ, Roberts MS, Seville PR. Selective inhibition of platelet cyclooxygenase with controlled release, low-dose aspirin. Aust N Z J Med 1990; 20:652-656.

134. Rautanen M, Gullichsen E, Riutta A, Kuttila K, Mucha I, Nelimarkka O, Niinikoski J. Experimental fat embolism induces urine 2,3-dinor-6-ketoprostaglandin Fialpha and 11-dehydrothromboxane $\mathrm{B}_{2}$ excretion in pigs. Crit Care Med 1997; 25:1215-1221.

135. Eldor A, Lellouche F, Goldfarb A, Rachmilewitz EA, Maclouf J. In vivo platelet activation in beta-thalassemia major reflected by increased platelet-thromboxane urinary metabolites. Blood 1991; 77:1749-1753.

136. Vilahur G, Choi BG, Zafar MU, VilesGonzalez JF, Vorchheimer DA, Fuster $\mathrm{V}$, Badimon JJ. Normalization of platelet reactivity in clopidogrel-treated subjects. J Thromb Haemost 2007; 5:82-90.

137. Collet JP, Montalescot G, Blanchet B, Tanguy ML, Golmard JL, Choussat R, Beygui F, Payot L, Vignolles N, Metzger $J P$, Thomas D. Impact of prior use or recent withdrawal of oral antiplatelet agents on acute coronary syndrome. Circulation 2004; 110:2361-2367.

138. Kaluza GL, Joseph J, Lee JR, Raizner $\mathrm{ME}$, Raizne AE. Catastrophic outcomes of noncardiac surgery soon after coro- nary stenting. J Am Coll Cardiol 2000; 35:1288-1294.

139. McFadden EP, Stabile E, Regar E, Cheneau E, Ong AT, Kinnaird T, Suddath WO, Weissman NJ, Torguson R, Kent KM, Pichard AD, Satler LF, Waksman R, Serruys PW. Late thrombosis in drugeluting coronary stents after discontinuation of antiplatelet therapy. Lancet 2004; 364:1519-1521.

140. Murphy JT, Brenda GF. Thrombosis of sirolimus-eluting coronary stent in the postanesthesia care unit. Anesth Analg 2005; 101:971-973.

141. Sharma AK, Ajani AE, Hamwi SM, Maniar P, Lakhani SV, Waksman R, Lindsay J. Major noncardiac surgery following coronary stenting: When is it safe to operate? Catheter Cardiovasc Interv 2004; 63:141-145.

142. Parodi G, Marcucci R, Valenti R, Gori AM, Migliorini A, Giusti B, Buonamici P, Gensini GF, Abbate R, Antoniucci D. High residual platelet reactivity after clopidogrel loading and long-term cardiovascular events among patients with acute coronary syndromes undergoing PCI. JAMA 2011; 306:1215-1223.

143. Burger W, Chemnitius JM, Kneiss I GD, Rücker G. Low-dose aspirin for secondary cardiovascular prevention - cardiovascular risks after its perioperative withdrawal versus bleeding risks with its continuation - review and meta-analysis. J Intern Med 2005; 257:399-414.

144. Angiolillo DJ, Fernandez-Ortiz A, Bernardo E, Ramírez C, Sabaté M, JimenezQuevedo P, Hernández R, Moreno R, Escaned J, Alfonso F, Bañuelos C, Costa MA, Bass TA, Macaya C. Clopidogrel withdrawal is associated with proinflammatory and prothrombotic effects in patients with diabetes and coronary artery disease. Diabetes 2006; 55:780-784.

145. Maulaz AB, Bezerra DC, Michel P, Bogousslavsky $\mathrm{J}$. Effect of discontinuing aspirin therapy on the risk of brain ischemic stroke. Arch Neurol 2005; 62:12171220.

146. Lardizabal JA, Joshi BK, Ambrose JA. The balance between anti-ischemic efficacy and bleeding risk of antithrombotic therapy in percutaneous coronary intervention: A Yin-Yang paradigm. J Invasive Cardiol 2010; 22:284-292.

147. Levy JH, Dutton RP, Hemphill JC 3rd, Shander A, Cooper D, Paidas MJ, Kessler CM, Holcomb JB, Lawson JH; Hemostasis Summit Participants. Multidisciplinary approach to the challenge of hemostasis. Anesth Analg 2010; 110:354-
364.

148. Huczek Z, Filipiak KJ, Kochman J, Michalak M, Roik M, Piatkowski R, Grabowski M, Postula M, Opolski G. Baseline platelet size is increased in patients with acute coronary syndromes developing early stent thrombosis and predicts future residual platelet reactivity. A casecontrol study. Thromb Res 2010; 125:406412.

149. Ray JG, Deniz S, Olivieri A, Pollex E, Vermeulen MJ, Alexander KS, Cain DJ, Cybulsky I, Hamielec CM. Increased blood product use among coronary artery bypass patients prescribed preoperative aspirin and clopidogrel. BMC Cardiovasc Disord 2003; 3:3.

150. Michlig C, Vu DH, Wasserfallen JB, Spahn DR, Schneider P, Tissot JD. Three years of haemo-vigilance in a general university hospital. Transfus Med 2003; 13:63-72.

151. Kearon C, Hirsh J. Current concepts: Management of anticoagulation before and after elective surgery. $N$ Engl J Med 1997; 336:1506-1511.

152. Ferrari E, Benhamou M, Cerboni $P$, Marcel B. Coronary syndromes following aspirin withdrawal: A special risk for late stent thrombosis. J Am Coll Cardiol 2005; 45:456-459.

153. Randelli F, Biggi F, Della Rocca G, Grossi P, Imberti D, Landolfi R, Palareti G, Prisco D. Italian intersociety consensus statement on antithrombotic prophylaxis in hip and knee replacement and in femoral neck fracture surgery. J Orthop Traumatol 2011; 12:69-76.

154. Bell AD, Roussin A, Cartier R, Chan WS, Douketis JD, Gupta A, Kraw ME, Lindsay TF, Love MP, Pannu N, Rabasa-Lhoret $R$, Shuaib $A$, Teal $P$, Théroux $P$, Turpie AG, Welsh RC, Tanguay JF; Canadian Cardiovascular Society. The use of antiplatelet therapy in the outpatient setting: Canadian Cardiovascular Society guidelines. Can J Cardiol 2011; 27:S1-S59.

155. Konstantatos A. Anticoagulation and cataract surgery: A review of the current literature. Anaesth Intensive Care 2001; 29:11-18.

156. Dunn AS, Turpie AG. Perioperative management of patients receiving oral anticoagulants: A systematic review. Arch Intern Med 2003; 163:901-908.

157. Joseph JJ, Pillai A, Bramley D. Clopidogrel in orthopaedic patients: A review of current practice in Scotland. Thromb J 2007; 5:6.

158. Cheng JS, Arnold PM, Anderson PA, Fischer D, Dettori JR. Anticoagulation 
risk in spine surgery. Spine (Phila $\mathrm{Pa}$ 1976) 2010; 35:S117-S124.

159. Chernoguz A, Telem DA, Chu E, OzaoChoy J, Tammaro Y, Divino CM. Cessation of clopidogrel before major abdominal procedures. Arch Surg 2011; 146:334-339.

160. Ono S, Fujishiro M, Kanzaki H, Uedo N, Yokoi C, Akiyama J, Sugawara M, Oda I, Suzuki S, Fujita Y, Tsubata S, Hirano $M$, Fukuzawa M, Kataoka M, Kamoshida T, Hirai S, Sumiyoshi T, Kondo H, Yamamoto Y, Okada K, Morita Y, Fujiwara S, Morishita S, Matsumoto M, Koike K. Conflicting clinical environment about the management of antithrombotic agents during the periendoscopic period in Japan. J Gastroenterol Hepatol 2011; 26:1434-1440.

161. Stone DH, Goodney PP, Schanzer A, Nolan BW, Adams JE, Powell RJ, Walsh DB, Cronenwett JL; Vascular Study Group of New England. Clopidogrel is not associated with major bleeding complications during peripheral arterial surgery. J Vasc Surg 2011; 54:779-784.

162. Abbate R, Cioni G, Marcucci R, Fatini $C$, Gensini GF. Antithrombotic drugs in women: Should we worry more about bleeding? G Ital Cardiol (Rome) 2012; 13:407-413.

163. Ono S, Fujishiro M, Kodashima S, Takahashi Y, Minatsuki C, Mikami-Matsuda R, Asada-Hirayama I, Konno-Shimizu M, Tsuji Y, Mochizuki S, Niimi K, Yamamichi N, Kaneko M, Yatomi Y, Koike K. Evaluation of safety of endoscopic biopsy without cessation of antithrombotic agents in Japan. J Gastroenterol 2012; 47:770-774.

164. Steinhubl SR, Bhatt DL, Brennan DM, Montalescot G, Hankey GJ, Eikelboom JW, Berger PB, Topol Ej; CHARISMA Investigators. Aspirin to prevent cardiovascular disease: The association of aspirin dose and clopidogrel with thrombosis and bleeding. Ann Intern Med 2009; 150:379-386.

165. Lip GY, Durrani OM, Roldan V, Lip PL, Marin F, Reuser TQ. Peri-operative management of ophthalmic patients taking antithrombotic therapy. Int J Clin Pract 2011; 65:361-371.

166. Gerstein NS, Schulman PM, Gerstein WH, Petersen TR, Tawil I. Should more patients continue aspirin therapy perioperatively?: Clinical impact of aspirin withdrawal syndrome. Ann Surg 2012; 255:811-819.

167. Smout J, Stansby. Current practice in the use of antiplatelet agents in the peri-operative period by UK vascular surgeons. Ann R Coll Surg Engl 2003; 85:97-101.

168. Manchikanti L, Datta S, Smith HS, Hirsch JA. Evidence-based medicine, systematic reviews, and guidelines in interventional pain management: Part 6. Systematic reviews and meta-analyses of observational studies. Pain Physician 2009; 12:819-850.

169. Stroup DF, Berlin JA, Morton SC, Olkin I, Williamson GD, Rennie D, Moher D, Becker BJ, Sipe TA, Thacker SB. Metaanalysis of observational studies in epidemiology: A proposal for reporting. Meta-analysis of Observational Studies in Epidemiology (MOOSE) group. JAMA 2000; 283:2008-2012.

170. Vandenbroucke JP, von Elm E, Altman DG, Gøtzsche PC, Mulrow CD, Pocock S), Poole C, Schlesselman JJ, Egger M; STROBE Initiative. Strengthening the Reporting of Observational Studies in Epidemiology (STROBE): Explanation and elaboration. Ann Intern Med 2007; 147:W163-W194.

171. Harris RP, Helfand M, Woolf SH, Lohr KN, Mulrow CD, Teutsch SM, Atkins D; Methods Work Group, Third US Preventive Services Task Force. Current methods of the US Preventive Services Task Force. Am J Prevent Med 2001; 20:21-35.

172. Lee LA, Posner KL, Kent CD, Domino KB. Complications associated with peripheral nerve blocks: Lessons from the ASA Closed Claims Project. Int Anesthesiol Clin 2011; 49:56-67.

173. Lee LA, Posner KL, Domino KB, Caplan RA, Cheney FW. Injuries associated with regional anesthesia in the 1980 os and 1990s: A closed claims analysis. Anesthesiology 2004; 101:143-152.

174. Cook TM, Counsell D, Wildsmith JA; Royal College of Anaesthetists Third National Audit Project. Major complications of central neuraxial block: Report on the Third National Audit Project of the Royal College of Anaesthetists. Br J Anaesth 2009; 102:179-190.

175. Tam NL, Pac-Soo C, Pretorius PM. Epidural haematoma after a combined spinal- epidural anaesthetic in a patient treated with clopidogrel and dalteparin. $\mathrm{Br}$ J Anaesth 2006; 96:262-265.

176. Maier C, Gleim M, Weiss T, Stachetzki $U$, Nicolas V, Zenz M. Severe bleeding following lumbar sympathetic blockade in two patients under medication with irreversible platelet aggregation inhibitors. Anesthesiology 2002; 97:740-743.
177. Benzon HT, Wong HY, Siddiqui T, Ondra S. Caution in performing epidural injections in patients on several antiplatelet drugs. Anesthesiology 1999; 91:1558-1559.

178. Williams KN, Jackowski A, Evans PJ. Epidural haematoma requiring surgical decompression following repeated cervical epidural steroid injections for chronic pain. Pain 1990; 42:197-199.

179. Weller RS, Gerancher JC, Crews JC, Wade KL. Extensive retroperitoneal hematoma without neurologic deficit in two patients who underwent lumbar plexus block and were later anticoagulated. Anesthesiology 2003; 98:581-585.

180. Stoll A, Sanchez M. Epidural hematoma after epidural block: Implications for its use in pain management. Surg Neurol 2002; 57:235-240.

181. Anderson TJ, Donaldson IM. Spontaneous resolution of cervical spine epidural haematoma. Postgrad Med J 1989; 65:488-490.

182. Lord, GM, Mendoza N. Spontaneous spinal epidural haematoma: A cautionary tale. Arch Emerg Med 1993; 10:339342.

183. Shioya H, Kikuchi K, Suda Y, Shindo K. Spontaneous spinal epidural hematoma with spontaneous remission, diagnosed in MRI on superacute stage. No To Shinkei 1998; 50:447-452.

184. Ruelle A, Datti R, Pisani R. Thoracic epidural hematoma after spinal manipulation therapy. J Spinal Disord 1999; 12:534536.

185. Van de Straete $S$, Demaerel P, Stockx L, Nuttin B. Spinal epidural hematoma and ankylosing spondylitis. J Belge Radiol 1997; 80:109-110.

186. Lobitz B, Grate I. Acute epidural hematoma of the cervical spine: An unusual cause of neck pain. South Med J 1995; 88:580-582.

187. Yagi S, Hida K, Iwasaki Y, Abe H, Akino $\mathrm{M}$, Saito H. Cervical epidural hematoma caused by cervical twisting after epidural anesthesia: A case report. No Shinkei Geka 1998; 26:627-632.

188. Agnetti V, Monaco F, Mutani R. Postconvulsive spinal epidural haematoma in ankylosing spondylitis. Eur Neurol 1979; 18:230-233.

189. Xu R, Bydon M, Gokaslan ZL Wolinsky $J P$, Witham TF, Bydon A. Epidural steroid injection resulting in epidural hematoma in a patient despite strict adherence to anticoagulation guidelines. J 
Neurosurg Spine 2009; 11:358-364.

190. Ain RJ, Vance MB. Epidural hematoma after epidural steroid injection in a patient withholding enoxaparin per guidelines. Anesthesiology 2005; 102:701-703.

191. Marcou TA, Mignon A, Ozier Y. Could an epidural hematoma after neuraxial blockade really be idiopathic? Anesth Analg 2006; 102:332-333.

192. Hussenbocus SM, Wilby MJ, Cain C, Hall D. Spontaneous spinal epidural hematoma: A case report and literature review. J Emerg Med 2009; 42:e31-e34.

193. Lee JH, Lee $H$, Jo DJ. An acute cervical epidural hematoma as a complication of dry needling. Spine (Phila Pa 1976) 2011; 36:E891-E893.

194. Glotzbecker MP, Bono CM, Wood KB, Harris MB. Postoperative spinal epidural hematoma: A systematic review. Spine (Phila Pa 1976) 2010; 35:E413-E420.

195. Wu CL, Perkins FM. Oral anticoagulant prophylaxis and epidural catheter removal. Reg Anesth 1996; 21:517-524.

196. Meikle J, Bird S, Nightingale J, White N. Detection and management of epidural haematomas related to anaesthesia in the UK: A national survey of current practice. Br J Anaesth 2008; 101:400-404.

197. Liu SS, Buvanendran A, Viscusi ER, Hutton E, Lubenow T, Zhou J, Shaw PM, Moric M, Lenart S. Uncomplicated removal of epidural catheters in 4365 patients with international normalized ratio greater than 1.4 during initiation of warfarin therapy. Reg Anesth Pain Med 2011; 36:231-235.

198. Tuman KJ, McCarthy RJ, March RJ, DeLaria GA, Patel RV, Ivankovich AD. Effects of epidural anesthesia and analgesia on coagulation and outcome after major vascular surgery. Anesth Analg 1991; 73:696-704.

199. Horlocker TT, Heit JA, Wedel DJ, Enneking FK, Rowlingson JC. Safe epidural catheter removal in the patient receiving warfarin: Does anybody really know what (prothrombin) time it is? Anesthesiology 2010; 113:759-761.

200. Yi S, Yoon do H, Kim KN, Kim SH, Shin HC. Postoperative spinal epidural hematoma: Risk factor and clinical outcome. Yonsei Med J 2006; 47:326-332.

201. Reitman CA, Watters W 3rd. Subdural hematoma after cervical epidural steroid injection. Spine (Phila Pa 1976) 2002; 27:E174-E176.

202. Urculo Bareño E, Arrazola Schlamich M. Spontaneous cervical epidural hemato- ma. Apropos of a case. Neurochirurgie 1987; 33:66-70.

203. Zupruk GM, Mehta Z. Brown-Séquard syndrome associated with posttraumatic cervical epidural hematoma: Case report and review of the literature. Neurosurgery 1989; 25:278-280.

204. Ozdemir O, Calisaneller T, Yildirim E, Altinors N. Acute intracranial subdural hematoma after epidural steroid injection: A case report.] Manipulative Physiol Ther 2007; 30:536-538.

205. Morán M, Modravý V, Fusek I. Spontaneous epidural hematoma with cervical localization--report of a case with etiopathologic analysis. Psychiatr Neurol Med Psychol (Leipz) 1990; 42:167-171.

206. Sannoh N, Kubokura T, Nishimura T, Koyama S, Tsubone K. A case of spontaneous cervical epidural hematoma associated with cervical spondylosis. No Shinkei Geka 1988; 16:539-543.

207. Crabbe DC, Mendelow AD, Pharoh P, Large DM, lons GK. Cervical spinal extradural haematoma causing a transient Brown-Sequard syndrome. ] Neurol Neurosurg Psychiatry 1992; 55:239.

208. Whedon JM, Quebada PB, Roberts DW, Radwan TA. Spinal epidural hematoma after spinal manipulative therapy in a patient undergoing anticoagulant therapy: A case report. J Manipulative Physiol Ther 2006; 29:582-585.

209. Owens EL, Kasten GW, Hessel EA 2nd. Spinal subarachnoid hematoma after lumbar puncture and heparinization: A case report, review of the literature, and discussion of anesthetic implications. Anesth Analg 1986; 65:1201-1207.

210. Lumpkin, M. FDA Public Health Advisory. Anesthesiology 1998 88:27A-28A.

211. Heye N. Is there a link between acute spinal epidural hematoma and aspirin? Spine (Phila Pa 1976) 1995; 20:1931-1932.

212. Gerancher JC, Waterer R, Middleton J. Transient paraparesis after postdural puncture spinal hematoma in a patient receiving ketorolac. Anesthesiology 1997; 86:490-494.

213. Gilbert A, Owens BD, Mulroy MF. Epidural hematoma after outpatient epidural anesthesia. Anesth Analg 2002; 94:77-78.

214. Zink $M$, Rath $M$, Waltensdorfer $A$, Engler J, Rumpold-Seitlinger G, Toller W, Reinhardt F. Unilateral presentation of a large epidural hematoma. Anesthesiology 2003; 98:1032-1033.

215. Maclean A. Antiplatelet therapy, regional anesthesia, and spinal hematomas.
Anesth Analg 1995; 81:1116.

216. Mayumi T, Dohi S. Spinal subarachnoid hematoma after lumbar puncture in a patient receiving antiplatelet therapy. Anesth Analg 1983; 62:777-779.

217. Muir JJ, Church EJ, Weinmeister KP. Epidural hematoma associated with dextran infusion. South Med J 2003; 96:811814.

218. Horlocker TT, Wedel DJ, Schlichting JL. Postoperative epidural analgesia and oral anticoagulant therapy. Anesth Analg 1994; 79:89-93.

219. Badenhorst $\mathrm{CH}$. Epidural hematoma after epidural pain control and concomitant postoperative anticoagulation. Reg Anesth 1996; 21:272-273.

220. Litz RJ, Hübler M, Koch T, Albrecht DM. Spinal-epidural hematoma following epidural anesthesia in the presence of antiplatelet and heparin therapy. Anesthesiology 2001; 95:1031-1033.

221. Stendel R, Danne M, Schulte T, Stoltenburg-Didinger G, Brock M. Chronic lumbar epidural haematoma presenting with acute paraparesis. Acta Neurochir (Wien) 2003; 145:1015-1018; discussion 1018.

222. Lee JY, Nassr A, Ponnappan RK. Epidural hematoma causing paraplegia after a fluoroscopically guided cervical nerveroot injection. A case report. J Bone Joint Surg Am 2007; 89:2037-2039.

223. Nourbakhsh A, Garges KJ. Lumbar synovial joint hematoma in a patient on anticoagulation treatment. Spine (Phila Pa 1976) 2007; 32:Е300-E302.

224. Morse $\mathrm{K}$, Weight $\mathrm{M}$, Molinari R. Extensive postoperative epidural hematoma after full anticoagulation: Case report and review of the literature.J Spinal Cord Med 2007; 30:282-287.

225. Song KJ, Lee KB. The poor outcome of the delayed diagnosis of acute spontaneous spinal epidural hematoma: Two cases report. J Korean Med Sci 2005; 20:331-334

226. Dickman CA, Shedd SA, Spetzler RF, Shetter AG, Sonntag VK. Spinal epidural hematoma associated with epidural anesthesia: Complications of systemic heparinization in patients receiving peripheral vascular thrombolytic therapy. Anesthesiology 1990; 72:947-950.

227. Onishchuk JL, Carlsson C. Epidural hematoma associated with epidural anesthesia: Complications of anticoagulant therapy. Anesthesiology 1992; 77:12211223.

228. Rabito SF, Ahmed S, Feinstein L, Winnie AP. Intrathecal bleeding after the intra- 
operative use of heparin and urokinase during continuous spinal anesthesia. Anesth Analg 1996; 82:409-411.

229. Wulf $\mathrm{H}$. Epidural anaesthesia and spinal haematoma. Can J Anaesth 1996; 43:1260-1271.

230. Han IS, Chung EY, Hahn YJ. Spinal epidural hematoma after epidural anesthesia in a patient receiving enoxaparin -A case report. Korean J Anesthesiol 2010; 59:119-122.

231. Heiner JD. Cervical epidural hematoma after chiropractic spinal manipulation. Am J Emerg Med 2009; 27:1023:E1-E2.

232. Abe $T$, Nagamine $Y$, Ishimatsu $S$, Tokuda Y. Spinal epidural hematoma after stretch exercise: A case report. Am J Emerg Med 2009; 27:902.e1-e2.

233. Kiran NA, Kasliwal MK, Kale SS, Singh M, Mahapatra AK. Two children with traumatic thoracic spinal epidural hematoma. J Clin Neurosci 2009; 16:13561358.

234. Riley CA, Spiegel JE. Complications following large-volume epidural blood patches for postdural puncture headache. Lumbar subdural hematoma and arachnoiditis: Initial cause or final effect? J Clin Anesth 2009; 21:355-359.

235. Wong YW, Luk KD. Spinal epidural hematoma in a scoliotic patient with long fusion: A case report. Spine J 2008; 8:538-543.

236. Bedforth NM, Aitkenhead AR, Hardman JG. Haematoma and abscess after epidural analgesia. $\mathrm{Br}$ J Anaesth 2008; 101:291-293.

237. Oh JY, Lingaraj K, Rahmat R. Spontaneous spinal epidural haematoma associated with aspirin intake. Singapore Med] 2008; 49:E353-E355.

238. Kato $Y$, Takeda H, Furuya D, Deguchi I, Tanahashi N. Spontaneous spinal epidural hematoma with unusual hemiparesis alternating from one side to the other side. Intern Med 2009; 48:17031705.

239. Carota A, Boscherini D. Exertional acute epidural cervical hematoma. Eur Neurol 2009; 62:127.

240. Toner A, Prabhu P. Reliable detection of epidural haematomas. $\mathrm{Br} \mathrm{J}$ Anaesth 2009; 102:140; author reply 140-141.

241. Lin HS, Chen SJ. Metastatic carcinoma related long segment thoracic spinal epidural hematoma: A case report. Spine (Phila Pa 1976) 2009; 34:E266-E268.

242. Elwood D, Koo C. Intraspinal hematoma following neuraxial anesthesia and lowmolecular-weight heparin in two pa- tients: Risks and benefits of anticoagulation. PM R 2009; 1:389-396.

243. Fakouri B, Srinivas S, Magaji S, Kunsky A, Cacciola F. Spinal epidural hematoma after insertion of a thoracic epidural catheter in the absence of coagulation disorders--a call for raised awareness. Neurol India 2009; 57:512-513.

244. Heer JS, Enriquez EG, Carter AJ. Spinal epidural hematoma as first presentation of hemophilia A.J Emerg Med 2008; 34:159-162.

245. Ohaegbulam CO, Dunn IF, d'Hemecourt $P$, Proctor MR. Lumbar epidural hematoma associated with spondylolyses. J Neurosurg Spine 2008; 8:174-180.

246. Sakakibara R, Yamazaki M, Mannouji C, Yamaguchi C, Uchiyama T, Ito T, Liu Z, Yamamoto T, Awa Y, Yamanishi T, Hattori T. Urinary retention without tetraparesis as a sequel to spontaneous spinal epidural hematoma. Intern Med 2008; 47:655-657.

247. Boco T, Deutsch H. Delayed symptomatic presentation of epidural hematoma after epidural catheter anesthesia: Case report. Spine (Phila Pa 1976) 2007; 32:E649-E651.

248. Carragee EJ, Golish SR, Scuderi GJ. A case of late epidural hematoma in a patient on clopidogrel therapy postoperatively: When is it safe to resume antiplatelet agents? Spine ] 2011; 11:E1-E4.

249. Daentzer D, Böker DK. Spontaneous spinal hemorrhage. Outcome after surgical therapy of epidural hematomas. Nervenarzt 2000; 71:116-122.

250. Garrott HM, Haynes RJ. Blindness from suprachoroidal haemorrhage in two patients with age-related macular degeneration on systemic anticoagulation therapy or an antiplatelet agent. Med J Aust 2010; 192:346-347.

251. Moon HJ, Kim JH, Kim JH, Kwon TH, Chung HS, Park YK. Spontaneous spinal epidural hematoma: An urgent complication of adding clopidogrel to aspirin therapy. J Neurol Sci 2009; 285:254-256.

252. Chalasani R, Qureshi S. Anticoagulation and intraocular haemorrhage in age-related macular degeneration: A probable link? Med J Aust 2010; 192:228-229.

253. Law SK, Song BJ, Yu F, Kurbanyan K, Yang TA, Caprioli J. Hemorrhagic complications from glaucoma surgery in patients on anticoagulation therapy or antiplatelet therapy. Am J Ophthalmol 2008; 145:736-746.

254. Kawaguchi S, Tokutomi S. A case of epidural hematoma associated with epi- dural catheterization which occurred on 12th days after the last medication of ticlopidine hydrochloride. Masui 2002; 51:526-528.

255. Parvizi J, Viscusi ER, Frank HG, Sharkey PF, Hozack WJ, Rothman RR. Can epidural anesthesia and warfarin be coadministered? Clin Orthop Relat Res 2007; 456:133-137.

256. Tank S, Gottschalk A, Radtke P, Nickler E, Freitag M, Standl T. Removal of an epidural catheter under ongoing antithrombotic therapy. Anasthesiol Intensiumed Notfallmed Schmerzther 2006; 41:274-277.

257. Yoo HS, Park SW, Han JH, Chung JY, Yi JW, Kang JM, Lee BJ, Kim DO. Paraplegia caused by an epidural hematoma in a patient with unrecognized chronic idiopathic thrombocytopenic purpura following an epidural steroid injection. Spine (Phila Pa 1976) 2009; 34: E376-E379.

258. Gurkanlar D, Acikbas C, Cengiz GK, Tuncer R. Lumbar epidural hematoma following lumbar puncture: The role of high dose LMWH and late surgery. A case report. Neurocirugia (Astur) 2007; 18:52-55.

259. Wildförster U, Schregel W, Harders A. Delayed lumbar epidural hematoma. Discussion of the risk factors: Hypertension, anticoagulation and spinal anesthesia. Anasthesiol Intensivmed Notfallmed Schmerzther 1998; 33:517-520.

26o. Borges G, Bonilha L, Maldaum MV, Menezes JR, Zanardi V. Acute cervical epidural hematoma: Case report. Arq Neuropsiquiatr 2000; 58:726-730.

261. Costabile G, Husag L, Probst C. Spinal epidural hematoma. Surg Neurol 1984; 21:489-492.

262. Vandermeulen EP, Van Aken H, Vermylen J. Anticoagulants and spinal-epidural anesthesia. Anesth Analg 1994; 79:11651177 .

263. Ng WH, Lim CC, Ng PY, Tan KK. Spinal epidural haematoma: MRI-aided diagnosis. J Clin Neurosci 2002; 9:92-94.

264. Szkup P, Stoneham G. Case report: Spontaneous spinal epidural haematoma during pregnancy: Case report and review of the literature. $\mathrm{Br}$ J Radiol 2004; 77:881-884.

265. Kloc W, Iwaniukowicz A, Imieliロski BL. Spontaneous chronic spinal epidural haematoma in a 14-year-old boy. Case report. Neurol Neurochir Pol 1992; 26:733738.

266. GoDciロski I, Skotnicki AB, Zawirska D, Moskała M, Krupa M. Traumatic epidur- 
al hematoma in a patient with von Willebrand's disease. Przegl Lek 2003; 60:489491.

267. Tashjian RZ, Bradley MP, Lucas PR. Spinal epidural hematoma after a pathologic compression fracture: An unusual presentation of multiple myeloma. Spine J 2005; 5:454-456.

268. Sokolowski MJ, Dolan M, Aminian A, Haak MH, Schafer MF. Delayed epidural hematoma after spinal surgery: A report of 4 cases. J Spinal Disord Tech 2006; 19:603-606.

269. Mohindra S, Mukherjee KK, Gupta R, Chhabra R, Gupta SK, Khosla VK. Decompressive surgery for acute subdural haematoma leading to contralateral extradural haematoma: A report of two cases and review of literature. $\mathrm{Br}] \mathrm{Neu}$ rosurg 2005; 19:490-494.

270. Rainov NG, Heidecke V, Burkert WL. Spinal epidural hematoma. Report of a case and review of the literature. Neurosurg Rev 1995; 18:53-60.

271. Miyazaki M, Takasita M, Matsumoto $\mathrm{H}$, Sonoda $H$, Tsumura $H$, Torisu T. Spinal epidural hematoma after removal of an epidural catheter: Case report and review of the literature.] Spinal Disord Tech 2005; 18:547-551.

272. Yu HP, Fan SW, Yang HL, Tang TS, Zhou $F$, Zhao $X$. Early diagnosis and treatment of acute or subacute spinal epidural hematoma. Chin Med J (Engl) 2007; 120:1303-1308.

273. Dinsmore AJ, Leonard RB, Manthey D. Spontaneous spinal epidural hematoma: A case report. J Emerg Med 2005; 28:423-426.

274. McLain RF, Fry M, Hecht ST. Transient paralysis associated with epidural steroid injection. J Spinal Disord 1997; 10:441-444.

275. Muthukumar N. Chronic spontaneous spinal epidural hematoma -- a rare cause of cervical myelopathy. Eur Spine J 2003; 12:100-103.

276. Bose B. Quadriparesis following cervical epidural steroid injections: Case report and review of the literature. Spine ] 2005; 5:558-563.

277. Phookan G, Lehman RA, Kuhlengel KR. Cervical spinal epidural haematoma: The double jeopardy. Ann Med 1996; 28:407-411.

278. Takano S, Saitoh M, Motoori T, Miyasaka Y, Yada K, Takagi H. A case of acute cervical spinal epidural hematoma caused by extradural arterio-venous malformation. No Shinkei Geka 1994; 22:845-849.
279. Yoshida T, Mori E, Yamadori A. Acute spinal epidural hematoma in MRI-CT, following continuous epidural anesthesia with spontaneous recovery. Rinsho Shinkeigaku 1989; 29:226-229.

280. Lang SA, Grau T. Spinal epidural hematoma and epidural analgesia. Can J Anaesth 2003; 50:422-423.

281. Kaiser MC, Capesius P, Ohanna F, Roilgen $\mathrm{A}$. Computed tomography of acute spinal epidural hematoma associated with cervical root avulsion. J Comput Assist Tomogr 1984; 8:322-323.

282. Usta B, Muslu B. Sedation during cervical vs. lumbar translaminar epidural steroid injections. Pain Pract 2009; 9:480; author reply 480-481.

283. Afzal A, Hawkins F, Rosenquist RW. Epidural hematoma in a patient receiving epidural analgesia and LMWH after total-knee arthroplasty. Reg Anesth Pain Med 2006; 31:480.

284. Neo M, Sakamoto T, Fujibayashi S, Nakamura T. Delayed postoperative spinal epidural hematoma causing tetraplegia. Case report. J Neurosurg Spine 2006; 5:251-253.

285. Mehta S, Khalil AA, Alshekhlee A. Air myelopathy following a cervical epidural injection. Pain Med 2010; 11:1678-1679.

286. Ikuta K, Tono O, Tanaka T, Arima J, Nakano S, Sasaki K, Oga M. Evaluation of postoperative spinal epidural hematoma after microendoscopic posterior decompression for lumbar spinal stenosis: A clinical and magnetic resonance imaging study. J Neurosurg Spine 2006; 5:404-409.

287. Furman MB, Giovanniello MT, O'Brien $E M$. Incidence of intravascular penetration in transforaminal cervical epidural steroid injections. Spine (Phila Pa 1976) 2003; 28:21-25.

288. Hodges SD, Castleberg RL, Miller T, Ward R, Thornburg C. Cervical epidural steroid injection with intrinsic spinal cord damage. Two case reports. Spine (Phila Pa 1976) 1998; 23:2137-2142; discussion 2141-2142.

289. Götz F, Lanfermann H, Becker H. Cervical epidural abscess following lumbar epidural steroid injections. Klin Neuroradiol 2009; 19:220-226.

290. Hyderally HA. Epidural hematoma unrelated to combined spinal-epidural anesthesia in a patient with ankylosing spondylitis receiving aspirin after total hip replacement. Anesth Analg 2005; 100:882-883.

291. Miñambres E, Burón J, Suberviola B,
Hernández MA, González-Castro A, González-Mandly A. Nonsurgical management of symptomatic posttraumatic thoracic epidural hematoma. Am J Emerg Med 2006; 24:134-136.

292. McHaourab AS. Cervical epidural steroid injection: Impact of cervical epidural anatomy. Anesthesiology 2004; 101:1238-1239; author reply 1239.

293. Ammirati M, Perino F. Symptomatic air trapped in the spine after lumbar epidural corticosteroid injection. Case report. J Neurosurg Spine 2006; 5:359-361.

294. Solheim O, Jorgensen JV, Nygaard OP. Lumbar epidural hematoma after chiropractic manipulation for lower-back pain: Case report. Neurosurgery 2007; 61:E170-E171; discussion E171.

295. Domenicucci M, Ramieri A, Salvati M, Brogna C, Raco A. Cervicothoracic epidural hematoma after chiropractic spinal manipulation therapy. Case report and review of the literature. J Neurosurg Spine 2007; 7:571-574.

296. Stafford-Smith M. Impaired haemostasis and regional anaesthesia. Can J Anaesth 1996; 43:R129-R141.

297. Connolly ES Jr, Winfree CJ, McCormick PC. Management of spinal epidural hematoma after tissue plasminogen activator. A case report. Spine (Phila Pa 1976) 1996; 21:1694-1698.

298. Fitzgibbon DR, Posner KL, Domino KB, Caplan RA, Lee LA, Cheney FW; American Society of Anesthesiologists. Chronic pain management: American Society of Anesthesiologists Closed Claims Project. Anesthesiology 2004; 100:98-105.

299. Adriani J, Naragi M. Paraplegia associated with epidural anesthesia. South Med J 1986; 79:1350-1355.

300. Darnat S, Guggiari M, Grob R, Guillaume A, Viars P. A case of spinal extradural hematoma during the insertion of an epidural catheter. Ann Fr Anesth Reanim 1986; 5:550-552.

301. Sollmann WP, Gaab MR, Panning B. Lumbar epidural hematoma and spinal abscess following peridural anesthesia. Reg Anaesth 1987; 10:121-124.

302. Gustafsson $H$, Rutberg $H$, Bengtsson M. Spinal haematoma following epidural analgesia. Report of a patient with ankylosing spondylitis and a bleeding diathesis. Anaesthesia 1988; 43:220-222.

303. Wulf H, Maier Ch, Striepling E. Epidurales häimatom nach katheterperiduralanaesthesie bei thrombozytopenie. Regional-Anaesthesie 1988; 11:26-27.

304. Bills DC, Blumbergs P, North JB. latro- 
genic spinal subdural haematoma. Aust N ZJ Surg 199l; 61:703-706.

305. Eastwood DW. Hematoma after epidural anesthesia: Relationship of skin and spinal angiomas. Anesth Analg 1991; 73:352-354.

306. Klement W, Rothe G, Peters J. Paraplegie nach entfernung eines epiduralkatheters. Reg Anaesth 1991; 14:88-91.

307. Metzger G, Singbartl G. Spinal epidural hematoma following epidural anesthesia versus spontaneous spinal subdura hematoma. Two case reports. Acta Anaesthesiol Scand 1991; 35:105-107.

308. Tekkok IH, Cataltepe O, Tahta K, Bertan V. Extradural haematoma after continuous extradural anaesthesia. $\mathrm{Br}$ J Anaesth 1991; 67:112-115.

309. Wille-Jørgensen $P$, Jørgensen LN, Rasmussen LS. Lumbar regional anaesthesia and prophylactic anticoagulant therapy. Anaesthesia 1991; 46:623-627.

310. Prevention of deep vein thrombosis with low molecular weight heparin in patients undergoing total hip replacement: A randomized trial. The German Hip Arthroplasty Trial (GHAT) Group. Arch Orthop Trauma Surg 1992; 111:110120.

311. Brockmeier V, Moen $\mathrm{H}$, Karlsson BR, Fjeld NB, Reiestad F, Steen PA. Interpleural or thoracic epidural analgesia for pain after thoracotomy. A double blind study. Acta Anaesthesiol Scand 1993; 38:317-321.

312. Lao TT, Halpern SH, MacDonald D, Huh C. Spinal subdural haematoma in a parturient after attempted epidural anaesthesia. Can J Anaesth 1993; 40:340-345.

313. Bent $U$, Gniffke S, Reinbold WD. Epidurales häimatom nach single shot-epiduralanäisthesie. Anaesthesist 1994; 43:245248.

314. Ganjoo P, Singh AK, Mishra VK, Singh PK, Bannerjee D. Postblock epidural hematoma causing paraplegia. Reg Anesth 1994; 19:62-65.

315. Nicholson A. Painless epidural haematoma. Anaesth Intensive Care 1994; 22:607-610.

316. Weis KH. Cave: Thorakale katheterepiduralanästhesie zur postoperativen schmerztherapie (Letter). Anästhesiologie und Intensivmedizin 1994; 35:202-203.

317. Tryba M. Hemostatic requirements for the performance of regional anesthesia. Workshop on hemostatic problems in regional anesthesia. Regional Anaesthesie 1989; 12:127-131.
318. Dahfgren N, Törnebrandt K. Neurological complications after anaesthesia. A follow-up of 18,000 spinal and epidural anaesthetics performed over three years. Acta Anaesthesiol Scand 1995; 39:872-880.

319. Gundag M, Hakan M, Dogan K, Kitis $S$, Ozkan N. Spontaneous resolution of paraparesis because of acute spontaneous thoracolumbar epidural hematoma. Iran Red Crescent Med J 2012; 14:574-577.

320. Hartigan JD. Dangerous sequelae of epidural anesthesia in geriatrics. Nebr Med J 1995; 80:80-83.

321. Morisaki H, Doi J, Ochiai R, Takeda J, Fukushima K. Epidural hematoma after epidural anesthesia in a patient with hepatic cirrhosis. Anesth Analg 1995; 80:1033-1035.

322. Scott DA, Beilby DSN, McClymont C. Postoperative analgesia using epidural infusions of fentanyl with bupivacaine. A prospective analysis of 1,014 patients. Anesthesiology 1995; 83:727-737.

323. Wulf H. Thromboembolieprophylaxe und rtickenmarksnahe regionalanasthesie. Anästhesiol Intensivmed 1995; 36:216217.

324. Wyderka T, Rust DS, Schindler T, Mahler M, Zickmann B, Thiel A. Bilaterales intrakranielles chronisches subduralhamatomals spätkomplikation nach einer geburtshilflichen periduralanästhesie. Anaesthesist 1995; 44:S92.

325. Ruppert $\mathrm{VH}$, Rosenberg $\mathrm{H}$. Lähmungen nach periduralanästhesie. Anaesthesist 1957; 6:346-348.

326. Eisen SM, Rosen $\mathrm{N}$, Winesanker $\mathrm{H}$, Hellman K, Axelrod HI, Rotenberg $M$, Relle A, Sheffman E. The routine use of lumbar epidural anaesthesia in obstetrics: A clinical review of 9,532 cases. Can Anaesth Soc J 1960; 7:280-289.

327. Mayer JA. Extradural spinal hemorrhage. Can Med Assoc J 1963; 89:10341037.

328. Honkomp J. Zur begutachtung bleibender neurologischer schäden nach peridural anaesthesie. Anaesthesist 1966; 15:246-248.

329. Zuev NS, Il'chenko NI. Complication of peridural anesthesia (Russian). Vestn Khir Im I I Grek 1980; 124:97-98.

330. Ballin NC. Paraplegia following epidural analgesia. Anaesthesia 1981; 36:952-953.

331. Skouen JS, Wainapel SF, Willock MM. Paraplegia following epidural anesthesia. A case report and a literature review. Acta Neurol Scand 1985; 72:437-443.

332. Jöhr M, Salathd M. Paraplegie nach pneumonektomie. Schweiz Med Wschr 1988; 118:1412-1414.

333. Puke M, Norlander O. Severe neurological complications in extradural and intrathecal blockades as reported to the Swedish Patient Insurance Consortium between 1980-1984. Schmerz/Pain/Douleur 1988; 9:76-78.

334. Kamo $M$, Watanabe $Y$, Numaguchi $Y$, Saida Y. Spinal subdural hematoma mimicking epidural lipomatosis. Magn Reson Med Sci 2012; 11:197-199.

335. Matsumoto H, Miki T, Miyaji Y, Minami H, Masuda A, Tominaga S, Yoshida Y, Yamaura I, Matsumoto S, Natsume S, Yoshida K. Spontaneous spinal epidural hematoma with hemiparesis mimicking acute cerebral infarction: Two case reports. J Spinal Cord Med 2012; 35:262266.

336. Sternlo J-E, Hybbinette C-H. Spinal subdural bleeding after attempted epidural and subsequent spinal anaesthesia in a patient on thromboprophylaxis with low molecular weight heparin. Acta Anaesthesiol Scand 1995; 39:557-559.

337. Lo CC, Chen JY, Lo YK, Lai PH, Lin YT. Spontaneous spinal epidural hematoma: A case report and review of the literatures. Acta Neurol Taiwan 2012; 21:31-34.

338. Ernst $S$, Heindel W, Fischbach R, Gawenda M, Langen HJ, Neubauer S, Krahe T. Complications of CT guided lumbar sympathectomy: Our own experiences and literature review. Rofo 1998; 168:77-83.

339. Reid W, Watt JK, Gray TG. Phenol injection of the sympathetic chain. $\mathrm{Br}$ J Surg 1970; 57:45-50.

340. Coubret PH, Lermusiaux $\mathrm{P}$, Becquemin JP, Etienne G, Melliere D. Are there indications for sympatholysis using phenol? J Mal Vasc 1985; 10:357-361.

341. Dreyfus A, Fondras JC, Loubrieu G, Ntarundenga $U$. Our experience of lumbar chemical sympathectomy in arterial occlusive diseases of the lower limbs. Agressologie 1990; 31:207-209.

342. Urmey WF, Rowlingson J. Do antiplatelet agents contribute to the development of perioperative spinal hematoma? Reg Anesth Pain Med 1998; 23:146151.

343. Russman BS, Kazi KH. Spinal epidural hematoma and the Brown-Séquard syndrome. Neurology 1971; 21:1066-1068.

344. Mustafa MH, Bernstein RA. Spontaneous spinal epidural hematoma, BrownSéquard syndrome, and factor XI deficiency. Ann Intern Med 1987; 106:477-478. 
345. Mattle H, Sieb JP, Rohner M, Mumenthaler M. Nontraumatic spinal epidural and subdural hematomas. Neurology 1987; 37:1351-1356.

346. Geuna E, Pazni CA. Considerazioni se di un caso di compromissione midollasa da emotoma extradurale cronico. Rassegna Medica Sardinia 1958; 60:645649.

347. Segelov JN. Spinal epidural haematoma: A report of two cases. Pac Med Surg 1967; 75:169.

348. Yang TK, Seo HM, Lee CS. Non-traumatic spinal epidural haematoma after breath-hold diving. $\mathrm{Br}$ ] Neurosurg 2012; 26:915-916.

349. Tremolizzo L, Patassini M, Malpieri M, Ferrarese C, Appollonio I. A case of spinal epidural haematoma during breathhold diving. Diving Hyperb Med 2012; 42:98-100.

350. Kim KT, Cho DC, Ahn SW, Kang SH Epidural hematoma related with lowdose aspirin: Complete recovery without surgical treatment. J Korean Neurosurg Soc 2012; 51:308-311.

351. Fuster S, Castañeda S, Ferrer E, Wang J, Poblete J. Spontaneous chronic epidural hematoma of the lumbar spine mimicking an extradural spine tumour. Eur Spine ] 2012 Jun 21. [Epub ahead of print]

352. Yabe H, Ishii A, Niikawa N, Matsubayashi H, Kakei M, Kawakami M, Sugawara $\mathrm{H}$. An elderly patient who developed spontaneous spinal epidural hematoma during warfarin therapy. Intern Med 2012; 51:1429-1432.

353. Mayr R, Troyer S, Kastenberger T, Krappinger D, Rosenberger R, Obwegeser A El Attal R. The impact of coagulopathy on the outcome of traumatic epidural hematoma. Arch Orthop Trauma Surg 2012; 132:1445-1450.

354. Baharvahdat $\mathrm{H}$, Etemadrezaie $\mathrm{H}, \mathrm{Zabi}-$ hyan S, Dashti S, Ganjeifar B. Acute interdural hematoma mimicking epidural hematoma: A case report. Turk Neurosurg 2012; 22:368-370.

355. Lemmens R, Ceuppens J, Wilms G, Depreitere $B$. Transient hemiparesis caused by spontaneous cervical epidural hematoma. Acta Neurol Belg 2012; 112:291-293.

356. Zuliani G, Guerra G, Dalla Nora E, Fainardi E. Spinal anterior epidural hemato$m a$ in an elderly man with unrecognized lupic anticoagulant taking warfarin. $\mathrm{Ag}$ ing Clin Exp Res 2011; 23:498-500.

357. Shima $H$, Yasuda $M$, Nomura $M$, Mori K, Miyashita K, Tamase A, Kitamura Y, Osuka K, Takayasu M. A spinal epidural hematoma with symptoms mimicking cerebral stroke. Nagoya J Med Sci 2012; 74:207-210.

358. Gwyn J, Shinton R. Spontaneous cervica epidural haematoma: Role of antiplatelets. JRSM Short Rep 2012; 3:20.

359. Nayil K, Laharwal M, Dhar A, Wani A, Ramzan A, Arif S. Vertex epidural hematoma with bilateral abducent nerve palsy: Case report and literature review. Turk Neurosurg 2012; 22:257-26o.

36o. Udoh DO. Bilateral post-traumatic acute extradural hematomas: A report of four cases and review of literature. Niger J Clin Pract 2012; 15:104-107.

361. Stauber B, Ma L, Nazari R. Cardiopulmonary arrest following cervical epidural injection. Pain Physician 2012; 15:147152.

362. Schwartz D, Arcot K, Grosberg BM, Robbins MS. Spontaneous cervical epidural hematoma associated with thunderclap headache. J Headache Pain 2012; 13:331333.

363. Gopalkrishnan CV, Dhakoji A, Nair S. Spontaneous cervical epidural hematoma of idiopathic etiology: Case report and review of literature. J Spinal Cord Med 2012; 35:113-117.

364. Azumagawa K, Yamamoto S, Tanaka K, Sakanaka H, Teraura H, Takahashi K, Tamai H. Non-operative treated spontaneous spinal epidural hematoma in a 12-year-old boy. Pediatr Emerg Care 2012; 28:167-169.

365. Yang SM, Kang SH, Kim KT, Park SW, Lee WS. Spontaneous spinal epidural hematomas associated with acute myocardial infarction treatment. Korean Circ J 2011; 41:759-762.

366. Fariña EM, Lavoyer Escudeiro R, Aguiar GB. Spontaneous spinal epidural hematoma. Medicina (B Aires) 2012; 72:43.

367. Kim SH, Jeon SH, Cho JL, Chong HT, Kim DJ, Kim MC, Eun JP. Chronic pure radiculopathy in patient with organizing epidural hematoma around C8 nerve root. Eur Spine ] 2012; 4:S450-S452.

368. Jacob JT, Tanaka S, Wood CP, Wijdicks EF, Lanzino G. Acute epidural spinal hemorrhage from vasculitis: Resolution with immunosuppression. Neurocrit Care 2012; 16:311-315.

369. Matsubara S. Spontaneous spinal epidural hematoma during pregnancy. Arq Neuropsiquiatr 2012; 70:81.

370. Son S, Kang DH, Choi DS, Kim SK, Lim $\mathrm{BH}$, Choi NC. A case of spontaneous spinal epidural hematoma mimicking a stroke. Neurologist 2012; 18:41-43.
371. Lee SB, Lee TG, Yoo DS, Huh PW, Cho KS. Thoracic spinal cord epidural hematoma after extracorporeal shock wave lithotripsy. J Neurosurg Spine 2012; 16:127-129.

372. Messerer M, Dubourg J, Diabira S, Robert T, Hamlat A. Spinal epidural hematoma: Not always an obvious diagnosis. Eur J Emerg Med 2012; 19:2-8.

373. Nakanishi K, Nakano N, Uchiyama T, Kato A. Hemiparesis caused by cervical spontaneous spinal epidural hematoma: A report of 3 cases. Adv Orthop 2011; 2011:516382.

374. Kokubo R, Kim K, Sugawara A, Nomura $R$, Morimoto D, Isu T, Kobayashi S, Teramoto A. Treatment of spontaneous spinal epidural hematoma. No Shinkei Geka 2011; 39:947-952.

375. Zhong W, Chen H, You C, Li J, Liu Y, Huang S. Spontaneous spinal epidural hematoma. J Clin Neurosci 2011; 18:14901494.

376. Puah KL, Tow BP, Yue WM, Guo CM, Chen JL, Tan SB. Spontaneous cervical spinal epidural hematoma in the postpartum period. Spine (Phila Pa 1976) 2012; 37:E408-E410.

377. Spennato P, De Paulis D, Bocchetti A, Michele Pipola A, Sica G, Galzio RJ. Spontaneous intracranial extradural haematoma associated with frontal sinusitis and orbital involvement. Neurol Sci 2012; 33:435-439.

378. Cai HX, Liu C, Zhang JF, Wan SL, Uchida K, Fan SW. Spontaneous epidural hematoma of thoracic spine presenting as Brown-Séquard syndrome: Report of a case with review of the literature. J Spinal Cord Med 2011; 34:432-436.

379. Kim SW, Kim HS. Clinical images: Epidural hematoma in ankylosing spondylitis. Arthritis Rheum 2011; 63:3896.

380. Jaeger $M$, Jeanneret $B$, Schaeren $S$. Spontaneous spinal epidural haematoma during Factor $X a$ inhibitor treatment (Rivaroxaban). Eur Spine J 2012; 21:S433S435.

381. Liou KC, Chen LA, Lin YJ. Cervical spinal epidural hematoma mimics acute ischemic stroke. Am J Emerg Med 2012; 30:1322.e1-3.

382. Stanworth PA. Acute spinal epidural haematoma causing cord compression after chiropractic neck manipulation: An under-recognised serious hazard? J $R$ Army Med Corps 2011; 157:197.

383. Segal DH, Lidov MW, Camins MB. Cervical epidural hematoma after chiropractic manipulation in a healthy young 
woman: Case report. Neurosurgery 1996; 39:1043-1045.

384. Tseng SH, Chen Y, Lin SM, Wang $\mathrm{CH}$. Cervical epidural hematoma after spinal manipulation therapy: Case report. J Trauma 2002; 52:585-586.

385. Saxler G, Barden B. Extensive spinal epidural hematoma-an uncommon entity following cervical chiropractic manipulation. Z Orthop Ihre Grenzgeb 2004; 142:79-82.

386. Litz RJ, Gottschlich B, Stehr SN. Spinal epidural hematoma after spinal anesthesia in a patient treated with clopidogrel and enoxaparin. Anesthesiology 2004; 101:1467-1470.

387. Sharma S, Kapoor MC, Sharma VK, Dubey AK. Epidural hematoma complicating high thoracic epidural catheter placement intended for cardiac surgery. J Cardiothorac Vasc Anesth 2004; 18:759762.

388. Chan L, Bailin MT. Spinal epidural hematoma following central neuraxial blockade and subcutaneous enoxaparin: A case report. J Clin Anesth 2004; 16:382385 .

389. Christie IW, McCabe S. Major complications of epidural analgesia after surgery: Results of a six-year survey. Anaesthesia 2007; 62:335-341.

390. Tyagi A, Bhattacharya A. Central neuraxial blocks and anticoagulation: $\mathrm{A}$ review of current trends. Eur ] Anaesthesiol 2002; 19:317-329.

391. Ghaly RF. Recovery after high-dose methylprednisolone and delayed evacuation: A case of spinal epidural hematoma. J Neurosurg Anesthesiol 2001; 13:323328.

392. Snarr J. Risk, benefits and complications of epidural steroid injections: A case report. AANA J 2007; 75:183-188.

393. Verduzco LA, Atlas SW, Riley ET. Subdural hematoma after an epidural blood patch. Int J Obstet Anesth 2012; 21:189192.

394. Dolgun $H$, TürkoDlu $E$, Kertmen $H$, YIImaz ER, Ergun BR, Sekerci Z. Rapid resolution of acute epidural hematoma: Case report and review of the literature. Ulus Travma Acil Cerrahi Derg 2011; 17:283-285.

395. Chiravuri S, Wasserman R, Chawla A, Haider N. Subdural hematoma following spinal cord stimulator implant. Pain Physician 2008; 11:97-101.

396. Horlocker TT, Wedel DJ. Neuraxial block and low-molecular-weight heparin: Balancing perioperative analgesia and thromboprophylaxis. Reg Anesth Pain Med 1998; 23:164-177.

397. Moen V, Dahlgren N, Irestedt L. Severe neurological complications after central neuraxial blockades in Sweden 19901999. Anesthesiology 2004; 101:950-959.

398. Wagner S, Forsting M, Hacke W. Spontaneous resolution of a large spinal epidural hematoma: Case report. Neurosurgery 1996; 38:816-818.

399. Bonicalzi V, Graziano A, Roero C, Canavero S. Reversible, hyperacute allodynia after evacuation of a cervical epidural hematoma. J Pain Symptom Manage 2012; 43:e9-ell.

400. Kaneda T, Urimoto G, Suzuki T. Spinal epidural hematoma following epidural catheter removal during antiplatelet therapy with cilostazol. J Anesth 2008; 22:290-293.

401. Benzon HT, McCarthy RJ, Benzon HA, Kendall MC, Robak S, Lindholm PF, Kallas PG, Katz JA. Determination of residual antiplatelet activity of clopidogrel before neuraxial injections. Br ] Anaesth 2011; 107:966-971.

402. Bouman HJ, Parlak E, van Werkum JW, Breet $N$ J, ten Cate $H$, Hackeng CM, ten Berg JM, Taubert D. Which platelet function test is suitable to monitor clopidogrel responsiveness? A pharmacokinetic analysis on the active metabolite of clopidogrel. J Thromb Haemost 2010; 8:482-488.

403. Collyer TC, Gray DJ, Sandhu R, Berridge J, Lyons G. Assessment of platelet inhibition secondary to clopidogrel and aspirin therapy in preoperative acute surgical patients measured by Thrombelastography Platelet Mapping. Br J Anaesth 2009; 102:492-498.

404. Lordkipanidzé M, Pharand C, Nguyen TA, Schampaert E, Palisaitis DA, Diodati JG. Comparison of four tests to assess inhibition of platelet function by clopidogrel in stable coronary artery disease patients. Eur Heart J 2008; 29:2877-2885.

405. Benzon HT, Avram MJ, Benzon HA, Kirby-Nolan M, Nader A. Factor VII levels and international normalized ratios in the early phase of warfarin therapy. Anesthesiology 2010; 12:298-304.

406. Paniccia R, Antonucci E, Gori AM, Marcucci R, Giglioli C, Antoniucci D, Gensini GF, Abbate R, Prisco D. Different methodologies for evaluating the effect of clopidogrel on platelet function in high-risk coronary artery disease patients. J Thromb Haemost 2007; 5:18391847.
407. Graham R, Mancher M, Wolman DM, Greenfield S, Steinberg E (eds); Committee on Standards for Systematic Reviews of Comparative Effectiveness Research; Institute of Medicine. Clinical Practice Guidelines We Can Trust. The National Academies Press, Washington, DC, 2011.

408. Manchikanti L, Caraway DL, Parr AT, Fellows B, Hirsch JA. Patient Protection and Affordable Care Act of 2010: Reforming health care reform for the new decade. Pain Physician 2011; 14:E35-E67.

409. Manchikanti L, Hirsch JA. Patient Protection and Affordable Care Act of 2010: A primer for neurointerventionalists. J Neurointervent Surg 2012; 4:141-146.

410. Manchikanti L, Helm II S, Hirsch JA. The evolution of the Patient-Centered Outcome Research Institute. J Neurointervent Surg 2012; 4:157-162.

411. Chou R, Huffman L. Use of Chronic Opioid Therapy in Chronic Noncancer Pain: Evidence Review. American Pain Society; Glenview, IL: 2009.

www.ampainsoc.org/library/pdf/Opioid_Final_Evidence_Report.pdf

412. American Society of Anesthesiologists Task Force on Chronic Pain Management; American Society of Regional Anesthesia and Pain Medicine. Practice guidelines for chronic pain management: An updated report by the American Society of Anesthesiologists Task Force on Chronic Pain Management and the American Society of Regional Anesthesia and Pain Medicine. Anesthesiology 2010; 112:810-833.

413. Van Zundert J, Vanelderen P, Kessels A, van Kleef M. Radiofrequency treatment of facet-related pain: Evidence and controversies. Curr Pain Headache Rep 2012; 16:19-25.

414. Manchikanti L, Singh V, Derby R, Schultz DM, Benyamin RM, Prager JP, Hirsch JA. Reassessment of evidence synthesis of occupational medicine practice guidelines for interventional pain management. Pain Physician 2008; 11:393482.

415. Classen DC, Resar R, Griffin F, Federico F, Frankel T, Kimmel N, Whittington JC, Frankel A, Seger A, James BC. "Global trigger tool" shows that adverse events in hospitals may be ten times greater than previously measured. Health Aff (Millwood) 2011; 30:581-589.

416. Public Law No: 111-5. H.R. 1. American Recovery and Reinvestment Act of 2009 signed by President Barack Obama on 2/17/2009. 
417. Public Law No: 111-148: H.R. 3590. Patient Protection and Affordable Care Act. March 23, 2010.

418. Manchikanti L, Malla Y, Wargo BW, Fellows B. Preoperative fasting before interventional techniques: Is it necessary or evidence-based? Pain Physician 2011; 14:459-467.

419. Manchikanti L, Malla Y, Wargo BW, Fellows B. Infection control practices (safe injection and medication vial utilization) for interventional techniques: Are they based on relative risk management or evidence? Pain Physician 2011; 14:425434 .

420. Partridge $A H$, Winer EP. On mammography - more agreement than disagreement. N Eng J Med 2009; 361:2499-2501.

421. Truog RD. Screening mammography and the "r" word. N Engl J Med 2009; 361:2501-2503.

422. Squiers LB, Holden DJ, Dolina SE, Kim $A E$, Bann CM, Renaud JM. The public's response to the U.S. Preventive Services Task Force's 2009 recommendations on mammography screening. Am J Prev Med 2011; 40:497-504.

423. Conde C. Mammogram mania: Task force screening recommendation creates chaos. Tex Med 2010; 106:29-36.

424. Sawaya GF, Gregory KD. The new mammographic screening guidelines: What were they thinking? Obstet Gynecol 2010; 116:1216; author reply 1216-1217.

425. Thrall JH. US Preventive Services Task Force recommendations for screening mammography: Evidence-based medicine or the death of science? J Am Coll Radiol 2010; 7:2-4.

426. Nelson HD, Tyne K, Naik A, Bougatsos C, Chan BK, Humphrey L; U.S. Preventive Services Task Force. Screening for breast cancer: An update for the U.S. Preventive Services Task Force. Ann Intern Med 2009; 151:727-737.

427. Brett AS, Ablin RJ. Prostate-cancer screening--what the U.S. Preventive Services Task Force left out. N Engl J Med 2011; 365:1949-1951.

428. McNaughton-Collins MF, Barry MJ. One man at a time--resolving the PSA controversy. N Engl] Med 2011; 365:19511953.

429. Schröder FH. Stratifying risk--the U.S. Preventive Services Task Force and prostate-cancer screening. $N$ Engl J Med 2011; 365:1953-1955.

430. Hoffman RM. Clinical practice. Screening for prostate cancer. $N$ Engl J Med 2011; 365:2013-2019.
431. Gomella LG, Liu XS, Trabulsi EJ, Kelly WK, Myers R, Showalter T, Dicker A, Wender R. Screening for prostate cancer: The current evidence and guidelines controversy. Can J Urol 2011; 18:58755883.

432. Liu H, Waxman DA, Main R, Mattke S. Utilization of anesthesia services during outpatient endoscopies and colonoscopies and associated spending in 20032009. JAMA 2012; 307:1178-1184.

433. Colliver V. Debate grows over colorectal cancer screenings. SFGate, March 14, 2012.

www.sfgate.com/health/article/Debategrows-over-colorectal-cancer-screenings-3407339.php

434. Tanner L; Associated Press. Multiple colon tests use costly sedation, study finds. USA Today, March 20, 2012.

www.usatoday.com/news/health/story/health/story/2012-03-20/Multiplecolon-tests-use-costly-sedation-studyfinds $/ 53673170 / 1$

435. Khiani VS, Soulos P, Gancayco J, Gross $\mathrm{CP}$. Anesthesiologist involvement in screening colonoscopy: Temporal trends and cost implications in the medicare population. Clin Gastroenterol Hepatol 2012; 10:58-64.

436. Terruzzi V, Paggi S, Amato A, Radaelli F. Unsedated colonoscopy: A never ending story. World J Gastrointest Endosc 2012; 4:137-141.

437. Study: Colonoscopies often come with costly, unnecessary sedation. CBS News, March 20, 2012.

www.cbsnews.com/8301-504763_16257401162-10391704/study-colonoscopies-often-come-with-costly-unnecessary-sedation/

438. Patel VB, Manchikanti L, Singh V, Schultz DM, Hayek SM, Smith HS. Systematic review of intrathecal infusion systems for long-term management of chronic non-cancer pain. Pain Physician 2009; 12:345-36o.

439. Deer TR, Smith HS, Burton AW, Pope JE, Doleys DM, Levy RM, Staats PS, Wallace MS, Webster LR, Rauck RL, Cousins M; Center For Pain Relief, Inc. Comprehensive consensus based guidelines on intrathecal drug delivery systems in the treatment of pain caused by cancer pain. Pain Physician 2011; 14:E283-E312.

440. Manchikanti L, Abdi S, Atluri S, Balog CC, Benyamin RM, Boswell MV, Brown KR, Bruel BM, Bryce DA, Burks PA, Burton AW, Calodney AK, Caraway DL, Cash KA, Christo PJ, Damron KS, Datta S,
Deer TR, Diwan S, Eriator I, Falco FJE, Fellows F, Geffert S, Gharibo CG, Glaser SE, Grider JS, Hameed H, Hameed $M$, Hansen $H$, Harned ME, Hayek SM, Helm II S, Hirsch JA, Janata JW, Kaye AD, Kaye AM, Kloth DS, Koyyalagunta D, Lee M, Malla Y, Manchikanti KN, McManus CD, Pampati V, Parr AT, Pasupuleti R, Patel VB, Sehgal N, Silverman SM, Singh V, Smith HS, Snook LT, Solanki DR, Tracy DH, Vallejo R, Wargo BW. American Society of Interventional Pain Physicians (ASIPP) guidelines for responsible opioid prescribing in chronic non-cancer pain: Part I - Evidence assessment. Pain Physician 2012; 15:S1-S66.

441. Manchikanti L, Abdi S, Atluri S, Balog CC, Benyamin RM, Boswell MV, Brown KR, Bruel BM, Bryce DA, Burks PA, Burton AW, Calodney AK, Caraway DL, Cash KA, Christo PJ, Damron KS, Datta S, Deer TR, Diwan S, Eriator I, Falco FJE, Fellows F, Geffert S, Gharibo CG, Glaser SE, Grider JS, Hameed H, Hameed M, Hansen $\mathrm{H}$, Harned ME, Hayek SM, Helm II S, Hirsch JA, Janata JW, Kaye AD, Kaye AM, Kloth DS, Koyyalagunta D, Lee M, Malla Y, Manchikanti KN, McManus $C D$, Pampati V, Parr AT, Pasupuleti R, Patel VB, Sehgal N, Silverman SM, Singh V, Smith HS, Snook LT, Solanki DR, Tracy DH, Vallejo R, Wargo BW. American Society of Interventional Pain Physicians (ASIPP) guidelines for responsible opioid prescribing in chronic non-cancer pain: Part 2-Guidance. Pain Physician 2012; 15:S67-S116.

442. Koyyalagunta D, Bruera E, Solanki DR, Nouri KH, Burton AW, Toro MP, Bruel BM, Manchikanti L. A systematic review of randomized trials on the effectiveness of opioids for cancer pain. Pain Physician 2012; 15:ES39-ES58.

443. Manchikanti L, Ailinani H, Koyyalagunta D, Datta S, Singh V, Eriator I, Sehgal N, Shah RV, Benyamin RM, Vallejo R, Fellows B, Christo PJ. A systematic review of randomized trials of long-term opioid management for chronic non-cancer pain. Pain Physician 2011; 14:91-121.

444. Colson J, Koyyalagunta D, Falco FJE, Manchikanti L. A systematic review of observational studies on the effectiveness of opioid therapy for cancer pain. Pain Physician 2011; 14:E85-E102.

445. Manchikanti L, Benyamin RM, Singh V, Falco FJE, Hameed H, Derby R, Wolfer LR, Helm II S, Calodney AK, Datta S, Snook LT, Caraway DL, Hirsch JA, Cohen SP. An update of the systematic appraisal of the accuracy of utility of lumbar discography in chronic low back pain. 
Pain Physician 2013; 16:SE55-SE95.

446. Singh V, Manchikanti L, Onyewu O, Benyamin RM, Datta S, Geffert S, Parr AT, Falco FJE. An update of appraisal of accuracy of thoracic discography as a diagnostic test for chronic spinal pain. Pain Physician 2012; 15:E757-E776.

447. Onyewu O, Manchikanti L, Falco FJE, Singh V, Geffert S, Helm II S, Cohen SP, Hirsch JA. An update of the appraisal of the accuracy and utility of cervical discography in chronic neck pain. Pain Physician 2012; 15:E777-E806.

448. Falco FJE, Manchikanti L, Datta S, Sehgal N, Geffert S, Onyewu O, Singh V, Bryce DA, Benyamin RM, Simopoulos TT, Vallejo R, Gupta S, Ward SP, Hirsch JA. An update of the systematic assessment of the diagnostic accuracy of lumbar facet joint nerve blocks. Pain Physician 2012; 15:E869-E907.

449. Falco FJE, Manchikanti L, Datta S, Sehgal N, Geffert S, Onyewu O, Zhu J, Coubarous S, Hameed M, Ward SP, Sharma M, Hameed H, Singh V, Boswell MV. An update of the effectiveness of therapeutic lumbar facet joint interventions. Pain Physician 2012; 15:E909-E953.

450. Falco FJE, Datta $S$, Manchikanti L, Sehgal N, Geffert S, Singh V, Smith HS, Boswell MV. An updated review of diagnostic utility of cervical facet joint injections. Pain Physician 2012; 15:E807-E838.

451. Falco FJE, Manchikanti L, Datta S, Wargo BW, Geffert S, Bryce DA, Atluri S, Singh V, Benyamin RM, Sehgal N, Ward S, Helm II S, Gupta S, Boswell MV. Systematic review of therapeutic effectiveness of cervical facet joint interventions: An update. Pain Physician 2012; 15:E839E868.

452. Atluri S, Singh V, Datta S, Geffert S, Sehgal N, Falco FJE. Diagnostic accuracy of thoracic facet joint nerve blocks: An update of the assessment of evidence. Pain Physician 2012; 15:E483-E496.

453. Falco FJE, Patel V, Hayek SM, Deer TR, Geffert S, Zhu J, Onyewu O, Coubarous S, Smith HS, Manchikanti L. Intrathecal infusion systems for long-term management of chronic non-cancer pain: An update of assessment of evidence. Pain Physician 2013; 16:SE185-SE216.

454. Helm II S, Hayek SM, Colson J, Chopra P, Deer TR, Justiz R, Hameed M, Falco FJE. Spinal endoscopic adhesiolysis in post lumbar surgery syndrome: An update of the assessment of the evidence. Pain Physician 2013; 16:SE125-SE150.

455. Singh V, Manchikanti L, Calodney AK,
Staats PS, Falco FJE, Caraway DL, Hirsch JA, Cohen SP. Percutaneous lumbar laser disc decompression: An update of current evidence. Pain Physician 2013; 16:SE229-SE26o.

456. Manchikanti L, Singh V, Calodney AK, Helm II S, Deer TR, Benyamin RM, Falco FJE, Hirsch JA. Percutaneous lumbar mechanical disc decompression utilizing Dekompressor ${ }^{\circledR}$ : An update of current evidence. Pain Physician 2013; 16:SE1-SE24.

457. Manchikanti L, Singh V, Falco, FJE, Calodney AK, Onyewu O, Helm II S, Benyamin R, Hirsch JA. An updated review of automated percutaneous mechanical lumbar discectomy for the contained herniated lumbar disc. Pain Physician 2013; 16:SE151-SE184.

458. Manchikanti L, Falco FJE, Benyamin RM, Caraway DL, Deer TR, Singh V, Hameed $\mathrm{H}$, Hirsch JA. An update of the systematic assessment of mechanical lumbar disc decompression with nucleoplasty. Pain Physician 2013; 16:SE25SE54.

459. Datta S, Manchikanti L, Falco FJE, Calodney AK, Atluri S, Benyamin RM, Buenaventura R, Cohen SP. Diagnostic utility of selective nerve root blocks in the diagnosis of lumbosacral radicular pain: Systematic review and update of current evidence. Pain Physician 2013; 16:SE97-SE124.

460. Smith HS, Colson J, Sehgal N. An update of evaluation of intravenous sedation on diagnostic spinal injection procedures. Pain Physician 2013; 16:SE217SE228.

461. Manchikanti L, Malla Y, Wargo BW, Cash KA, Pampati V, Fellows B. A prospective evaluation of complications of 10,000 fluoroscopically directed epidural injections. Pain Physician 2012; 15:131-140.

462. Manchikanti L, Malla Y, Wargo BW, Cash KA, Pampati V, Fellows B. Complications of fluoroscopically directed facet joint nerve blocks: A prospective evaluation of 7,500 episodes with 43,000 nerve blocks. Pain Physician 2012; 15:E143-E150.

463. Jacobson I, Maccabe JJ, Harris P, Dott NM. Spontaneous spinal epidural haemorrhage during anticoagulant therapy. Br Med J 1966; 26:522-523.

464. Maingi M, Glynn MF, Scully HE, Graham AF, Floras JS Spontaneous spinal epidural hematoma in a patient with a mechanical aortic valve taking warfarin. Can J Cardiol 1995; 11:429-432.

465. Van Schaeybroeck P, Van Calenbergh F, Van De Werf F, Demaerel P, Goffin
J, Plets C. Spontaneous spinal epidural hematoma associated with thrombolysis and anticoagulation therapy: Report of three cases. Clin Neurol Neurosurg 1998; 100:283-287.

466. Cohen JE, Ginsberg HJ, Emery D, Schwartz ML. Fatal spontaneous spinal epidural hematoma following thrombolysis for myocardial infarction. Surg Neurol 1998; 49:520-522; discussion 523.

467. Brunori A, Scarano P, Simonetti G, Delitala A, Chiappetta F. Spontaneous spinal epidural hematomas: Is the role of dural arteriovenous malformations underestimated. Eur Spine ] 1996; 5:264-267.

468. Olivero WC, Hanigan WC, McCluney KW. Angiographic demonstration of a spinal epidural arteriovenous malformation. Case report. J Neurosurg 1993; 79:119-120.

469. Brawn LA, Bergval UE, Davies-Jones GA. Spontaneous spinal epidural hematoma with spontaneous resolution. Postgrad Med J 1986; 62:885-887.

470. Hanna JW, Ball MR, Lee KS, McWhorter JM. Spontaneous spinal epidural hematoma complicating Paget's disease of the spine. Case report. Spine (Phila Pa 1976) 1989; 14:900-902.

471. Groen RJ, van Alphen HA. Operative treatment of spontaneous spinal epidural haematomas: A study of factors determining postoperative outcome. Neurosurgery 1996; 39:494-509.

472. Clarke DB, Bertrand G, Tampieri D. Spontaneous spinal epidural hematoma causing paraplegia: Resolution and recovery without surgical decompression. Neurosurgery 1992; 30:108-111.

473. Clarke CE, Hall DJ, Zagnoon A, Loizou LA. Successful conservative management of spontaneous spinal extradural hematoma. Br J Neurosurg 1993; 7:209211.

474. Egido Herrero JA, Saldana C, Jimenez A, Vazquez A, Varela de Seijas E, Mata P. Spontaneous cervical epidural hematoma with Brown-Sequard syndrome and spontaneous resolution. Case report. J Neurosurg Sci 1992; 36:117-119.

475. Kato S, Seki H, Koshu K Acute cervical spinal epidural hematoma with spontaneous resolution: Case report. Neurol Med Chir (Tokyo) 1994; 34:23-26.

476. Kingery WS, Seibel M, Date ES, Marks MP. The natural resolution of a lumbar spontaneous epidural hematoma and associated radiculopathy. Spine (Phila Pa 1976) 1994; 1:67-69.

477. Miyagi Y, Miyazono M, Kamikaseda K. 
Spinal epidural vascular malformation presenting in association with a spontaneously resolved acute epidural hematoma. Case report. J Neurosurg 1998; 88:909-911.

478. Pahapill PA, Lownie SP. Conservative treatment of acute spontaneous spinal epidural hematoma. Can J Neurol Sci 1998; 25:159-163.

479. Saito $S$, Katsube H, Kobayashi Y. Spinal epidural hematoma with spontaneous recovery demonstrated by magnetic resonance imaging. Spine (Phila Pa 1976) 1994; 15:483-486.

480. Sei A, Nakamura T, Hashimoto N, Mizuta $\mathrm{H}$, Sasaki A, Takagi K. Cervical spinal epidural hematoma with spontaneous remission. J Spinal Disord 1991; 4:234237.

481. Silber SH. Complete nonsurgical resolution of a spontaneous spinal epidural hematoma. Am J Emerg Med 1996; 14:391-393.

482. Tryba M. Epidural regional anesthesia and low molecular heparin: Pro. Anasthesiol Intensivmed Notfallmed Schmerzther 1993; 28:179-181.

483. Kreppel D, Antoniadis G, Seeling W. Spinal hematoma: A literature survey with meta-analysis of 613 patients. Neurosurg Rev 2003; 26:1-49.

484. Horlocker TT, Heit JA. Low molecular weight heparin: Biochemistry, pharmacology, perioperative prophylaxis regimens, and guidelines for regional anesthetic management. Anesth Analg 1997; 85:874-885.

485. Abbasi A, Malhotra G, Malanga G, Elovic EP, Kahn S. Complications of interlaminar cervical epidural steroid injections: A review of the literature. Spine (Phila PA 1976) 2007; 32:2144-2151.

486. Botwin KP, Castellanos R, Rao S, Hanna AF, Torres-Ramos FM, Gruber RD, Bouchlas CG, Fuoco GS. Complications of fluoroscopically guided interlaminar cervical epidural injections. Arch Phys Med Rehabil 2003; 84:627-633.

487. Trentman TL, Rosenfeld DM, Seamans DP, Hentz JG, Stanek JP. Vasovagal reactions and other complications of cervical vs. lumbar translaminar epidural steroid injections. Pain Pract 2008; 9:59-64.

488. Kennedy DJ, Dreyfuss P, Aprill CN, Bogduk N. Paraplegia following image guided transforaminal lumbar spine epidural steroid injection: Two case reports. Pain Med 2009; 10:1389-1394.

489. Glaser SE, Shah RV. Root cause analysis of paraplegia following transforaminal epidural steroid injections: The 'unsafe' triangle. Pain Physician 2010; 13:237-244.

490. Huntoon MA. Anatomy of the cervical intervertebral foramina: Vulnerable arteries and ischemic neurologic injuries after transforaminal epidural injections. Pain 2005; 117:104-111.

491. Butterworth JF 4th, Rathmell JP. Standard care, standards for care, or standard of care? Anesthesiology 2010; 112:277-278.

492. Douketis JD, Berger PB, Dunn AS, Jaffer AK, Spyropoulos AC, Becker RC, Ansell J; American College of Chest Physicians. The perioperative management of antithrombotic therapy: American College of Chest Physicians EvidenceBased Clinical Practice Guidelines (8th Edition). Chest 2008; 133:299S-339S.

493. American Society of Anesthesiologists Committee on Standards and Practice Parameters. Practice alert for the perioperative management of patients with coronary artery stents: A report by the American Society of Anesthesiologists Committee on Standards and Practice Parameters. Anesthesiology 2009; 110:2223.

494. Horlocker TT. Regional anaesthesia in the patient receiving antithrombotic and antiplatelet therapy. $\mathrm{Br}$ ] Anaesth 2011; 107:ig6-i106.

495. Llau Pitarch JV, De Andrés Ibáñez J, Gomar Sancho C, Gómez Luque A, Hidalgo Martínez F, Torres Morera LM. Guidelines of hemostasis inhibiting drugs and neuraxial anaesthesia (Spanish). Revista Espanola de Anestesiologia y Reanimacion 2005; 52:413-420.

496. Botwin KP, Guirguis R. Cervical interlaminar epidural steroid injections. In: Manchikanti L (ed). Interventional Techniques in Chronic Non-Spinal Pain. ASIPP Publishing, Paducah, KY, 2009, pp 401422.

497. Bowsher D. A comparative study of the azygous venous system in man, monkey, dog, cat, rat and rabbit. J Anat 1954; 88:400-406.

498. Woollam DHM, Millen JW. The arterial supply of the spinal cord and its significance. J Neurochem 1955; 18:97-102.

499. Standring S. Macroscopic anatomy of the spinal cord and spinal nerves. In: Gray's Anatomy: The Anatomical Basis of Clinical Practice. 39th ed. Churchill Livingstone, London, 2005, pp 775-788.

500. Bridenbaugh PO, Green NM. Spinal (subarachnoid) neural blockage. In: Cousins MJ, Bridenbaugh PO (eds). Neural Blockade in Clinical Anesthesia and Management of Pain. J.B. Lippincott, Philadelphia, PA, 1998, pp 213-251.

501. Standring S. The back. In: Gray's Anatomy: The Anatomical Basis of Clinical Practice. 39th ed. Churchill Livingstone, London, 2005, pp 733-774.

502. Ho PS, Yu SW, Sether LA, Wagner M, Ho KC, Haughton VM. Ligamentum flavum: Appearance on sagittal and coronal MR images. Radiology 1988; 168:469472.

503. Lirk P, Kolbitsch C, Putz G, Colvin J, Colvin $\mathrm{HP}$, Lorenz I, Keller C, Kirchmair L, Rieder J, Moriggl B. Cervical and high thoracic ligamentum flavum frequently fails to fuse in the midline. Anesthesiology 2003; 99:1387-1390.

504. Tatarek NE. Variation in the human cervical neural canal. Spine J 2005; 5:623631.

505. Eismont FJ, Clifford S, Goldberg M, Green B. Cervical sagittal spinal canal size in spine injury. Spine 1984; 9:663666.

506. Lim JK, Wong HK. Variation of the cervical spinal Torg ratio with gender and ethnicity. Spine ] 2004; 4:396-401.

507. Goel A, Pollan JJ. Contrast flow characteristics in the cervical epidural space: An analysis of cervical epidurograms. Spine 2006; 31:1576-1579.

508. Mendel T, Wink CS, Zimny ML. Neural elements in human cervical intervertebral discs. Spine (Phila Pa 1976) 1992; 17:132-135.

509. Shenouda P, Cunningham B. Assessing the superiority of saline versus air for use in the epidural loss of resistance technique: A literature review. Reg Anesth Pain Med 2003; 28:48-53.

510. Gutierrez A. Valor de la aspiracion liquada en al espacio peridural en la anesthesia peridural. Rev Circ 1933; 12:225-226.

511. Collier CB. Accidental subdural block: Four more cases and a radiographic review. Anaesth Intensive Care 1992; 20:215232.

512. Ajar AM, Rathmel JP, Mukherji SK. The subdural compartment. Reg Anesth Pain Med 2002; 27:72-76.

513. Catchlove RF, Braha R. The use of cervical epidural nerve blocks in the management of chronic head and neck pain. Can Anaesth Soc J 1984; 31:188-191.

514. Collier CB. Accidental subdural injection during attempted lumbar epidural block may present as a failed or inadequate block: Radiographic evidence. Reg Anesth Pain Med 2004; 29:45-51.

515. Stojanovic MP, Vu TN, Caneris O, 
Slezak J, Cohen SP, Sang CN. The role of fluoroscopy in cervical epidural steroid injections: An analysis of contrast dispersal patterns. Spine (Phila Pa 1976) 2002; 27:509-514.

516. Kim KS, Shin SS, Kim TS, Jeong CY, Yoon $\mathrm{MH}$, Choi Jl. Fluoroscopically guided cervical interlaminar epidural injections using the midline approach: An analysis of epidurography contrast patterns. Anesth Analg 2009; 108:1658-1661.

517. Goodman B, Petalcorin JS, Mallempati S. Optimizing patient positioning and fluoroscopic imaging for the performance of cervical interlaminar epidura steroid injections. PM R 2010; 2:783-786.

518. Jeganathan VS, Ghosh S, Ruddle JB, Gupta V, Coote MA, Crowston JG. Risk factors for delayed suprachoroidal haemorrhage following glaucoma surgery. $\mathrm{Br}$ J Ophthalmol 2008; 92:13931396.

519. Tuli SS, WuDunn D, Ciulla TA, Cantor LB. Delayed suprachoroidal hemorrhage after glaucoma filtration procedures. Ophthalmology 2001; 108:1808 1811.

520. Cobb C), Chakrabarti S, Chadha V, Sanders R. The effect of aspirin and warfarin therapy in trabeculectomy. Eye (Lond) 2007; 21:598-603.

521. Fabinyi DC, O'Neill EC, Connell PP, Clark JB. Vitreous cavity haemorrhage post-vitrectomy for diabetic eye disease: The effect of perioperative anticoagulation and antiplatelet agents. Clin Experiment Ophthalmol 2011; 39:878-884.

522. Gedde SJ, Herndon LW, Brandt JD, Budenz DL, Feuer WJ, Schiffman JC. Surgical complications in the Tube Versus Trabeculectomy Study during the first year of follow-up. Am J Ophthalmol 2007; 143:23-31.

523. Passemard $M$, Koehrer P, Juniot A, Bron AM, Creuzot-Garcher C. Maintenance of anticoagulant and antiplatelet agents for patients undergoing peribulbar anesthesia and vitreoretinal surgery. Retina 2012; 32:1868-1873.

524. Kuhli-Hattenbach C, Fischer IB, Schalnus R, Hattenbach LO. Subretinal hemorrhages associated with age-related macular degeneration in patients receiving anticoagulation or antiplatelet therapy. Am J Ophthalmol 2010; 149:316321.

525. Radhakrishnan S, Quigley HA, Jampel HD, Friedman DS, Ahmad SI, Congdon NG, McKinnon S. Outcomes of surgical bleb revision for complications of trabeculectomy. Ophthalmology 2009; 116:1713-1718.

526. Brown JS, Mahmoud TH. Anticoagulation and clinically significant postoperative vitreous hemorrhage in diabetic vitrectomy. Retina 2011; 31:1983-1987.

527. Gainey SP, Robertson DM, Fay W, Ilstrup D. Ocular surgery on patients receiving long-term warfarin therapy. Am J Ophthalmol 1989; 108:142-146.

528. Robinson GA, Nylander A. Warfarin and cataract extraction. $\mathrm{Br}$ J Ophthalmo 1989; 73:702-703.

529. Roberts CW, Woods SM, Turner LS. Cataract surgery in anticoagulated patients. J Cataract Refract Surg 1991; 17:309-312.

530. McCormack P, Simcock PR, Tullo AB. Management of the anticoagulated patient for ophthalmic surgery. Eye (Lond) 1993; 7:749-750.

531. Lumme P, Laatikainen LT. Risk factors for intraoperative and early postoperative complications in extracapsular cataract surgery. Eur J Ophthalmol 1994; 4:151-158.

532. Carter K, Miller KM. Phacoemulsification and lens implantation in patients treated with aspirin or warfarin. ] Cataract Refract Surg 1998; 24:1361-1364.

533. Saitoh AK, Saitoh A, Taniguchi H, Amemiya T. Anticoagulation therapy and ocular surgery. Ophthalmic Surg Lasers 1998; 29:909-915.

534. Tamcelik N, Ozkiris A. Long-term results of viscotrabeculotomy in congenital glaucoma: Comparison to classical trabeculotomy. Br J Ophthalmol 2008; 92:36-39.

535. Jeganathan VS, Ghosh S, Ruddle JB, Gupta V, Coote MA, Crowston JG. Risk factors for delayed suprachoroidal haemorrhage following glaucoma surgery. $\mathrm{Br}$ J Ophthalmol 2008; 92:13931396.

536. Konstantatos A. Anticoagulation and cataract surgery: A review of the current literature. Anaesth Intensive Care 2001; 29:11-18.

537. Vicenzi MN, Meislitzer T, Heitzinger B, Halaj M, Fleisher LA, Metzier H. Coronary artery stenting and non-cardiac surgery-a prospective outcome study. $\mathrm{Br}$ J Anaesth 2006; 96:686-693.

538. Breivik $\mathrm{H}$, Bang $\mathrm{U}$, Jalonen J, Vigfússon G, Alahuhta S, Lagerkranser M. Nordic guidelines for neuraxial blocks in disturbed haemostasis from the Scandinavian Society of Anaesthesiology and Intensive Care Medicine. Acta Anaesthesiol
Scand 2010; 54:16-41.

539. Gogarten W, Vandermeulen E, Van Aken $H$, Kozek S, Llau JV, Samama CM; European Society of Anaesthesiology. Regional anaesthesia and antithrombotic agents: Recommendations of the European Society of Anaesthesiology. Eur J Anaesthesiol 2010; 27:999-1015.

540. Green L, Machin SJ. Managing anticoagulated patients during neuraxial anaesthesia. Br J Haematol 2010; 149:195208.

541. Vandermeulen E. Regional anaesthesia and anticoagulation. Best Pract Res Clin Anaesthesiol 2010; 24:121-131.

542. Catella-Lawson F, Reilly MP, Kapoor SC, Cucchiara AJ, DeMarco S, Tournier B, Vyas SN, FitzGerald GA. Cyclooxygenase inhibitors and the antiplatelet effects of aspirin. N Engl J Med 2001; 345:18091817.

543. FitzGerald G, Oates J, Hawiger J, Maas RL, Roberts LJ 2nd, Lawson JA, Brash AR. Endogenous biosynthesis of prostacyclin and thromboxane and platelet function during chronic administration of aspirin in man. J Clin Invest 1983; 71:676-688.

544. Gibbs NM, Weightman WM, Thackray NM, Michalopoulos N, Weidmann C. The effects of recent aspirin ingestion on platelet function in cardiac surgical patients. J Cardiothorac Vasc Anesth 2001; 15:55-59.

545. Serebruany VL, Steinhubl SR, Berger PB, Malinin Al, Baggish JS, Bhatt DL, Topol EJ. Analysis of risk of bleeding complications after different doses of aspirin in 192,036 patients enrolled in 31 randomized controlled trials. Am J Cardiol 2005; 95:1218-1222.

546. McQuaid KR, Laine L. Systematic review and meta-analysis of adverse events of low-dose aspirin and clopidogrel in randomized controlled trials. Am J Med 2006; 119:624-638.

547. Patrono C, Baigent C, Hirsh J, Roth G; Physicians American College of Chest Physicians. Antiplatelet drugs: American College of Chest Physicians EvidenceBased Clinical Practice Guidelines (8th Edition). Chest 2008; 133:199S-233S.

548. Sharis PJ, Cannon CP, Loscalzo J. The antiplatelet effects of ticlopidine and clopidogrel. Ann Intern Med 1998; 129:394405 .

549. Weber AA, Schrör K. Pharmacology of ticlopidine and clopidogrel in comparison with acetylsalicylic acid. Internist (Berl) 1997; 38:1115-1120. 
550. Buur T, Larsson R, Berglund U, Donat $F$, Tronquet C. Pharmacokinetics and effect of ticlopidine on platelet aggregation in subjects with normal and impaired renal function. J Clin Pharmacol 1997; 37:108-115.

551. Denninger $\mathrm{MH}$, Necciari J, Serre-Lacroix E, Sissmann J. Clopidogrel antiplatelet activity is independent of age and presence of atherosclerosis. Semin Thromb Hemost 1999; 25:41-45.

552. Englberger L, Faeh B, Berdat PA, Eberli F, Meier B, Carrel T. Impact of clopidogrel in coronary artery bypass grafting. Eur J Cardiothorac Surg 2004; 26:96-101.

553. Kapetanakis EI, Medlam DA, Petro KR, Haile E, Hill PC, Dullum MK, Bafi AS, Boyce SW, Corso PJ. Effect of clopidogrel premedication in off-pump cardiac surgery: Are we forfeiting the benefits of reduced hemorrhagic sequelae? Circulation 2006; 113:1667-1674.

554. Purkayastha $S$, Athanasiou T, Malinovski V, Tekkis P, Foale R, Casula R, Glenville $B$, Darzi A. Does clopidogrel affect outcome after coronary artery bypass grafting? A meta-analysis. Heart 2006; 92:531-532.

555. Gremmel T, Steiner S, Seidinger D, Koppensteiner R, Panzer S, Kopp CW. A high maintenance dose increases the inhibitory response to clopidogrel in patients with high on-treatment residual platelet reactivity. Int J Cardiol 2012; 160:109-113.

556. Prandoni, P, Piovella C, Spiezia L, Valle FD, Pesavento R. Optimal duration of anticoagulation in patients with venous thromboembolism. Indian J Med Res 2011; 134:15-21.

557. [No authors listed] CLASP (Collaborative Low-dose Aspirin Study in Pregnancy) Collaborative Group. CLASP: A randomised trial of low-dose aspirin for the prevention and treatment of pre-eclampsia among 9364 pregnant women. Lancet 1994; 343:619-629.

558. Moshfegh K, Redondo M, Julmy F, Wuillemin WA, Gebauer MU, Haeberli A, Meyer BJ. Antiplatelet effects of clopidogrel compared with aspirin after myocardial infarction: Enhanced inhibitory effects of combination therapy. J Am Coll Cardiol 2000; 36:699-705.

559. Tanaka KA, Key NS, Levy JH. Blood coagulation: Hemostasis and thrombin regulation. Anesth Analg 2009; 108:14331446.

560. Li JS, Yow E, Berezny KY, Bokesch PM, Takahashi M, Graham TP Jr, Sanders SP, Sidi $D$, Bonnet D, Ewert $P$, Jennings LK, Michelson AD; PICOLO Investigators.
Dosing of clopidogrel for platelet inhibition in infants and young children: Primary results of the Platelet Inhibition in Children On cLOpidogrel (PICOLO) trial. Circulation 2008; 117:553-559.

561. Karabulut H, Toraman F, Evrenkaya S, Goksel O, Tarcan S, Alhan C. Clopidogrel does not increase bleeding and allogenic blood transfusion in coronary artery surgery. Eur J Cardiothorac Surg 2004; 25:419-423.

562. CAPRIE Steering Committee. A randomised, blinded, trial of Clopidogrel versus Aspirin in Patients at Risk of Ischaemic Events (CAPRIE). Lancet 1996; 348:1329-1339.

563 Effient: Highlights of prescribing information. http://pi.lilly.com/us/effient.pdf

564. O'Donoghue $M$, Antman EM, Braunwald E, Murphy SA, Steg PG, Finkelstein A, Penny WF, Fridrich V, McCabe $\mathrm{CH}$, Sabatine MS, Wiviott SD. The efficacy and safety of prasugrel with and without a glycoprotein IIb/IIla inhibitor in patients with acute coronary syndromes undergoing percutaneous intervention: A TRITON-TIMI 38 (Trial to Assess Improvement in Therapeutic Outcomes by Optimizing Platelet Inhibition With Prasugrel-Thrombolysis In Myocardial Infarction 38) analysis. J Am Coll Cardiol 2009; 54:678-685.

565. Bhatt DL. Intensifying platelet inhibition - navigating between scylla and charybdis. N Engl J Med 2007; 357:20782081.

566. Duggan ST, Keating GM. Prasugrel: A review of its use in patients with acute coronary syndromes undergoing percutaneous coronary intervention. Drugs 2009; 69:1707-1726.

567. O'Riordan M. Switching from clopidogrel to prasugrel further reduces platelet function. Acute Coronary Syndromes. theheart.org, September 20, 2010.

http://www.theheart.org/article/1123367. do

568. Angiolillo DJ, Saucedo JF, DeRaad R, Frelinger AL, Gurbel PA, Costigan TM, Jakubowski JA, Ojeh CK, Effron MB; SWAP Investigators. Increased platelet inhibition after switching from maintenance clopidogrel to prasugrel in patients with acute coronary syndromes. J Am Coll Cardiol 2010; 56:1017-1023.

569. Roe MT, Armstrong PW, Fox KA, White HD, Prabhakaran D, Goodman SG, Cornel JH, Bhatt DL, Clemmensen P, Martinez F, Ardissino D, Nicolau JC, Boden
WE, Gurbel PA, Ruzyllo W, Dalby AJ, McGuire DK, Leiva-Pons JL, Parkhomenko A, Gottlieb S, Topacio GO, Hamm C, Pavlides G, Goudev AR, Oto A, Tseng CD, Merkely B, Gasparovic V, Corbalan $R$, Cintez $\square$, McLendon RC, Winters KJ, Brown EB, Lokhnygina Y, Aylward PE, Huber K, Hochman JS, Ohman EM; TRILOGY ACS Investigators. Prasugrel versus clopidogrel for acute coronary syndromes without revascularization. $N$ Engl J Med 2012; 367:1297-1309.

570. Wiviott SD, Braunwald E, McCabe $\mathrm{CH}$, Montalescot G, Ruzyllo W, Gottlieb S, Neumann FJ, Ardissino D, De Servi S, Murphy SA, Riesmeyer J, Weerakkody G, Gibson CM, Antman EM; TRITONTIMI 38 Investigators. Prasugrel versus clopidogrel in patients with acute coronary syndromes. N Engl J Med 2007; 357:2001-2015.

571. Mehta SR, Yusuf S, Peters RJ, Bertrand ME, Lewis BS, Natarajan MK, Malmberg K, Rupprecht H, Zhao F, Chrolavicius S, Copland I, Fox KA; Clopidogrel in Unstable angina to prevent Recurrent Events trial (CURE) Investigators. Effects of pretreatment with clopidogrel and aspirin followed by long-term therapy in patients undergoing percutaneous coronary intervention: The PCI-CURE study. Lancet 2001; 358:527-533.

572. Wilson SH, Fasseas $P$, Orford JL, Lennon RJ, Horlocker T, Charnoff NE, Melby S, Berger PB. Clinical outcome of patients undergoing non-cardiac surgery in the two months following coronary stenting. J Am Coll Cardiol 2003; 42:234240.

573. Joner M, Finn A, Farb A, Mont EK, Kolodgie FD, Ladich E, Kutys R, Skorija K, Gold HK, Virmani R. Pathology of drug-eluting stents in humans: Delayed healing and late thrombotic risk. J Am Coll Cardiol 2006; 48:193-202.

574. Grines CL, Bonow RO, Casey DE Jr, Gardner TJ, Lockhart PB, Moliterno DJ, O'Gara P, Whitlow P; American Heart Association; American College of Cardiology; Society for Cardiovascular Angiography and Interventions; American College of Surgeons; American Dental Association; American College of Physicians. Prevention of premature discontinuation of dual antiplatelet therapy in patients with coronary artery stents. Circulation 2007; 115:813-818.

575. Butler J, Leonard BE. The platelet serotonergic system in depression and following sertraline treatment. Int Clin Psychopharmacol 1988; 3:343-347. 
576. Helmeste DM, Tang SW, Reist C, Vu R. Serotonin uptake inhibitors modulate intracellular Ca2p mobilization in platelets. Eur J Pharmacol 1995; 288:373-377.

577. Markovitz JH, Shuster JL, Chitwood WS, May RS, Tolbert LC. Platelet activation in depression and effects of sertraline treatment: An open-label study. Am J Psychiatry 2000; 157:1006-1008.

578. Norred CL, Finlayson CA. Hemorrhage after the preoperative use of complementary and alternative medicines. AANA J 2000; 68:217-220.

579. Sewnath $M E$, van Hillegersberg $R$, Koopman MM, Levi MM, Gouma DJ. Increased perioperative blood loss during treatment with paroxetine. Ned Tijdschr Geneeskd 2002; 146:1800-1802.

580. Turner MS, May DB, Arthur RR, Xiong GL. Clinical impact of selective serotonin reuptake inhibitors therapy with bleeding risks. J Intern Med 2007; 261:205-213.

581. Movig KL, Janssen MW, de Waal Malefijt J, Kabel PJ, Leufkens HG, Egberts AC. Relationship of serotonergic antidepressants and need for blood transfusion in orthopedic surgical patients. Arch Intern Med 2003; 163:2354-2358.

582. Andreasen JJ, Riis A, Hjortdal VE, Jørgensen J, Sørensen HT, Johnsen SP. Effect of selective serotonin reuptake inhibitors on requirement for allogeneic red blood cell transfusion following coronary artery bypass surgery. Am J Cardiovasc Drugs 2006; 6:243-250.

583. Kim DH, Daskalakis C, Whellan DJ, Whitman IR, Hohmann S, Medvedev S, Kraft WK. Safety of selective serotonin reuptake inhibitor in adults undergoing coronary artery bypass grafting. Am J Cardiol 2009; 103:1391-1395.

584. Schalekamp T, Klungel $\mathrm{OH}$, Souverein PC, de Boer A. Increased bleeding risk with concurrent use of selective serotonin reuptake inhibitors and coumarins. Arch Intern Med 2008; 168:180-185.

585. Wallerstedt SM, Gleerup H, Sundström A, Stigendal L, Ny L. Risk of clinically relevant bleeding in warfarin-treated patients: influence of SSRI treatment. Pharmacoepidemiol Drug Saf 2009; 18:412-416.

586. Mansour A, Pearce M, Johnson B, Sey MS, Oda N, Collegala N, Krishnadev U, Bhalerao S. Which patients taking SSRIs are at greatest risk of bleeding? J Fam Pract 2006; 55:206-208.

587. Perakis PG, Yunus T, Long G, Cheema ZF, Hammond R, Shanley CJ. Platelet function after cessation of chronic clopidogrel therapy. Am Surg 2012; 78:51-56.

588. Glenn E, Mehl J, Rosinia FA, Liu H. Safe removal of an epidural catheter 72 hours after clopidogrel and aspirin administrations guided by platelet function analysis and thromboelastography. J Anaesthesiol Clin Pharmacol 2013; 29:99101.

589. Gremmel T, Steiner S, Seidinger D, Koppensteiner R, Panzer S, Kopp CW. The influence of proton pump inhibitors on the antiplatelet potency of clopidogrel evaluated by 5 different platelet function tests. J Cardiovasc Pharmacol 2010; 56:532-539.

590. Lau WC, Welch TD, Shields T, Rubenfire M, Tantry US, Gurbel PA. The effect of St John's Wort on the pharmacodynamic response of clopidogrel in hyporesponsive volunteers and patients: Increased platelet inhibition by enhancement of $\mathrm{CYP}_{3} \mathrm{~A}_{4}$ metabolic activity. J Cardiovasc Pharmacol 2011; 57:86-93.

591. Gajos G, Rostoff P, Undas A, Piwowarska W. Effects of polyunsaturated omega-3 fatty acids on responsiveness to dual antiplatelet therapy in patients undergoing percutaneous coronary intervention: The OMEGA-PCI (OMEGA-3 fatty acids after pci to modify responsiveness to dual antiplatelet therapy) study. J Am Coll Cardiol 2010; 55:1671-1678.

592. Schror K. The pharmacology of cilostazol. Diabetes Obes Metab 2002; 4:S14Sig.

593. Woo SK, Kang WK, Kwon KI. Pharmacokinetic and pharmacodynamic modeling of the antiplatelet and cardiovascular effects of cilostazol in healthy humans. Clin Pharmacol Ther 2002; 71:246252.

594. Dipyridamole at Dorland's Medical Dictionary.

http://en.wikipedia.org/wiki/ Dorland\%27s_Medical_Dictionary

595. Sobel M, Verhaeghe R; American College of Chest Physicians. Antithrombotic therapy for peripheral artery occlusive disease: American College of Chest Physicians Evidence-Based Clinical Practice Guidelines (8th Edition). Chest 2008; 133:815S-843S.

596. ESPRIT Study Group, Halkes PH, van Gijn J, Kappelle LJ, Koudstaal PJ, Algra A. Aspirin plus dipyridamole versus aspirin alone after cerebral ischaemia of arterial origin (ESPRIT): Randomised controlled trial. Lancet 2006; 367:1665-1673.

597. Russell TL, Berardi RR, Barnett JL,
O'Sullivan TL, Wagner JG, Dressman JB. $\mathrm{pH}$-related changes in the absorption of dipyridamole in the elderly. Pharm Res 1994; 11:136-143.

598. Derendorf H, VanderMaelen CP, Brickl R-S, MacGregor TR, Eisert W. Dipyridamole bioavailability in subjects with reduced gastric acidity. J Clin Pharmacol 2005; 45:845-850.

599. De Schryver EL, Algra A, van Gijn J. Dipyridamole for preventing stroke and other vascular events in patients with vascular disease. Cochrane Database Syst Rev 2007; 3:CDool820.

600. Center for Drug Evaluation and Research. Approval of Cilostazol. U.S. Food and Drug Administration, August 11, 1999.

http://www.fda.gov/cder/news/cilostazol/approval.htm.

601. Cilostazol: Official FDA information, side effects and uses. Drugs.com. February 2008. http://www.drugs.com/pro/ cilostazol.html.

602. Taniguchi K, Ohtani H, Ikemoto T, Miki A, Hori S, Sawada Y. Possible case of potentiation of the antiplatelet effect of cilostazol by grapefruit juice. J Clin Pharm Ther 2007; 32:457-459.

603. Cilostazol for peripheral arterial disease. Yahoo! Health.

http://health.yahoo.com/other-other/cilostazol-for-peripheral-arterial-disease/ healthwise--aa127481.html.

604. Cilostazol. MedicineNet.com. May 25, 1999. http://www.medicinenet.com/cilostazol/article.htm.

605. Cerner-Multum, Inc. (November 29, 2007). Consumer Drug Information: $\mathrm{Ci}-$ lostazol. Drugs.com.

http://www.drugs.com/mtm/cilostazol.html.

606. Fata-Hartley CL, Palmenberg AC. Dipyridamole reversibly inhibits mengovirus RNA replication. J Virol 2005; 79:1106211070.

607. Persantin Retard 200 mg. emc medicines. http://emc.medicines.org.uk/ medicine/304/SPC/Persantin+Retard+2 oomg/\#EXCIPIENTS

608. Stockley I. Stockley's Drug Interactions. The Pharmaceutical Press, 2009.

609. Lee SW, Chun KJ, Park SW, Kim HS, Kim YH, Yun SC, Kim WJ, Lee JY, Park DW, Lee CW, Hong MK, Rhee KS, Chae JK, Ko JK, Park JH, Lee JH, Choi SW, Jeong JO, Seong IW, Jon S, Cho YH, Lee NH, Kim JH, Park SJ. Comparison of triple antiplatelet therapy and dual antiplatelet therapy in patients at high risk of restenosis after drug-eluting stent implan- 
tation (from the DECLAREDIABETES and -LONG Trials). Am J Cardiol 2010; 105:168-173.

610. Chen KY, Rha SW, Li YJ, Poddar KL, Jin Z, Minami Y, Wang L, Kim EJ, Park CG, Seo $\mathrm{HS}$, Oh DJ, Jeong MH, Ahn YK, Hong TJ, Kim YJ, Hur SH, Seong IW, Chae JK, Cho MC, Bae JH, Choi DH, Jang YS, Chae IH, Kim CJ, Yoon JH, Chung WS, Seung KB, Park S); Korea Acute Myocardial Infarction Registry Investigators. Investigators KAMIR. Triple versus dual antiplatelet therapy in patients with acute ST-segment elevation myocardial infarction undergoing primary percutaneous coronary intervention. Circulation 2009; 119:3207-3214.

611. Coller BS. Anti-GPIIb/IIla drugs: Current strategies and future directions. Thromb Haemost 2001; 86:427-443.

612. Harrington RA, Armstrong PW, Graffagnino C, Van De Werf F, Kereiakes DJ, Sigmon KN, Card T, Joseph DM, Samuels R, Granett J, Chan R, Califf RM, Topol EJ. Dose-finding, safety, and tolerability study of an oral platelet glycoprotein IIb/IIla inhibitor, lotrafiban, in patients with coronary or cerebral atherosclerotic disease. Circulation 2000; 102:728-735

613. Bhatt DL, Topol EJ. Current role of platelet glycoprotein Ilb/llla inhibitors in acute coronary syndromes. JAMA 2000; 284:1549-1558.

614. Brown DL, Fann CS, Chang CJ. Metaanalysis of effectiveness and safety of abciximab versus eptifibatide or tirofiban in percutaneous coronary intervention. Am J Cardiol 2001; 87:537-541.

615. Gogarten W. The influence of new antithrombotic drugs on regional anesthesia. Curr Opin Anaesthesiol 2006; 19:545550.

616. Kristensen SD, Würtz M, Grove EL, De Caterina R, Huber K, Moliterno DJ, Neumann FJ. Contemporary use of glycoprotein Ilb/Illa inhibitors. Thromb Haemost 2012; 107:215-224.

617. Lippi G, Montagnana M, Danese E, Favaloro EJ, Franchini M. Glycoprotein Ilb/ Illa inhibitors: An update on the mechanism of action and use of functional testing methods to assess antiplatelet efficacy. Biomark Med 2011; 5:63-70.

618. Leclerc JR. Platelet glycoprotein IIb/IIla antagonists: Lessons learned from clinical trials and future directions. Crit Care Med 2002; 30:S332-S340.

619. Schneider DJ. Current issues with glycoprotein IIb-IIla antagonists. Curr Drug
Targets 2011; 12:1813-1820.

620. Hagemeyer CE, Peter K. Targeting the platelet integrin GPIIb/IIla. Curr Pharm Des 2010; 16:4119-4133.

621. Samama CM, Albaladejo P, Benhamou $D$, Bertin-Maghit M, Bruder N, Doublet JD, Laversin S, Leclerc S, Marret E, Mismetti P, Samain E, Steib A; Committee for Good Practice Standards of the French Society for Anaesthesiology and Intensive Care (SFAR). Venous thromboembolism prevention in surgery and obstetrics: Clinical practice guidelines. Eur J Anaesthesiol 2006; 23:95-116.

622. Geerts WH, Jay RM, Code KI, Chen E, Szalai JP, Saibil EA, Hamilton PA. A comparison of low-dose heparin with lowmolecular-weight heparin as prophylaxis against venous thromboembolism after major trauma. N Engl J Med 1996; 335:701-707.

623. Warkentin TE, Levine MN, Hirsh J, Horsewood P, Roberts RS, Gent M, Kelton JG. Heparin-induced thrombocytopenia in patients treated with low-molecular-weight heparin or unfractionated heparin. N Engl J Med 1995; 332:13301335.

624. Weitz Jl. Low-molecular-weight heparins. N Engl J Med 1997; 337:688-698.

625. Sanderink GJ, Guimart CG, Ozoux ML, Jariwala NU, Shukla UA, Boutouyrie BX. Pharmacokinetics and pharmacodynamics of the prophylactic dose of enoxaparin once daily over 4 days in patients with renal impairment. Thromb Res 2002; 105:225-231.

626. Bacher P, Welzel D, lqbal O, Hoppensteadt D, Callas D, Walenga JM, Fareed J. The thrombolytic potency of LMWheparin compared to urokinase in a rabbit jugular vein clot lysis model. Thromb Res 1992; 66:151-158.

627. Bergqvist D, Lindblad B, Mätzsch T. Risk of combining low molecular weight heparin for thromboprophylaxis and epidural or spinal anesthesia. Semin Thromb Hemost 1993; 19:147-151.

628. Douketis JD, Kinnon K, Crowther MA. Anticoagulant effect at the time of epidural catheter removal in patients receiving twice-daily or once-daily lowmolecular-weight heparin and continuous epidural analgesia after orthopedic surgery. Thromb Haemost 2002; 88:3740.

629. Subbiah M, Avadhani A, Shetty AP, Rajasekaran S. Acute spontaneous cervical epidural hematoma with neurological deficit after low-molecular-weight hep- arin therapy: Role of conservative management. Spine J 2010; 10:e11-e115.

630. Kasodekar SV, Goldszmidt E, Davies SR. Atypical presentation of an epidural hematoma in a patient receiving aspirin and low molecular weight heparin. Was epidural analgesia the right choice? J Clin Anesth 2009; 21:595-598.

631. Forsnes E, Occhino A, Acosta R. Spontaneous spinal epidural hematoma in pregnancy associated with using low molecular weight heparin. Obstet Gynecol 2009; 113:532-533.

632. Silva RC, Morais E Silva A, Laffitte FS, Jamus G. Epidural hematoma after general anesthesia associated with postoperative analgesia with epidural catheter in patient using low molecular weight heparin: case report. Rev Bras Anestesiol 2006; 56:174-182.

633. Wysowski DK, Talarico L, Bacsanyi J, Botstein P. Spinal and epidural hematoma and low-molecular-weight heparin. N Engl J Med 1998; 338:1774-1775.

634. Haschke M. Clinical pharmacological aspects of new oral anticoagulants. Ther Umsch 2012; 69:657-66o.

635. Ansell J, Hirsh J, Hylek E, Jacobson A, Crowther M, Palareti G; American College of Chest Physicians. Pharmacology and management of the vitamin $\mathrm{K}$ antagonists: American College of Chest Physicians Evidence-Based Clinical Practice Guidelines (8th Edition). Chest 2008; 133:160S-198S.

636. Enneking FK, Benzon $\mathrm{H}$. Oral anticoagulants and regional anesthesia: $\mathrm{A}$ perspective. Reg Anesth Pain Med 1998; 23:140Y145.

637. Xi M, Beguin S, Hemker HC. The relative importance of the factors II, VII, IX and $X$ for the prothrombinase activity in plasma of orally anticoagulated patients. Thromb Haemost 1989; 62:788Y791.

638. Benzon HA, Benzon HT, Kirby-Nolan M, Avram MJ, Nader A. Factor VII levels during the early phase of warfarin therapy. ASA Annual Meeting.

http://www.asaabstracts.com/strands/asaabstracts/searchArticle.htm;jsessionid=6 B6Fo96809096565Fo8863AoDF3390AF ?index $=0$ \&highlight=true\&highlightcol or $=0 \&$ bold=true\&italic=false. $2008: \mathrm{Ab}-$ stract A432.

639. Chan TY. Adverse interactions between warfarin and nonsteroidal antiinflammatory drugs: mechanisms, clinical significance, and avoidance. Ann Pharmacother 1995; 29:1274Y1283.

640. Holbrook A, Schulman S, Witt DM, 
Vandvik PO, Fish J, Kovacs MJ, Svensson PJ, Veenstra DL, Crowther M, Guyatt GH; American College of Chest Physicians. Evidence-based management of anticoagulant therapy: Antithrombotic Therapy and Prevention of Thrombosis, 9th ed: American College of Chest Physicians Evidence-Based Clinical Practice Guidelines. Chest 2012; 141:e152Se1584S.

641. Kochert E, Goldhahn L, Hughes I, Gee K, Stahlman B. Cost-effectiveness of routine coagulation testing in the evaluation of chest pain in the ED. Am J Emerg Med 2012; 30:2034-2038.

642. Masotti L, Di Napoli M, Godoy DA, Rafanelli D, Liumbruno $\mathrm{G}$, Koumpouros $\mathrm{N}$ Landini G, Pampana A, Cappelli R, Poli $D$, Prisco $D$. The practical management of intracerebral hemorrhage associated with oral anticoagulant therapy. Int J Stroke 2011; 6:228-240.

643. Wiltrout C, Kondo KL. Correction of coagulopathy for percutaneous interventions. Semin Intervent Radiol 2010; 27:338-347.

644. Booth SL. Dietary vitamin K guidance: An effective strategy for stable control of oral anticoagulation? Nutr Rev 2010; 68:178-181.

645. Madrid C, Sanz M. What influence do anticoagulants have on oral implant therapy? A systematic review. Clin Oral Implants Res 2009; 20:96-106.

646. Levi M. Epidemiology and management of bleeding in patients using vitamin K antagonists. J Thromb Haemost 2009; 7:103-106.

647. Prasad S, Wootten MR, Kulinski N, Chapman SA. What to do when warfarin therapy goes too far. J Fam Pract 2009; 58:346-352.

648. Safaoui MN, Aazami R, Hotz H, Wilson MT, Margulies DR. A promising new alternative for the rapid reversal of warfarin coagulopathy in traumatic intracranial hemorrhage. Am J Surg 2009; 197:785-790.

649. Denas G, Marzot F, Offelli P, Stendardo A, Cucchini U, Russo R, Nante G, Iliceto $S$, Pengo V. Effectiveness and safety of a management protocol to correct over-anticoagulation with oral vitamin K: A retrospective study of 1,043 cases. J Thromb Thrombolysis 2009; 27:340-347.

650. Louzada ML, Majeed H, Wells PS. Efficacy of low-molecular-weight-heparin versus vitamin $\mathrm{K}$ antagonists for long term treatment of cancer-associated venous thromboembolism in adults: $A$ systematic review of randomized controlled trials. Thromb Res 2009; 123:837844 .

651. Shah NL, Caldwell SH, Berg CL. The role of anti-fibrinolytics, rFVIla and other pro-coagulants: Prophylactic versus rescue? Clin Liver Dis 2009; 13:87-93.

652. Lippi G, Franchini M, Favaloro EJ. Pharmacogenetics of vitamin $\mathrm{K}$ antagonists: Useful or hype? Clin Chem Lab Med 2009; 47:503-515.

653. Levy JH, Tanaka KA, Dietrich W. Perioperative hemostatic management of patients treated with vitamin $\mathrm{K}$ antagonists. Anesthesiology 2008; 109:918-926.

654. Kalina M, Tinkoff G, Gbadebo A, Veneri P, Fulda G. A protocol for the rapid normalization of INR in trauma patients with intracranial hemorrhage on prescribed warfarin therapy. Am Surg 2008; 74:858-561.

655. Stein DM, Dutton RP, Hess JR, Scalea TM. Low-dose recombinant factor VIla for trauma patients with coagulopathy. Injury 2008; 39:1054-1061.

656. Clark NP, Witt DM, Delate T, Trapp M, Garcia D, Ageno W, Hylek EM, Crowther MA; Warfarin-Associated Research Projects and Other Endeavors Consortium. Thromboembolic consequences of subtherapeutic anticoagulation in patients stabilized on warfarin therapy: The low INR study. Pharmacotherapy 2008; 28:960-967.

657. Frazee LA, Bourguet CC, Gutierrez W, Elder-Arrington J, Elackattu AE, Haller NA. Retrospective evaluation of a method to predict fresh-frozen plasma dosage in anticoagulated patients. Am J Ther 2008; 15:111-118.

658. Leissinger CA, Blatt PM, Hoots WK, Ewenstein $B$. Role of prothrombin complex concentrates in reversing warfarin anticoagulation: a review of the literature. Am J Hematol 2008; 83:137-143.

659. Gebuis EP, Rosendaal FR, van Meegen E, van der Meer FJ. Vitamin Kı supplementation to improve the stability of anticoagulation therapy with vitamin $\mathrm{K}$ antagonists: A dose-finding study. Haematologica 2011; 96:583-589.

660. Samarasinghe V, Marsland AM. Class action of oral coumarins in the treatment of a patient with chronic spontaneous urticaria and delayed-pressure urticaria. Clin Exp Dermatol 2012; 37:741743.

661. Patriquin C, Crowther M. Treatment of warfarin-associated coagulopathy with vitamin K. Expert Rev Hematol 2011;
4:657-665.

662. Wilairatana P, Krudsood S, Tangpukdee $\mathrm{N}$. Vitamin $\mathrm{K}$ injection in spontaneous bleeding and coagulopathy in severe malaria: Pros and cons. Southeast Asian ] Trop Med Public Health 2010; 41:514-516.

663. de Assis MC, Rabelo ER, Avila CW, Polanczyk CA, Rohde LE. Improved oral anticoagulation after a dietary vitamin k-guided strategy: A randomized controlled trial. Circulation 2009; 120:11151122.

664. Crowther MA, Ageno W, Garcia D, Wang L, Witt DM, Clark NP, Blostein MD, Kahn SR, Vesely SK, Schulman S, Kovacs MJ, Rodger MA, Wells P, Anderson D, Ginsberg J, Selby R, Siragusa S, Silingardi $M$, Dowd MB, Kearon C. Oral vitamin $\mathrm{K}$ versus placebo to correct excessive anticoagulation in patients receiving warfarin: A randomized trial. Ann Intern Med 2009; 150:293-300.

665. Ford SK, Moll S. Vitamin K supplementation to decrease variability of International Normalized Ratio in patients on vitamin $\mathrm{K}$ antagonists: A literature review. Curr Opin Hematol 2008; 15:504508.

666. Rohde LE, de Assis MC, Rabelo ER. Dietary vitamin $\mathrm{K}$ intake and anticoagulation in elderly patients. Curr Opin Clin Nutr Metab Care 2007; 10:1-5.

667. American Academy of Pediatrics Committee on Fetus and Newborn. Controversies concerning vitamin $\mathrm{K}$ and the newborn. Pediatrics 2003; 112:191-192.

668. Sundaram KS, Fan JH, Engelke JA, Foley AL, Suttie JW, Lev M. Vitamin K status influences brain sulfatide metabolism in young mice and rats.] Nutr 1996; 126:2746-2751.

669. Preusch P, Suttie J. Vitamin K-dependent reactions in rat liver: Role of flavoproteins. J Nutr 1981; 111:2087-2097.

670. Will B, Usui Y, Suttie J. Comparative metabolism and requirement of vitamin $\mathrm{k}$ in chicks and rats. J Nutr 1992; 122:23542360.

671. Dentali F, Ageno W, Crowther M. Treatment of coumarin-associated coagulopathy: A systematic review and proposed treatment algorithms.] Thromb Haemost 2006; 4:1853-1863.

672. Angelo M, Stockner I, Wiedermann CJ. Bleeding risk and perioperative management of patients anticoagulated with vitamin $\mathrm{K}$ antagnosists. Wien Med Wochenschr 2008; 158:615-620.

673. Crowther MA, Douketis JD, Schnurr T, Steidl L, Mera V, Ultori C, Venco A, Age- 
no W. Oral vitamin $\mathrm{K}$ lowers the international normalized ratio more rapidly than subcutaneous vitamin $\mathrm{K}$ in the treatment of warfarin-associated coagulopathy. A randomized, controlled trial. Ann Intern Med 2002; 137:251-254.

674. Dezee KJ, Shimeall WT, Douglas KM, Shumway NM, O'malley PG. Treatment of excessive anticoagulation with phytonadione (vitamin K): A meta-analysis. Arch Intern Med 2006; 166:391-397.

675. Rosencher N, Bonnet MP, Sessler DI. Selected new antithrombotic agents and neuraxial anaesthesia for major orthopaedic surgery: management strategies. Anaesthesia 2007; 62:1154-1166o.
676. Dabigatran (Pradaxa ${ }^{\circledR}$ ) Principles and Guidance for the Reversal of Effect and Management of Life Threatening or Major Bleeding. University of Utah Health Care Thrombosis Service.

http://healthcare.utah.edu/thrombosis/newagents/TS.Dabi_Bleeding.pdf

677. Pradaxa - Interruption for Colonoscopy, Dental Work, Surgery, etc. Patient Education Blog.

htt p: //patientblog. clotconnect. org/2011/04/14/pradaxa-interruptionfor-colonoscopy-dental-proceduressurgery-etc/

678. Herman WW, Konzelman JL Jr., Sutley
$\mathrm{SH}$. Current perspectives on dental patients receiving coumarin anticoagulant therapy. J Am Dent Assoc 1997; 128:327335.

679. Van Ryn J, Stangier J, Haertter S, Liesenfeld $\mathrm{KH}$, Wienen W, Feuring M, Clemens A. Dabigatran etexilate - a novel, reversible, oral direct thrombin inhibitor: Interpretation of coagulation assays and reversal of anticoagulant activity. Thromb Haemost 2010; 103:1116-1127.

680. Full prescribing information. Xarelto (rivaroxaban).

http://www.xareltohcp.com/sites/default/files/ pdf/xarelto_o.pdf\#zoom=100 